UNIVERSIDADE DE SÃO PAULO

Instituto de Astronomia, Geofísica e Ciências Atmosféricas

O GEÓIDE GRAVIMÉTRICO E O NÍVEL MÉDIO DO MAR NA REGIÃO DO DATUM ALTIMÉTRICO BRASILEIRO:

UM ESTUDO COMPARATIVO

ALEXANDRE BERNARDINO LOPES

São Paulo

2006 


\section{O GEÓIDE GRAVIMÉTRICO E O NÍVEL MÉDIO DO MAR NA REGIÃO DO DATUM ALTIMÉTRICO BRASILEIRO: \\ UM ESTUDO COMPARATIVO}

ALEXANDRE B. LOPES

Dissertação apresentada ao Instituto de Astronomia, Geofísica e Ciências Atmosféricas da Universidade de São Paulo para obtenção do título de mestre em geofísica .

Orientador: Prof. Dr. Nelsi Côgo de Sá

São Paulo

2006 


\section{AGRADECIMENTOS}

Ao Programa de Pós-Graduação em Geofísica do IAG/USP, pela oportunidade e pelo convívio durante o curso de mestrado;

Ao Prof. Nelsi Côgo de Sá, pela orientação e sugestões sempre oportunas;

Ao Prof. Eder Cassola Molina, pelo acompanhamento e sugestões nos relatórios semestrais;

Ao técnico Clarino do Divino Vieira, pela dedicação nos trabalhos de campo;

À CAPES, pela bolsa de estudos concedida, e à FAPESP, pelo apoio financeiro na implantação da Rede GPS no Sul/Sudeste do Brasil (RGSB) pelo IAG/USP;

Aos colegas, Ahmed, Gelvam, Ivam, Marcelo, Robsom, Éric, Francisca, Mário, Danilo, Emilson e Marcos, pela sincera amizade;

Aos colegas do IAG, pela amizade e apoio ao longo do curso;

Ao Luiz Tadeu, Lopes, pela amizade, compreensão e apoio;

Aos meus pais João B. Lopes, Maria N. F. Lopes e aos meus irmãos Agnaldo, Rodrigo e Álvaro por serem minha inesgotável fonte de apoio, motivação compreensão e amizade;

À todos aqueles que direta ou indiretamente contribuíram para o desenvolvimento do trabalho. 


\section{SUMÁRIO}

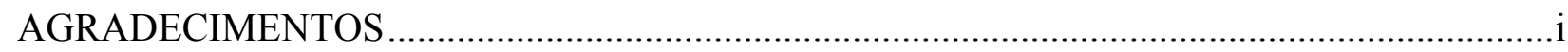

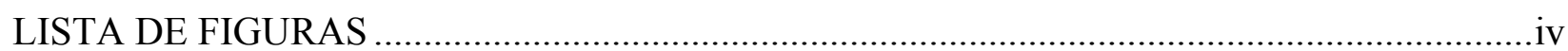

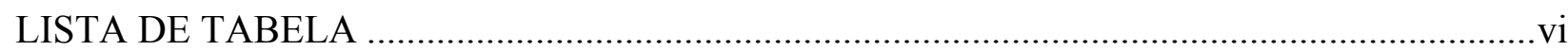

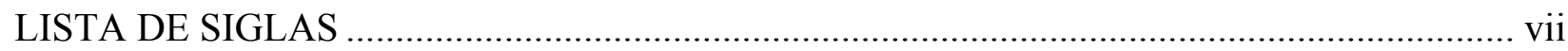

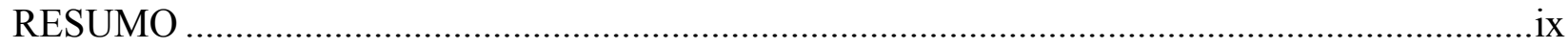

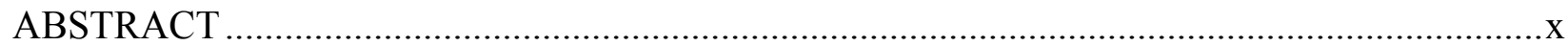

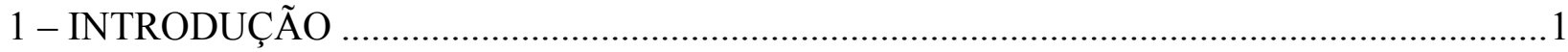

2 - O CAMPO DA GRAVIDADE TERRESTRE................................................................... 3

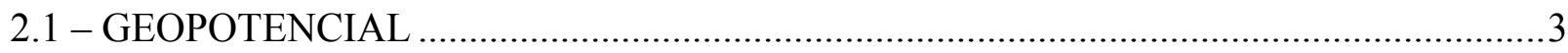

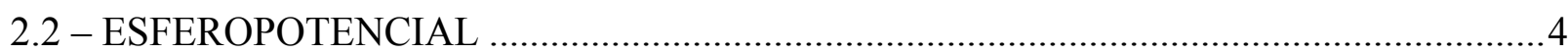

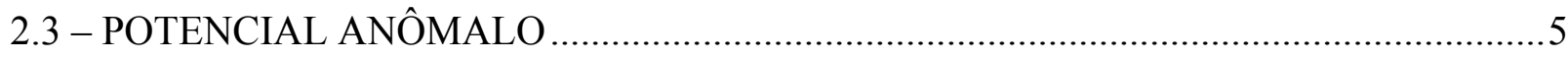

2.4 - AVANÇOS NA REPRESENTAÇÃO DO CAMPO DE GRAVIDADE............................9

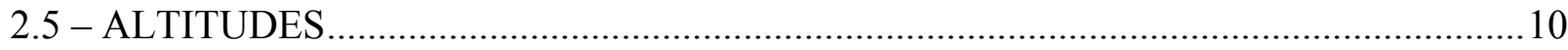

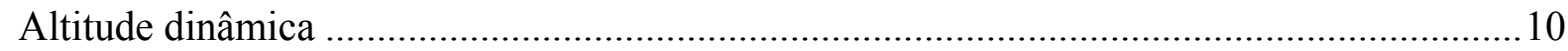

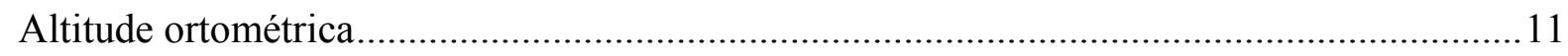

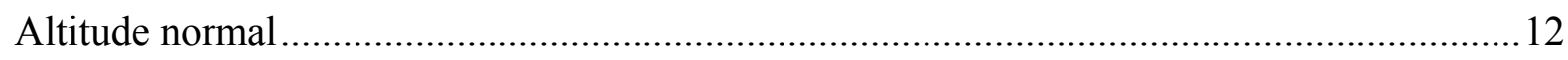

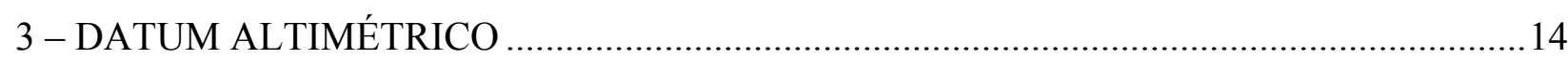

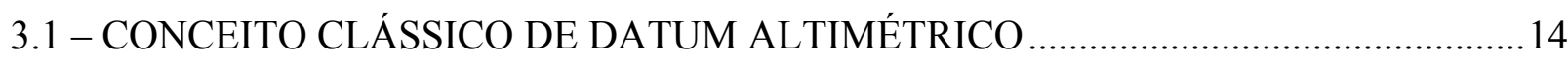

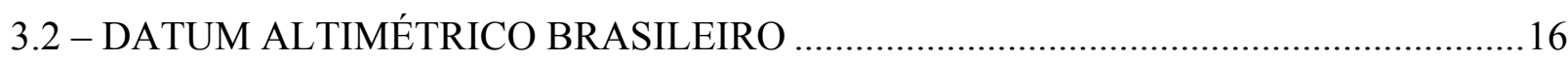

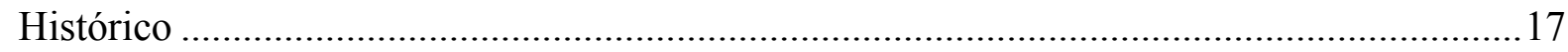

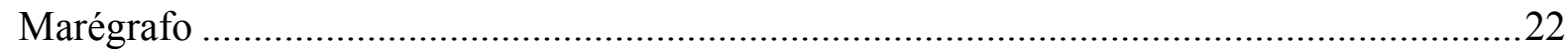

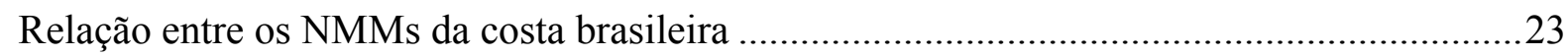

Características oceanográficas e o nível médio do mar.......................................................24

Rede Maregráfica Permanente para Geodésia (RMPG) ...................................................... 31

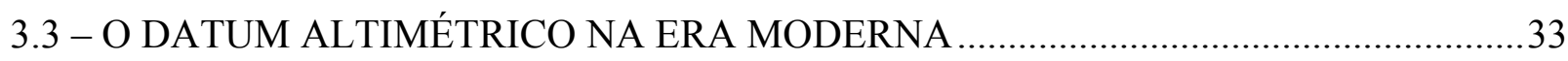

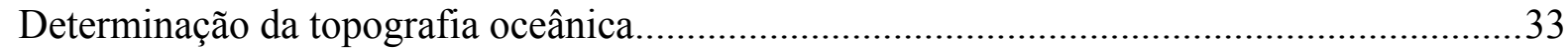

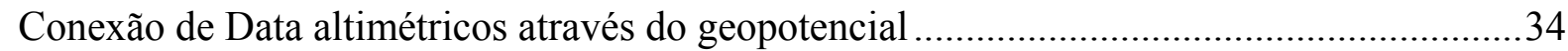

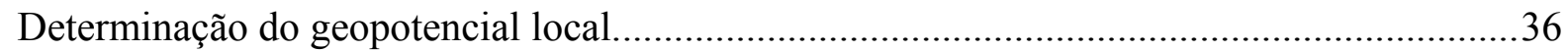

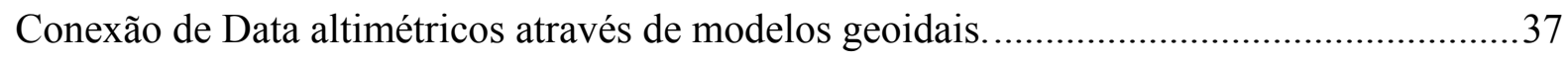

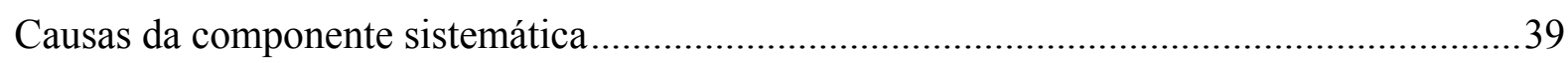

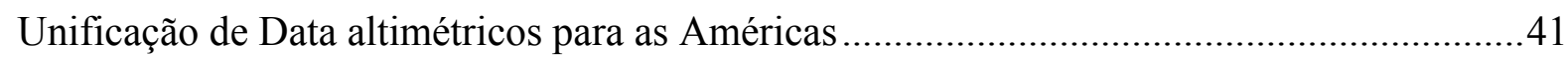

Importância da unificação de Data altimétricos ................................................................42 


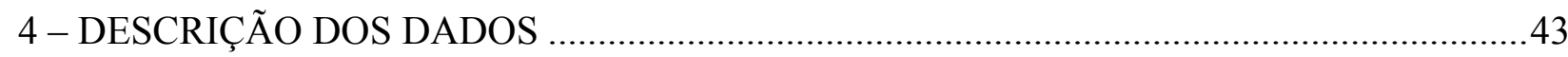

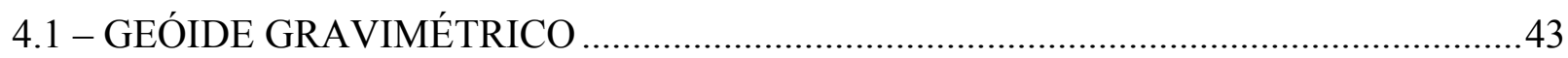

Dados empregados no cálculo do geóide gravimétrico ………………………………….......44

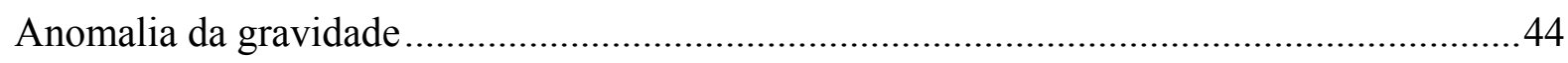

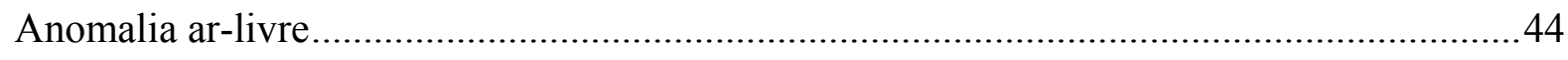

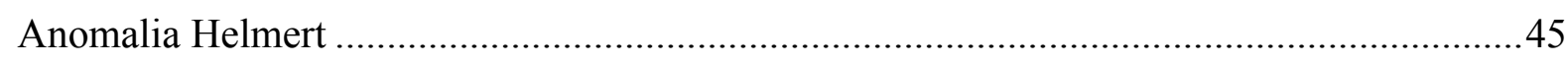

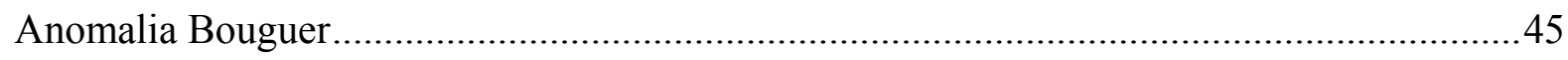

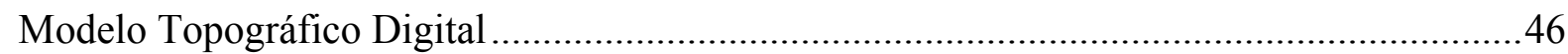

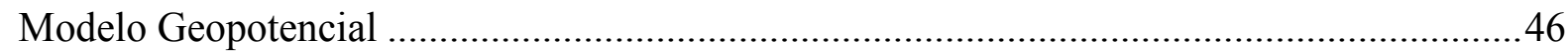

Metodologia utilizada no cálculo do geóide gravimétrico ……………………………….....47

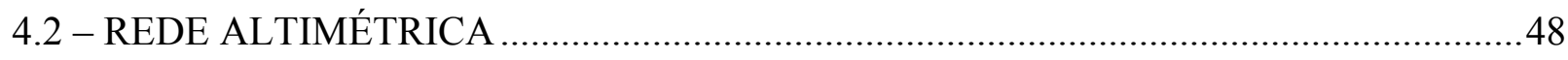

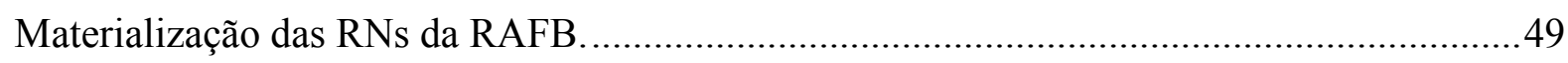

4.3 - REDE BRASILEIRA DE MONITORAMENTO CONTÍNUO_.........................................51

4.4 - DADOS DA REDE GPS DO SUL/SUDESTE DO BRASIL ……………………….......51

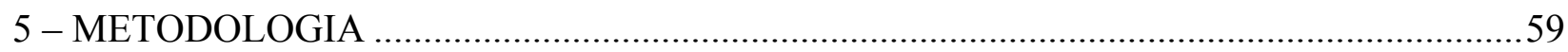

5.1 - IMPLANTAÇÃO DA REDE GPS NA REGIÃO DO DATUM ALTIMÉTRICO ...........59

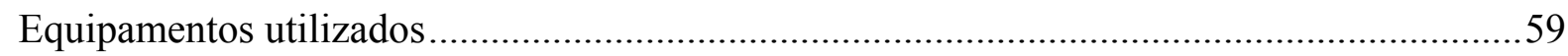

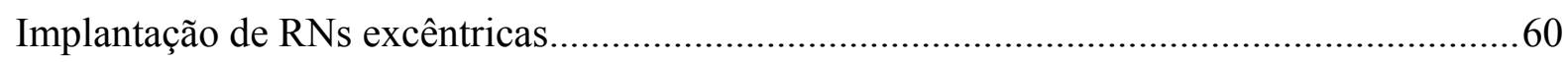

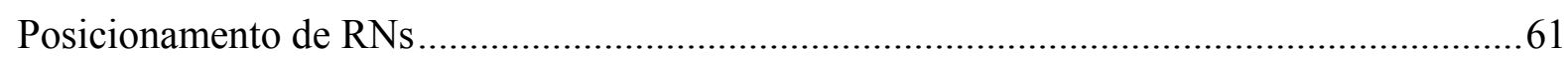

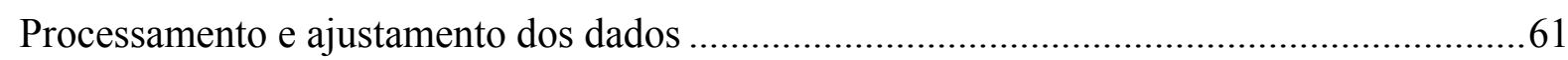

5.2 - DETERMINAÇÃO DA COMPONENTE SISTEMÁTICA …………………………........62

Determinação da componente sistemática no Datum altimétrico brasileiro .............................63

Determinação da componente sistemática através da transformação de similaridade .............65

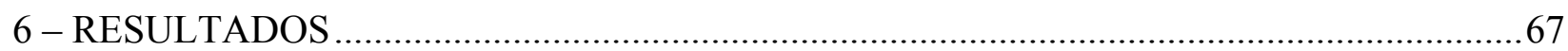

6.1 - A COMPONENTE SISTEMÁTICA NA REGIÃO DO DATUM.......................................67

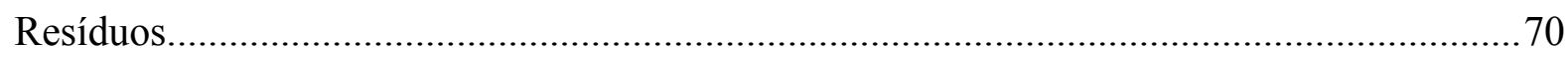

6.2- IMPLICAÇÕES DA COMPONENTE SISTEMÁTICA PARA A RAFB. ……………......72

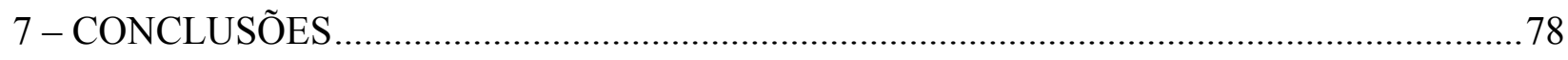

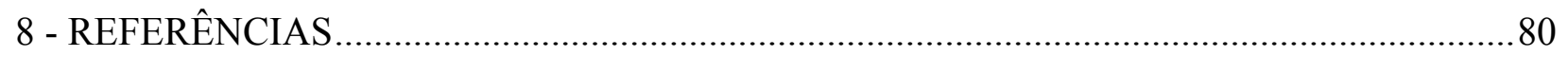




\section{LISTA DE FIGURAS}

Figura 2.1 - Elementos do campo de gravidade ................................................................

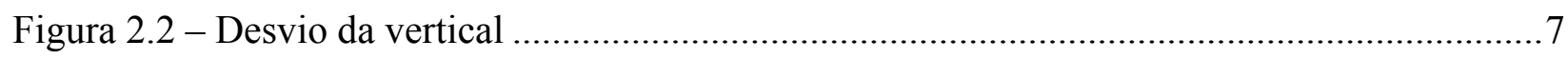

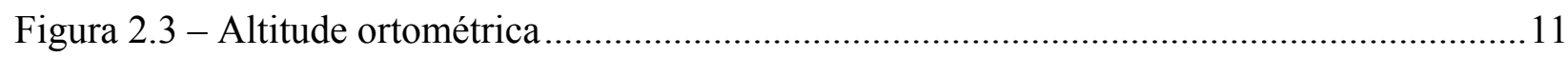

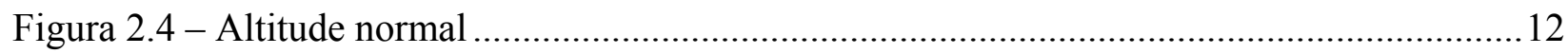

Figura 3.1 - Materialização do Datum altimétrico através do NMM ...........................................15

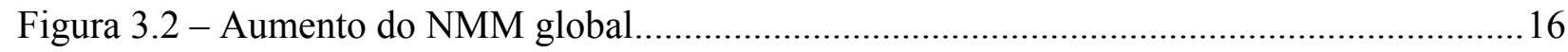

Figura 3.3 - Localização do marégrafo e das estações GPS ......................................................17

Figura 3.4 - Detalhe da referência de nível fundamental da rede de nivelamento do Brasil......... 18

Figura 3.5 - Histograma das médias mensais para o período 1949-1957 ................................... 19

Figura 3.6 - Médias anuais e mensais para o período de 9 anos de observações. ........................20

Figura 3.7 - Altitude da RN 4X em relação ao zero da régua do marégrafo e ao NMM. ............20

Figura 3.8 - Histograma das observações maregráficas para o período 1949-1969.....................21

Figura 3.9 - Médias mensais e anuais para o período 1949-1969..............................................22

Figura 3.10 - Sistema de registro do marégrafo de Imbituba ...................................................23

Figura 3.11 - Diferenças entre os marégrafos da costa brasileira...............................................24

Figura 3.12 - Variações de densidade em função da temperatura para salinidade constante ........25

Figura 3.13 - Localização dos rios e marégrafos implantados na costa brasileira .......................26

Figura 3.14 - Mapa de salinidade no oceano Atlântico .................................................................28

Figura 3.15 - Mapa de temperatura da água no oceano Atlântico ................................................29

Figura 3.16 - Diferenças dos níveis do mar na costa brasileira em relação à Imbituba ................31

Figura 3.17- Localização da Rede Maregráfica Permanente para Geodésia................................32

Figura 3.18 - Marégrafos analógico e digital do Datum de Imbituba. ........................................32

Figura 3.19 - Registro maregráfico das estações da RPMG ........................................................33

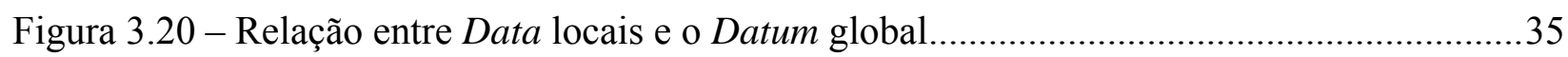

Figura 3.21 - Geopotencial local, anomalia de altitude e altitudes normal e elipsoidal...............36

Figura 3.22 - Relação entre o geóide GPS e o geóide gravimétrico.............................................38

Figura 4.1 - Geóide gravimétrico da região de interesse ...........................................................43

Figura 4.2 - Referências de nível da rede altimétrica fundamental do Brasil .............................49

Figura 4.3 - Chapa metálica cravada em concreto.................................................................49

Figura 4.4 - Marco de concreto utilizado na implantação de RNs ............................................50

Figura 4.6 - Rede GPS do Sul/Sudeste do Brasil implantada pelo IAG/USP .............................53 
Figura 4.7 - Rede GPS do Sul/Sudeste do Brasil no Estado de Santa Catarina .55

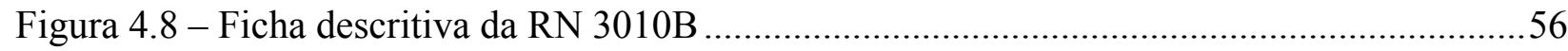

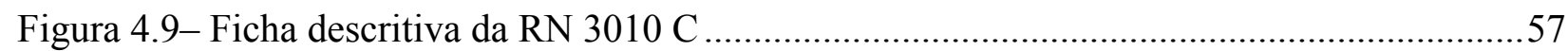

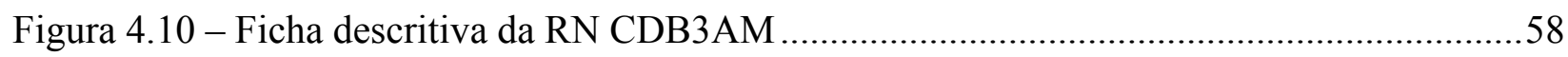

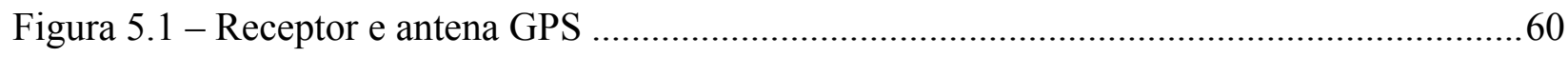

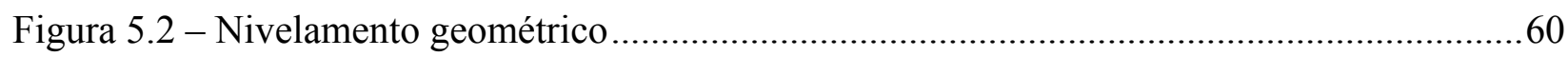

Figura 5.3 - Dados envolvidos na determinação da componente sistemática. .............................63

Figura 5.4 - Distribuição das estações mais próximos ao Datum altimétrico de Imbituba...........64

Figura 6.1 - Superfície determinada a partir da componente sistemática. ...................................68

Figura 6.2 - Superfície calculada a partir dos parâmetros ........................................................... 71

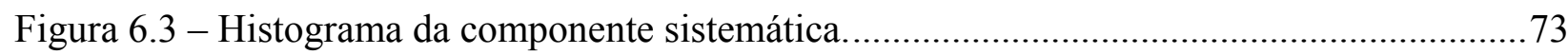

Figura 6.4 - Histograma das componentes residuais resultante da remoção da componente sistemática determinada no marco geodésico SAT 91854 .........................................75

Figura 6.5 - Histograma das componentes residuais resultante da remoção da componente sistemática estimada através da média ponderada

Figura 6.6 - Histograma das componentes residuais resultante da remoção da componente sistemática estimada através da transformação de similaridade no marco geodésico SAT9 1854

Figura 6.7 - Histograma das componentes residuais resultante da remoção da componente sistemática estimada através do modelo matemático 


\section{LISTA DE TABELA}

Tabela 3.1 - Médias anuais do nível médio do mar em relação à régua do marégrafo de Imbituba

Tabela 3.2 - Estatísticas das observações maregráficasno período 1949-1957. 19

Tabela 3.3 - Estatísticas dos valores mensais para o período 1949-1969....................................21

Tabela 3.4 - Características oceanográficas e diferenças entre os níveis do mar.........................30

Tabela 4.1 - Estatísticas dos erros das altitudes ortométricas......................................................51

Tabela 4.2 - Estatísticas dos erros da altitude geométrica .........................................................52

Tabela 4.3 - Estações da RGSB no Estado de Santa Catarina........................................................53

Tabela 4.4 - Estatísticas dos erros da altitude geométrica da RGSB no Estado de Santa

Catarina. 55

Tabela 6.1 - Componente sistemática na região do Datum de Imbituba.

Tabela 6.2 - Estatísticas da componente sistemática nas 25 estações GPS mais próximas ao Datum altimétrico brasileiro .68

Tabela 6.3 - Componente sistemática nas RNs localizadas no Porto de Imbituba. 69

Tabela 6.4 - Parâmetros da transformação de similaridade .70

Tabela 6.5 - Componente sistemática modelada nas RNs localizadas nas proximidades do

Datum .70

Tabela 6.6 - Comparação dos resíduos determinados a partir de diferentes modelos matemáticos .71

Tabela 6.7 - Resíduos nas RNs localizadas no Porto de Imbituba. .72

Tabela - 6.8 Componentes sistemáticas determinadas no Datum de Imbituba. .72

Tabela 6.9- Estatística da componente sistemática .73

Tabela 6.10 - Estatísticas das componentes residuais da rede RGSB 74 
LISTA DE SIGLAS

CHAMP
CMQ
GEOS
GEOSAT
GPS
GRACE
GRS67
GRS80
GSFC
GSFT
IAGS
IBGE

IERS

IGSN71

MTU

NASA

NGDC

NIMA

NMM

PSMSL

RAFB

RBMC

RGFB

RGSB

RINEX

Format
Challenging Minisatellite Payload

Colocação por Mínimos Quadrados

Geodynamics Experiment Ocean Satellite

Geodetic Satellite

Global Positioning System

Gravity Recovery and Climate Experiment

Geodetic Reference System 1967

Geodetic Reference System 1980

Goddard Space Flight Center

Global Sea Floor Topography

Inter American Geodetic Survey

Fundação Instituto Brasileiro de Geografia

e Estatística

International Earth Rotation Service

International Gravity Standartization

Network 1971

Modelo Topográfico Unificado

National Aeronautic and Space

Administration

National Geophysical Data Center

National Imagery and Mapping Agency

Nível Médio do Mar

Permanent Service for Mean Sea Level

Rede Altimétrica Fundamental do Brasil

Rede Brasileira de Monitoramento

Contínuo

Rede Gravimétrica Fundamental

Brasileira

Rede GPS no Sul/Sudeste do Brasil

Receiver Independent Data Exchange 
RMPG

RMS

$\mathrm{RN}$

SGB

SGE

SIRGAS

SRTM

OSU

EGM96

TO

WGS84
Rede Maregráfica Permanente para Geodésia

Root Mean Square

Referência de Nível

Sistema Geodésico Brasileiro

Serviço Geográfico do Exército

Sistema de Referência Geocêntrica para as Américas

Shuttle Radar Topography Mission

Ohio State University

Earth Gravitational Model 1996

Topografia Oceânica

World Geodetic System 1984 


\section{RESUMO}

Um estudo sobre a compatibilidade de um geóide gravimétrico recente com o nível médio do mar no Datum altimétrico do Sistema Geodésico Brasileiro (SGB), foi realizado. A metodologia usada consiste na comparação do geóide gravimétrico com o nível médio do mar, materializado pelo marégrafo de Imbituba (SC), e análise dos desníveis entre os marégrafos da costa brasileira em relação ao de Imbituba, determinados por nivelamento geométrico e dados oceanográficos. A unificação de Data altimétricos, investigada em vários centros de pesquisas geodésicas, visa homogeneizar altitudes ortométricas em escalas regional e global através de técnicas espaciais de posicionamento e modelos geoidais gravimétricos. Entre as propostas para a unificação de Data altimétricos, a utilização de modelos geoidais gravimétricos vem se mostrando adequada tanto do ponto de vista teórico como prático. Assim, foi determinada a componente sistemática no Datum de Imbituba, a partir da comparação de um geóide gravimétrico da América do Sul, obtido através da colocação por mínimos quadrados, e o geóide GPS/nivelamento, determinado através dos dados da Rede GPS do Sul/Sudeste do Brasil (RGSB). Para representar a componente sistemática no Datum altimétrico brasileiro, foram usados três formas: 1) determinação da componente sistemática na $\mathrm{RN}$ fundamental da RAFB (RN 4X), 2) cálculo da média ponderada da componente sistemática a partir das RNs mais próximas ao Datum, e 3) modelagem da componente sistemática usando modelo matemático da transformação de similaridade a partir de todos os dados da RGSB.

Os resultados, obtidos no cálculo do nível médio do mar a partir de dados oceanográficos, mostram que as diferenças em relação ao marégrafo de Imbituba são, em grande parte, causadas por mudanças das características oceanográficas (salinidade, temperatura, densidade e pressão) ao longo da costa.

A remoção da componente sistemática, obtida no Datum, diminuiu significativamente a diferença entre os geóides gravimétrico e GPS/nivelamento nas RNs da RAFB; entretanto o ajuste da componente sistemática, através da transformação de similaridade, utilizando todos os dados da RGSB, apresentou os melhores resultados na compatibilização dos geóides gravimétricos e GPS/nivelamento. 


\section{ABSTRACT}

A study on the compatibility of a recent gravimetric geoid with the mean sea level in altimetric Datum of the Sistema Geodésico Brasileiro (SGB) was accomplished. The used methodology consists in comparing gravimetric geoid with mean sea level, at the tide gauge of Imbituba (SC), and the analysis of differences among tide gauges of Brazilian coast with respecto Imbituba, obtained by geometric levelling and oceanographic data. The unification of altimetric Data, investigated in several geodetic research centres, aiming the standardization of orthometric heights in regional and global scales by using spatial positioning techniques, and gravimetric geoid models. Among the suggestions for the altimetric Data unification, the use of gravimetric geoid models is adequate in both, theoretical and practical points of view. Thus, a systematic component at Imbituba Datum was determined by comparing a South American gravimetric geoid, obtained by least-squares collocation, and GPS/levelling geoid, determined at stations of the Rede GPS no Sul/Sudeste do Brasil (RGSB). To represent the systematic component in Brazilian altimetric Datum, three aproaches were used: 1) determining the systematic component at the fundamental benchmark of the RAFB (RN 4X); 2) computing the weighted mean from the stations closer to the Datum, and 3) modelling the systematic component by using the similarity transformation model from all stations of the RGSB,

The results of mean sea level, computed from oceanographic data, show that differences with respect to Imbituba tide gauge are mostly due to oceanographic characteristics, (salinity, temperature, density, and pressure) along the coast.

The removal of systematic component at Datum, has significantly reduced the difference between gravimetric and GPS/levelling geoids; however, the adjustment of systematic component by using the similarity transformation model, has shown the best results in representing the differences between gravimetric and GPS/levelling geoids. 


\section{1 - INTRODUÇÃO}

Os avanços resultantes do advento da era espacial, como o posicionamento e a determinação do campo de gravidade usando dados de satélites artificiais, têm contribuído para solucionar muitos problemas em Geodésia; entretanto, ainda não foi possível solucionar de maneira eficiente e prática o problema da unificação dos Data altimétricos locais.

A maioria dos Data altimétricos existentes no mundo são definidos pelo nível médio do mar (NMM) local, que varia com a posição geográfica e o tempo, por causa da topografia oceânica (TO), que somada aos erros inerentes às redes nivelamento, geram inconsistências entre os Data altimétricos definidos pelo nível médio do mar (NMM) e, consequentemente, entre as redes de nivelamento.

As causas da TO são as mudanças das características oceanográficas ao longo da costa (temperatura, salinidade, descargas de rios, etc.). No Brasil, foram registradas, por meio do nivelamento, diferenças que variam aproximadamente de -12 a $90 \mathrm{~cm}$ entre o marégrafo de Imbituba e os demais marégrafos da costa brasileira (Alencar, 1990).

Outro problema relacionado aos Data altimétricos definidos pelo NMM, é a obtenção da altitude ortométrica por nivelamento geométrico, que apresenta limitações práticas em países de dimensões continentais como o Brasil. Os problemas associados à obtenção da altitude ortométrica através do nivelamento convencional são:morosidade na implantação de redes altimétricas, dificuldades na distribuição homogênea das redes devido ao acesso a determinadas regiões, falta de controle no ajustamento, e alto custo, entre outros.

O problema da unificação dos Data altimétricos vem sendo estudado por geodesistas do mundo inteiro. A adoção de um Datum altimétrico unificado tem como principais objetivos: obter altitudes ortométricas compatíveis em escalas regional e global, e substituir os métodos tradicionais pelos modernos de posicionamento na obtenção de altitudes.

As principais idéias que vêm sendo exploradas para a unificação de Data altimétricos são: a unificação através de modelos geoidais (Rapp \& Balasubramania, 1992), cuja metodologia foi utilizada neste trabalho para compatibilizar o geóide gravimétrico ao Datum de Imbituba, e a unificação através do geopotencial (Bursa et al., 1999).

A diferença entre o geóide GPS e o geóide gravimétrico, conhecida como componente sistemática, é causada pela incompatibilidade dos sistemas de referência do geóide gravimétrico, altitude ortométrica e altitude geométrica, além dos erros sistemáticos e aleatórios (Kotsakis \& Sideris, 1999).

A determinação da componente sistemática permite compatibilizar o geóide gravimétrico ao geóide GPS (definido a partir do Datum local) e conseqüentemente as 
altitudes ortométricas obtidas através do nivelamento geométrico a partir do Datum local, às determinadas através da combinação de dados GPS e geóide gravimétrico.

A representação do campo de gravidade é fundamental na realização do Datum altimétrico global, visto que a determinação de modelos geoidais e a definição de altitudes físicas dependem desse campo. Atualmente, os recursos computacionais e o aprimoramento dos modelos globais do potencial gravitacional, expresso em harmônicos esféricos, estão proporcionando geóides cada vez mais precisos, que são essenciais na solução de problemas com os referenciais altimétricos.

Assim, os objetivos deste trabalho são: determinar a componente sistemática na região do Datum altimétrico, investigar suas causas e suas implicações para a Rede Altimétrica Fundamental do Brasil (RAFB), e fazer um estudo comparativo do NMM em marégrafos da costa brasileira, através de dados oceanográficos.

Dessa forma, o Capítulo 2 apresenta os elementos constituintes do campo de gravidade e suas relações. O Capítulo 3 trata de Datum altimétrico, tendo como objetivo apresentar a definição clássica de Datum altimétrico, enfatizando o Datum altimétrico brasileiro (localização, histórico, realização, marégrafo, implantação da Rede Maregráfica Permanente para Geodésia (RMPG) e comparação dos NMMs na costa brasileira com o NMM registrado em Imbituba por meio dos dados oceanográficos), descrever as causas da diferença entre o geóide GPS e o geóide gravimétrico e apresentar estudos e propostas para a realização de Datum altimétrico na era moderna. O Capítulo 4 descreve os dados utilizados neste trabalho. O Capítulo 5 apresenta a metodologia empregada na implantação da rede GPS em Santa Catarina e descrição dos modelos matemáticos utilizados na determinação da componente sistemática. O Capítulo 6 apresenta os resultados obtidos. Finalmente, o Capítulo 7 apresenta as conclusões. 


\section{2 - O CAMPO DA GRAVIDADE TERRESTRE}

A representação do campo de gravidade é fundamental para a Geodésia, pois está diretamente relacionado com a forma e os processos dinâmicos que ocorrem no interior da Terra.

A determinação de modelos geoidais de alta precisão atualmente é tema de trabalho em vários centros que desenvolvem pesquisas de Geodésia. A necessidade de unificação de Data altimétricos e a utilização do GPS na obtenção de altitude ortométrica, justificam os esforços para determinar modelos geoidais precisos e de alta resolução espacial.

Neste Capítulo, serão apresentados alguns aspectos conceituais do campo de gravidade com o objetivo de auxiliar na compreensão dos capítulos posteriores.

\section{1 - GEOPOTENCIAL}

O campo de gravidade é expresso em termos do geopotencial por

$$
\mathbf{g}=\operatorname{grad} \mathrm{W}
$$

onde W é o geopotencial, composto pelo potencial gravitacional V, decorrente da atração gravitacional das massas, e o potencial centrífugo $\Phi$, decorrente da rotação da Terra

$$
\mathrm{W}(\mathrm{r}, \phi, \lambda)=\mathrm{V}(\mathrm{r}, \phi, \lambda)-\Phi(\mathrm{r}, \phi, \lambda)
$$

onde $r, \phi, \lambda$ são as coordenadas geocêntricas (Figura 2.1).

No exterior das massas atrativas, o geopotencial reduz-se ao potencial gravitacional que, por ser uma função harmônica, satisfaz a equação de Laplace.

$$
\nabla^{2} \mathrm{~V}(\mathrm{r}, \phi, \lambda)=0
$$

Assim, o geopotencial pode ser expresso em harmônicos esféricos na forma (Moritz, 1980) 


$$
\mathrm{V}(\mathrm{r}, \phi, \lambda)=\sum_{\mathrm{n}=0}^{\infty} \frac{1}{\mathrm{r}^{\mathrm{n}+1}} \sum_{\mathrm{m}=0}^{\mathrm{n}}\left(\mathrm{A}_{\mathrm{nm}} \cos \mathrm{m} \lambda+\mathrm{B}_{\mathrm{nm}} \sin \mathrm{m} \lambda\right) \mathrm{P}_{\mathrm{nm}}(\cos \phi)
$$

onde $(\mathrm{r}, \phi, \lambda)$ são as coordenadas geocêntricas, $\mathrm{A}_{\mathrm{nm}}$ e $\mathrm{B}_{\mathrm{nm}}$ são coeficientes obtidos a partir de elementos conhecidos do campo de gravidade, e $\mathrm{P}_{\mathrm{nm}}(\cos \phi)$ representa os polinômios de Legendre associados de grau $\mathrm{n}$ e ordem $\mathrm{m}$.

O potencial centrífugo não pode ser representado em harmônicos esféricos por não ser uma função harmônica.

As superfícies equipotenciais do campo de gravidade real, satisfazem a condição

$$
\mathrm{W}=\text { cons tan te }
$$

Entre essas superfícies, a que coincide com o nível médio dos mares não perturbados é denominada superfície geoidal.

\section{2 - ESFEROPOTENCIAL}

Do ponto de vista geométrico, o modelo mais adequado para a aproximação da forma e dimensões da Terra, é o modelo elipsoidal. Esse modelo tem a forma de um elipsóide de revolução, com a mesma massa e velocidade da Terra real. O campo de gravidade gerado por esse modelo pode ser expresso por

$$
\gamma=\operatorname{grad} U
$$

O esferopotencial (U), é constituído pelo potencial gravitacional normal e pelo potencial centrífugo.

$$
\mathrm{U}(\mathrm{r}, \phi, \lambda)=\mathrm{V}^{\prime}(\mathrm{r}, \phi, \lambda)+\Phi^{\prime}(\mathrm{r}, \phi, \lambda)
$$

onde $V^{\prime}$ é o potencial gravitacional e $\Phi^{\prime}$ é o potencial centrífugo ( Heiskanen \& Moritz, 1967). 
A superfície limitante deste modelo é equipotencial, ou seja, satisfaz a condição

$$
\mathrm{U}(\mathrm{r}, \phi, \lambda)=\text { constante }
$$

\section{3 - POTENCIAL ANÔMALO}

A diferença entre o geopotencial e o esferopotencial no mesmo ponto é chamado potencial anômalo $(\mathrm{T})$, o qual descreve variações de grandezas físicas e geométricas da Terra real em relação à terra normal. Essas variações são decorrentes da distribuição heterogênea de massa da Terra. O potencial anômalo independe do potencial centrífugo, que se cancela por se tratar do mesmo ponto. Assim, o potencial anômalo tem a forma.

$$
\mathrm{T}(\mathrm{r}, \varphi, \lambda)=\mathrm{W}(\mathrm{r}, \varphi, \lambda)-\mathrm{U}(\mathrm{r}, \varphi, \lambda)
$$

Os elementos do campo de gravidade associados ao potencial anômalo são mostrados na Figura 2.1. O teluróide é a forma geométrica limitada pela superfície $\Sigma$, cujo esferopotencial em cada ponto é igual ao geopotencial do ponto correspondente na superfície física. A anomalia de altitude ( $\zeta$ ), é a diferença entre a altitude geométrica (h) e a altitude normal $\left(\mathrm{H}_{\mathrm{n}}\right)$. A altura geoidal $(\mathrm{N})$ representa a separação entre o geóide e o elipsóide.

A anomalia gravimétrica $(\Delta \mathrm{g})$ é a diferença entre a gravidade real reduzida ao geóide $(\mathrm{g})$, e a gravidade normal obtida no ponto correspondente no elipsóide $(\gamma)$.

$$
\Delta \mathrm{g}=\mathrm{g}-\gamma
$$




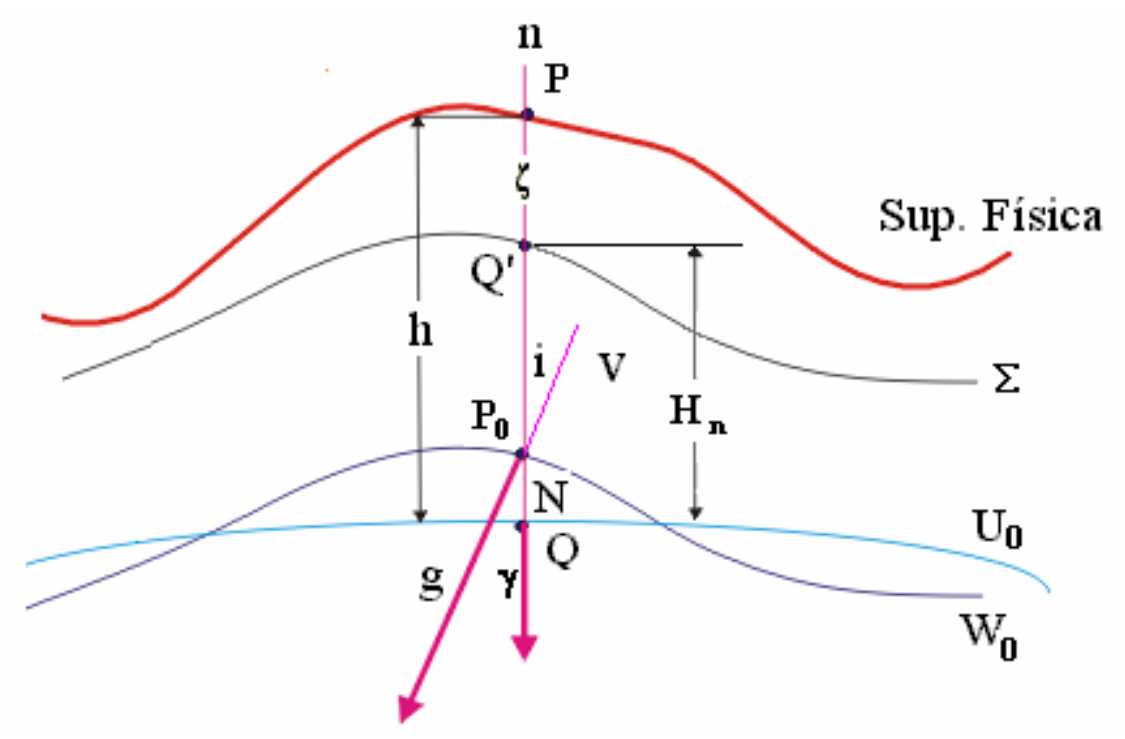

Figura 2.1 - Elementos do campo de gravidade

O desvio da vertical (i) representa o ângulo formado pela vertical e a normal no ponto considerado (Figura 2.2).

$$
\begin{aligned}
& \xi=\Phi-\varphi \\
& \eta=(\Lambda-\lambda) \cos \varphi
\end{aligned}
$$

onde $(\Phi)$ é a latitude astronômica, o ângulo formado pela a vertical do ponto (P) com sua projeção sobre o plano do equador, e $(\Lambda)$ é a longitude astronômica, ângulo formado entre o meridiano médio de Greenwich e o meridiano local do ponto ( Figura 2.2).

Para relacionar as observações do campo de gravidade com o potencial anômalo normalmente é usada a aproximação esférica, que consiste em substituir o esferopotencial pelo potencial gravitacional de uma esfera nas expressões envolvendo o campo anômalo (Sá, 2004). Os erros desta aproximação são, geralmente, admissíveis em aplicações práticas. 


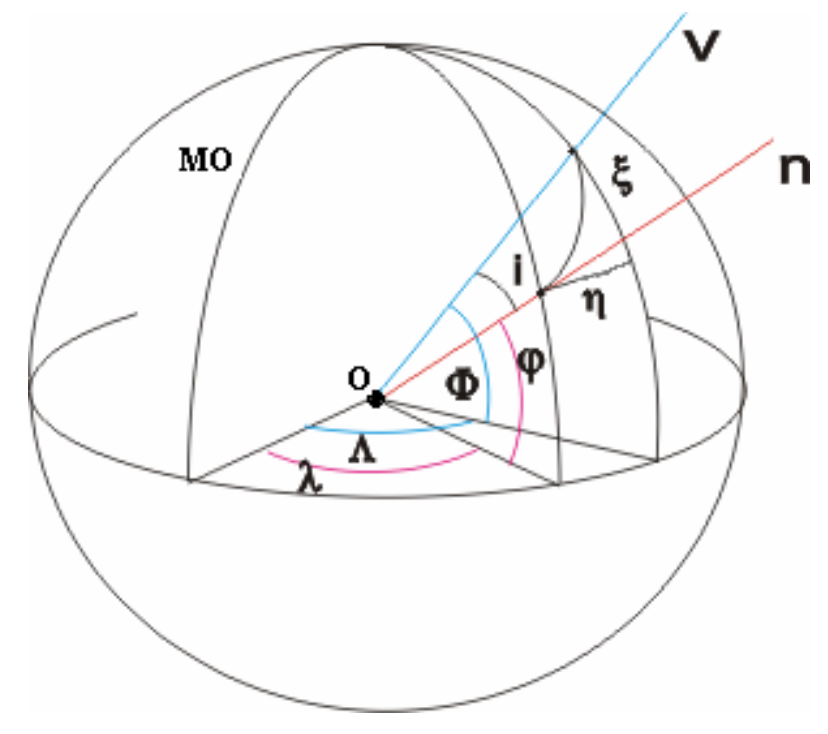

Figura 2.2 - Desvio da vertical

A relação entre a altura geoidal e a anomalia gravimétrica com o potencial anômalo, tem aplicações práticas importantes; e é dada pela fórmula de Bruns e pela equação fundamental da Geodésia Física, respectivamente (Heiskanen \& Moritz, 1967)

$$
\begin{aligned}
& \mathrm{N}=\frac{\mathrm{T}}{\gamma} \\
& \Delta \mathrm{g}=-\frac{\partial \mathrm{T}}{\partial \mathrm{h}}+\frac{1}{\gamma} \frac{\partial \gamma}{\partial \mathrm{h}} \mathrm{T}
\end{aligned}
$$

onde $\gamma$ é a aceleração de gravidade normal.

A relação entre o potencial anômalo e o desvio da vertical é feita pelas componentes meridiana e primeiro vertical (Vanicek \& Krakiwsky, 1982)

$$
\xi=-\frac{1}{\mathrm{r} \gamma} \frac{\partial \mathrm{T}}{\partial \varphi}
$$

e

$$
\eta=-\frac{1}{r \cos \varphi \gamma} \frac{\partial T}{\partial \lambda}
$$


O potencial anômalo externo é uma função harmônica, que pode ser expressa em harmônicos esféricos por (Heiskanen \& Moritz, 1967)

$$
\begin{aligned}
& \mathrm{T}(\mathrm{r}, \phi, \lambda)=\sum_{\mathrm{n}=0}^{\infty}\left(\frac{\mathrm{R}}{\mathrm{r}}\right)^{\mathrm{n}+1} \mathrm{~T}_{\mathrm{n}}(\phi, \lambda) \\
& \mathrm{T}(\phi, \lambda)=\sum_{\mathrm{m}=0}^{\mathrm{n}}\left(\overline{\mathrm{C}}_{\mathrm{nm}} \cos \mathrm{m} \lambda+\overline{\mathrm{S}}_{\mathrm{nm}} \operatorname{sen} \mathrm{m} \lambda\right) \overline{\mathrm{P}}_{\mathrm{nm}}(\cos \phi)
\end{aligned}
$$

onde $T_{n}(\phi, \lambda)$ representa os harmônicos esféricos de superfície, $\mathrm{R}$ é o raio terrestre médio, e $\mathrm{r}$ é o raio vetor do ponto de coordenadas geográficas $(\phi, \lambda)$.

Os coeficientes e polinômios de Legendre totalmente normalizados são dados pelas expressões:

$$
\begin{aligned}
& \bar{C}_{n m}=\sqrt{\frac{(n+m) !}{K(2 n+1)(n-m) !}} C_{n m} \\
& \bar{S}_{n m}=\sqrt{\frac{(n+m) !}{K(2 n+1)(n-m) !}} S_{n m} \\
& \bar{P}_{n m}(\cos \phi)=\sqrt{\frac{K(2 n+1)(n-m) !}{(n-m) !}} P_{n m}(\cos \phi)
\end{aligned}
$$

$\operatorname{com} \mathrm{K}=1$ se $\mathrm{m}=0$ e $\mathrm{K}=2$ se $\mathrm{m} \neq 0$.

onde $\mathrm{C}_{\mathrm{nm}}$ e $\mathrm{S}_{\mathrm{nm}}$ são coeficientes determinados a partir de dados associados ao campo de gravidade terrestre e $\mathrm{P}_{\mathrm{nm}} \cos (\phi)$ representa os polinômios de Legendre.

Utilizando a aproximação esférica, a expressão (2.17) assume a forma 


$$
\mathrm{T}(\mathrm{r}, \phi, \lambda)=\sum_{\mathrm{n}=0}^{\infty} \mathrm{T}_{\mathrm{n}}(\phi, \lambda)
$$

Assim, a anomalia ar-livre sobre o geóide pode ser representada em harmônicos esféricos a partir da derivada do potencial anômalo (2.22)

$$
-\frac{\partial \mathrm{T}}{\partial \mathrm{r}}=\frac{1}{\mathrm{R}} \sum_{\mathrm{n}=0}^{\infty}(\mathrm{n}+1) \mathrm{T}_{\mathrm{n}}(\phi, \lambda)
$$

a qual, substituindo-se em (2.14), resulta

$$
\Delta \mathrm{g}(\mathrm{r}, \phi, \lambda)=\frac{1}{\mathrm{R}} \sum_{\mathrm{n}=0}^{\infty}(\mathrm{n}-1) \mathrm{T}_{\mathrm{n}}(\phi, \lambda)
$$

A altura geoidal pode ser obtida substituindo-se (2.22) em (2.13)

$$
\mathrm{N}=\frac{1}{\gamma} \sum_{\mathrm{n}=0}^{\infty} \mathrm{T}_{\mathrm{n}}(\phi, \lambda)
$$

\section{4 - AVANÇOS NA REPRESENTAÇÃO DO CAMPO DE GRAVIDADE}

As técnicas espaciais e os recursos computacionais, revolucionaram a metodologia para representação do campo de gravidade. Até o início da década de 60, os modelos do geopotencial eram determinados usando apenas dados gravimétricos terrestres.

Nessa época, os modelos globais do potencial gravitacional expresso em harmônicos esféricos eram representados até o grau 4. Na década de 90, os dados de satélites, combinados com outros, possibilitaram a representação do campo de gravidade terrestre até o grau 1800 (Wenzel, 1999). 
Com o sucesso do experimento realizado com o SKYLAB, a altimetria por satélite justificou as missões seguintes Geodynamics Experiment Ocean Satellite (GEOS-3), SEASAT, Geodetic Satellite (GEOSAT), International Earth Rotation Service (IERS), entre outros, as quais forneceram dados para a representação do campo de gravidade e da topografia do fundo oceânico com alta resolução.

O modelo geopotencial OSO91A (Rapp et al., 1991), desenvolvido pela Ohio State University (OSU) e expandido até o grau e a ordem 360, foi desenvolvido visando aplicações geodésicas. Os dados utilizados nesse modelo foram dados de Gravimetria terrestre e dados de observações de satélites, incluindo satélites altimétricos (Nerem, 1995).

No desenvolvimento do modelo Earth Gravitational Model 1996 (EGM96) (Lemoine et al., 1998), foram incorporados novos dados gravimétricos de superfície, além de dados de órbita de satélite e altimetria, obtendo assim melhora considerável em relação ao modelo OSO91A.

Recentemente, foram divulgados os modelos do campo de gravidade EIGEN-CG01C e o CG03C, que resultaram da combinação de dados do campo de gravidade terrestres, oceânicos e derivados da altimetria por satélite, com os coletados nas missões Challenging Minisatellite Payload (CHAMP) e Gravity Recovery and Climate Experiment (GRACE).

\section{5 - ALTITUDES}

Existem vários tipos de altitudes em Geodésia, das quais, as mais usadas são: altitude dinâmica, altitude ortométrica e altitude normal. As definições dessas altitudes, que são as mais utilizadas na prática, serão vistas a seguir.

\section{Altitude dinâmica}

Representando por $\gamma_{0}$ a gravidade normal para a latitude de $45^{\circ}$ (podendo também ser utilizado um valor constante de gravidade ou a gravidade média da região), tem-se a altitude dinâmica $\left(\mathrm{H}_{\mathrm{d}}\right)$ expressa por 


$$
\mathrm{H}_{\mathrm{d}}=\frac{\mathrm{C}}{\gamma_{0}}
$$

onde C é o número geopotencial, cuja expressão será descrita a seguir.

Realizando o nivelamento em conjunto com a medição gravimétrica, obtém-se o número geopotencial, que é a diferença entre o potencial gravitacional no geóide e no ponto $\mathrm{P}$, localizado na superfície terrestre (Heiskanen \& Moritz, 1967).

$$
\mathrm{C}=\mathrm{W}_{\mathrm{P}_{0}}-\mathrm{W}_{\mathrm{P}}
$$

onde

$$
\mathrm{C}=\int_{\mathrm{P}_{0}}^{\mathrm{P}} \mathrm{gdH}
$$

e

$$
\mathrm{C}=\overline{\mathrm{g}} \mathrm{H}
$$

onde $\overline{\mathrm{g}}$ é a gravidade média ao longo de $\mathrm{P}_{0} \mathrm{P}$ (Heiskanen \& Moritz, 1967).

\section{Altitude ortométrica}

Denomina-se altitude ortométrica $(\mathrm{H})$ a distância contada ao longo da vertical entre o ponto $\mathrm{P}$, na superfície física da Terra, e a superfície geoidal (Figura 2.3).

No Brasil, aplica-se uma correção na altitude ortométrica conhecida como correção ortométrica, que elimina o efeito da variação da distância entre os geopes em função da latitude, porém, nessa correção não são usadas observações gravimétricas.

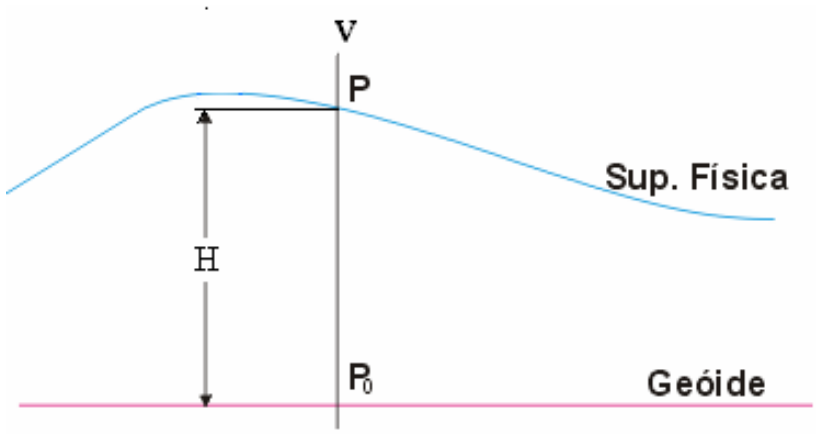

Figura 2.3 - Altitude ortométrica 
Através da expressão (2.29), tem-se a altitude ortométrica definida por

$$
\mathrm{H}=\frac{\mathrm{C}}{\overline{\mathrm{g}}}
$$

O cálculo exato de $\overline{\mathrm{g}}$ requer o conhecimento da estrutura da crosta, dificultando o uso da altitude ortométrica (Jekeli, 2000).

\section{Altitude normal}

A superfície sobre a qual o esferopotencial no ponto correspondente é igual ao geopotencial em P é conhecida como teluróide; a separação entre o teluróide e o elipsóide é denominada altitude normal $\left(H_{n}\right)$, expressa por (Figura 2.4) (Heiskanen \& Moritz, 1967)

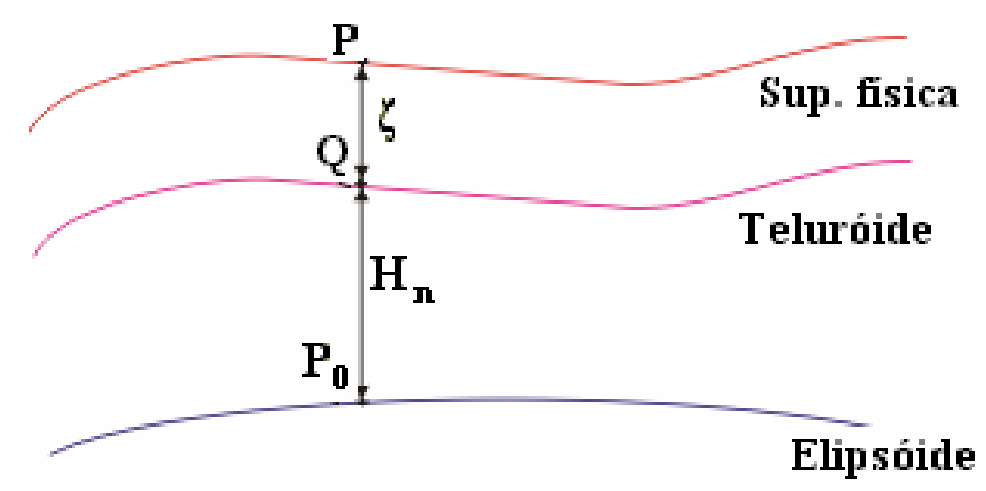

Figura 2.4 - Altitude normal

$$
\mathrm{H}_{\mathrm{n}}=\frac{\mathrm{C}}{\bar{\gamma}}
$$

sendo 


$$
\bar{\gamma}=\frac{1}{\mathrm{H}_{\mathrm{n}}} \int_{\mathrm{P}_{0}}^{\mathrm{Q}} \gamma \mathrm{dH_{ \textrm {n } }}
$$

onde $\bar{\gamma}$ é a gravidade normal média entre o elipsóide $\mathrm{P}_{0}$ e o teluróide (Q) .

No próximo capítulo, será enfatizada a importância do conhecimento do campo de gravidade na conexão de Data altimétricos e na realização de um Datum altimétrico global. 


\section{3 - DATUM ALTIMÉTRICO}

Mesmo com a tecnologia GPS, os problemas referentes aos Data altimétricos e a obtenção de altitudes ainda não foram solucionados. A superfície de referência da maioria dos Data altimétricos é o NMM registrado nas regiões costeiras, e a altitude ortométrica é obtida por nivelamento geométrico. Atualmente, existem esforços em todo o mundo para unificar e modernizar os Data altimétricos, visando a obtenção de altitudes de maneira prática, precisa e eficiente.

Neste capítulo, serão abordados os conceitos e os problemas referentes aos Data altimétricos, com base em estudos recentes realizados sobre o tema.

\section{1 - CONCEITO CLÁSSICO DE DATUM ALTIMÉTRICO}

O termo Datum é utilizado para designar um conjunto de parâmetros e dados que constituem a base para a obtenção de outros dados. O Datum altimétrico clássico é constituído de uma ou mais referências de nível (RNs), cuja altitude ortométrica é referida diretamente a uma superfície definida pelo NMM local, determinado a partir de medições do nível instantâneo do mar, realizadas por marégrafos. A altitude ortométrica da referência de nível (RN) que materializa o Datum altimétrico é determinada por nivelamento geométrico (Figura 3.1), a partir da relação

$$
\mathrm{H}_{\mathrm{RN}}=\mathrm{H}_{\mathrm{MRN}}-\mathrm{H}_{\mathrm{NML}}
$$

onde $\mathrm{H}_{\mathrm{NML}}$ é o desnível entre o NMM local e o zero da régua do marégrafo, e $\mathrm{H}_{\mathrm{MRN}}$ é o desnível entre o zero da régua do marégrafo e a $\mathrm{RN}$ (Figura 3.1). O valor de $\mathrm{H}_{\mathrm{MRN}}$ é obtido pelo nivelamento geométrico entre o zero da régua do marégrafo e a $\mathrm{RN}$ associada ao marégrafo.

A diferença entre o geóide e o NMM (Figura 3.1), denominada topografia oceânica (TO)é causada por agentes físicos, meteorológicos e oceanográficos tais como:

1. Variação da salinidade das águas do oceano;

2. Variação da pressão atmosféricas;

3. Correntes marinhas;

4. Ventos; 
5. Variações nas configurações batimétricas ao longo da costa;

6. Variações de temperatura;

7. Descarga de água doce através de rios.

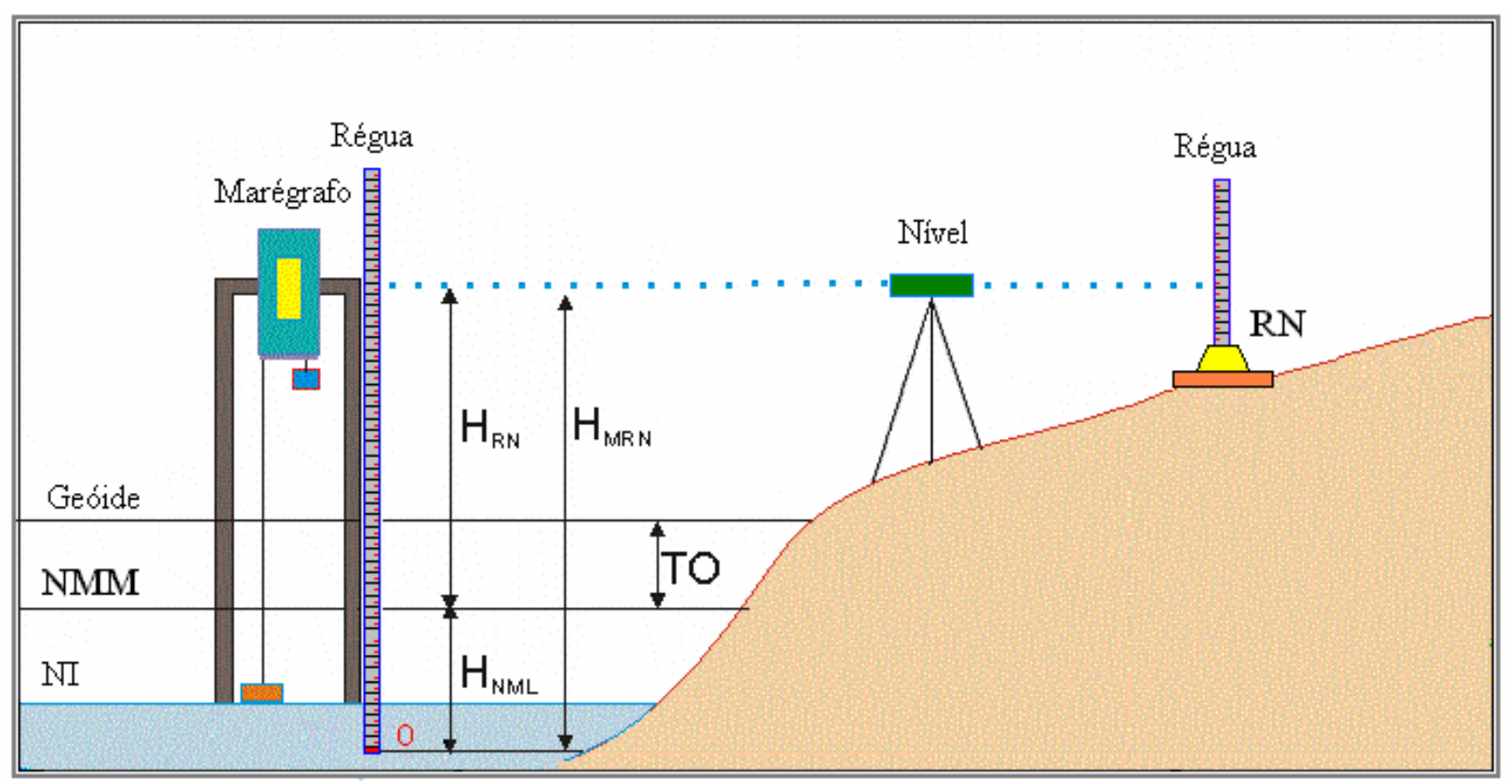

Figura 3.1 - Materialização do Datum altimétrico através do NMM

As observações maregráficas permitem obter uma superfície de referência local, pois a TO é gerada por fatores oceanográficos e meteorológicos que variam em função da posição geográfica, e do tempo. Segundo observações de altimetria por satélite (TOPEX/POSEIDON), o NMM vem aumentando na razão de 2,4 $\pm 0,1 \mathrm{~mm} /$ ano na última década (Figura 3.2) (Cazenave et. al., 2002).

$\mathrm{O}$ uso do NMM como referência pode causar incompatibilidade entre redes de nivelamento, referidas a Data locais diferentes, e problemas de revitalização de bairros portuários, que podem encontrar problemas de drenagem de águas pluviais se não forem considerados o NMM local e o nível máximo (Luz \& Guimarães, 2003). 


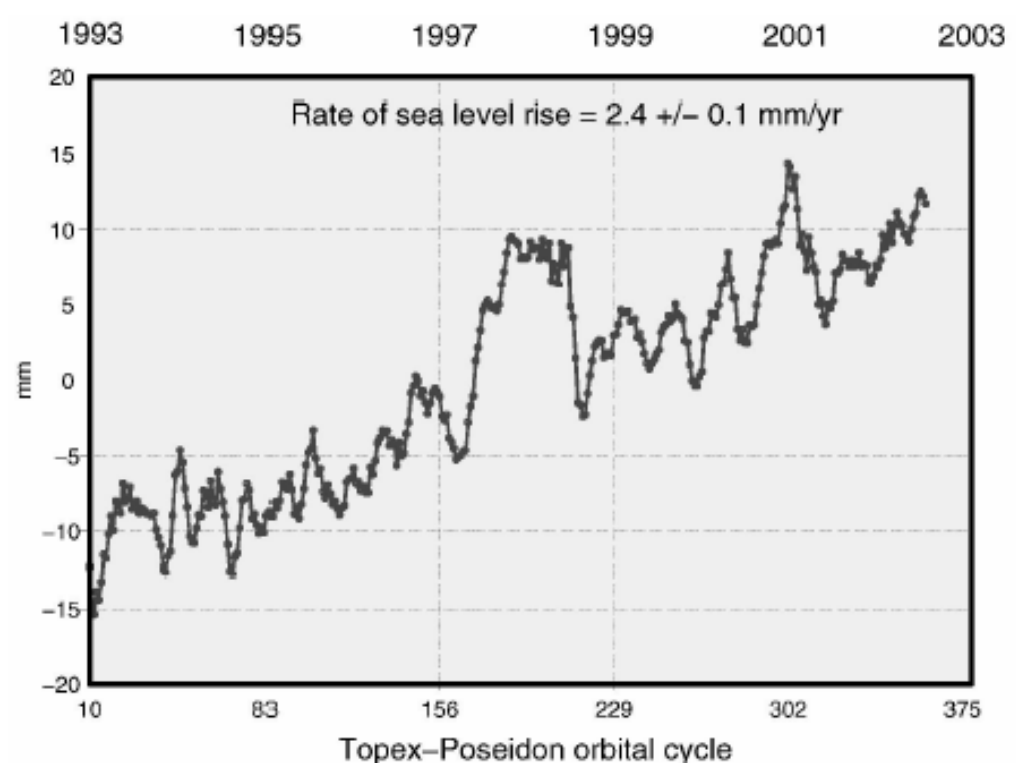

Figura 3.2 - Aumento do NMM global

(Fonte: Cazenave, 2002)

\section{2 - DATUM ALTIMÉTRICO BRASILEIRO}

O Datum altimétrico brasileiro está localizado na cidade de Imbituba (SC), na propriedade da Companhia Docas Imbituba, onde foram coletadas observações do nível do mar no período 1949-1957 e realizada a conexão da rede de nivelamento à RN 4X pela Fundação Instituto Brasileiro de Geografia e Estatística (IBGE) .

A localização da $\mathrm{RN} 4 \mathrm{X}$ próxima à uma edificação não permite o posicionamento por GPS. Assim, o IBGE construiu o marco SAT 91854, próximo à RN 4X, no qual determinou a altitude ortométrica a partir da RN 4X, e as coordenadas geodésicas a partir da Rede Brasileira de Monitoramento Contínuo (RBMC).

A Figura 3.3 mostra a localização do marégrafo, da RN 4X e das estações GPS implantadas pelo Instituto de Astronomia, Geofísica e Ciências Atmosféricas da Universidade de São Paulo (IAG/USP). 


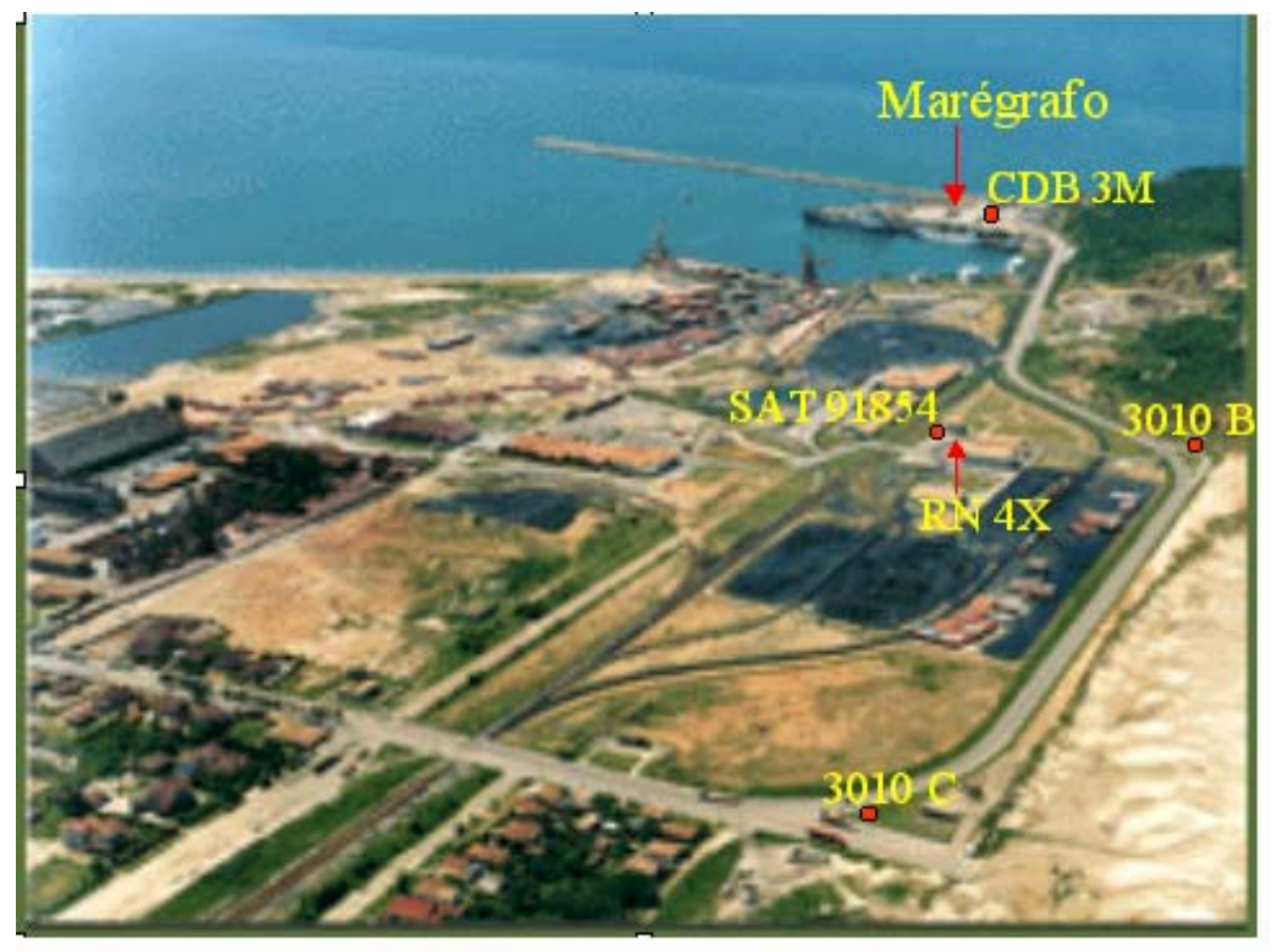

Figura 3.3 - Localização do marégrafo e das estações GPS

\section{Histórico}

Com base na descrição de Alencar (1990), a implantação da RAFB teve início em 1945, pelo IBGE, no município de Uruçanga (SC); entretanto, só foi possível calcular a altitude das RNs dessa rede, referidas ao NMM, em 1946, quando foi adotado o Datum de Torres (RS).

O curto período de observações do nível do mar no Datum de Torres (apenas no ano de 1919), justificou sua substituição, em 1958, pelo Datum de Imbituba, que contava com 9 anos de observações maregráficas (1949-1957), sob a supervisão do Inter American Geodetic Survey (IAGS). Também no ano de 1958, foi feita a conexão do nivelamento existente com a RN 4X (Figura 3.4). O NMM determinado no período 1949-1957, é usado até hoje como referência, apesar de ser recomendado um período mínimo de 19 anos de observações, para que sejam reduzidos os efeitos das variações periódicas de origens astronômicas. 


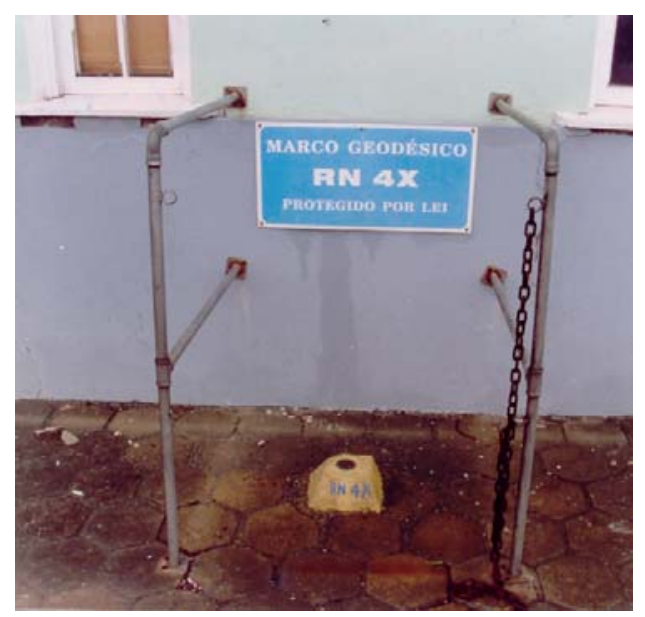

Figura 3.4 - Detalhe da referência de nível fundamental da rede de nivelamento do Brasil.

Após a conexão do nivelamento existente com a RN 4X, foi calculada a sua altitude, com base nos dados maregráficos fornecidos pelo IAGS, para o período 1949-1957, conforme os valores da Tabela 3.1.

Tabela 3.1 - Médias anuais do nível médio do mar em relação à régua do marégrafo de Imbituba

(Fonte: PSMSL, 2005)

\begin{tabular}{|l|c|c|}
\hline Ano & $\begin{array}{c}\text { NMM } \\
(\mathrm{m})\end{array}$ & $\begin{array}{c}\text { Desvio padrão } \\
(\mathrm{m})\end{array}$ \\
\hline 1949 & 2,261 & 0,0116 \\
\hline 1950 & 2,277 & 0,0038 \\
\hline 1951 & 2,258 & 0,0145 \\
\hline 1952 & 2,286 & 0,0128 \\
\hline 1953 & 2,255 & 0,0177 \\
\hline 1954 & 2,304 & 0,0312 \\
\hline 1955 & 2,283 & 0,0099 \\
\hline 1956 & 2,273 & 0,0006 \\
\hline 1957 & 2,258 & $-0,0145$ \\
\hline
\end{tabular}

As estátisticas das observações maregráficas no período 1949-1957, são mostradas na Tabela 3.2 e o histograma das médias mensais para o mesmo período, na Figura 3.5. 
Tabela 3.2 - Estatísticas das observações maregráficas no período 1949-1957.

\begin{tabular}{|l|c|}
\hline Estatísticas & $\begin{array}{c}\text { Valor numérico } \\
(\mathrm{m})\end{array}$ \\
\hline Média & 2,273 \\
\hline Desvio Padrão & 0,065 \\
\hline Máximo & 2,426 \\
\hline Mínimo & 2,118 \\
\hline
\end{tabular}

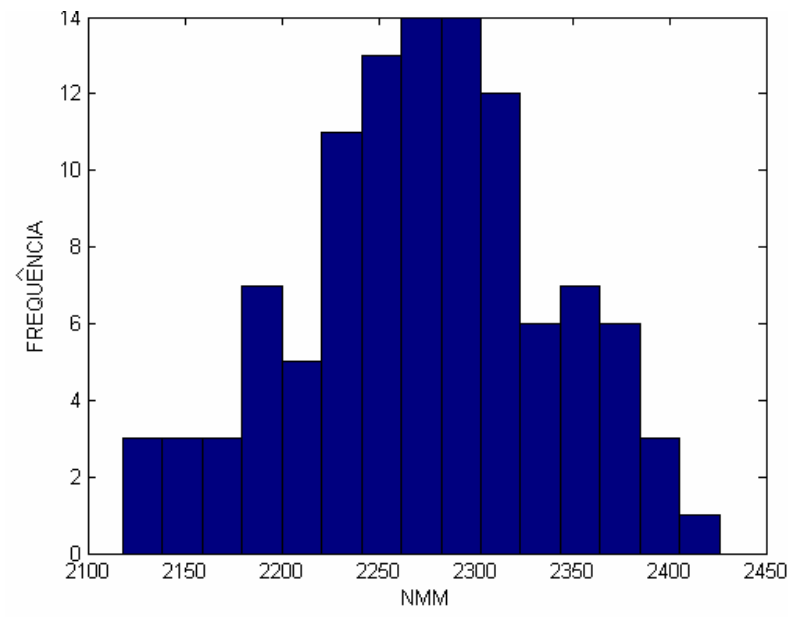

Figura 3.5 - Histograma das médias mensais para o período 1949-1957

A Figura 3.6, mostra as variações anual e mensal do NMM em Imbituba, para o período 1949-1957. A diferença de nível entre o zero da régua e a RN 4X é 10,9094 m; subtraindo o valor da altitude nivelada, a patir do zero da régua, do valor do NMM obtém-se a altitude da RN 4X igual a 8,6362 m em relação ao NMM (Figura 3.7). A determinação da altitude ortométrica na $\mathrm{RN} 4 \mathrm{X}$, diretamente vinculada ao marégrafo, é apresentada com detalhes na Seção 3.1. 


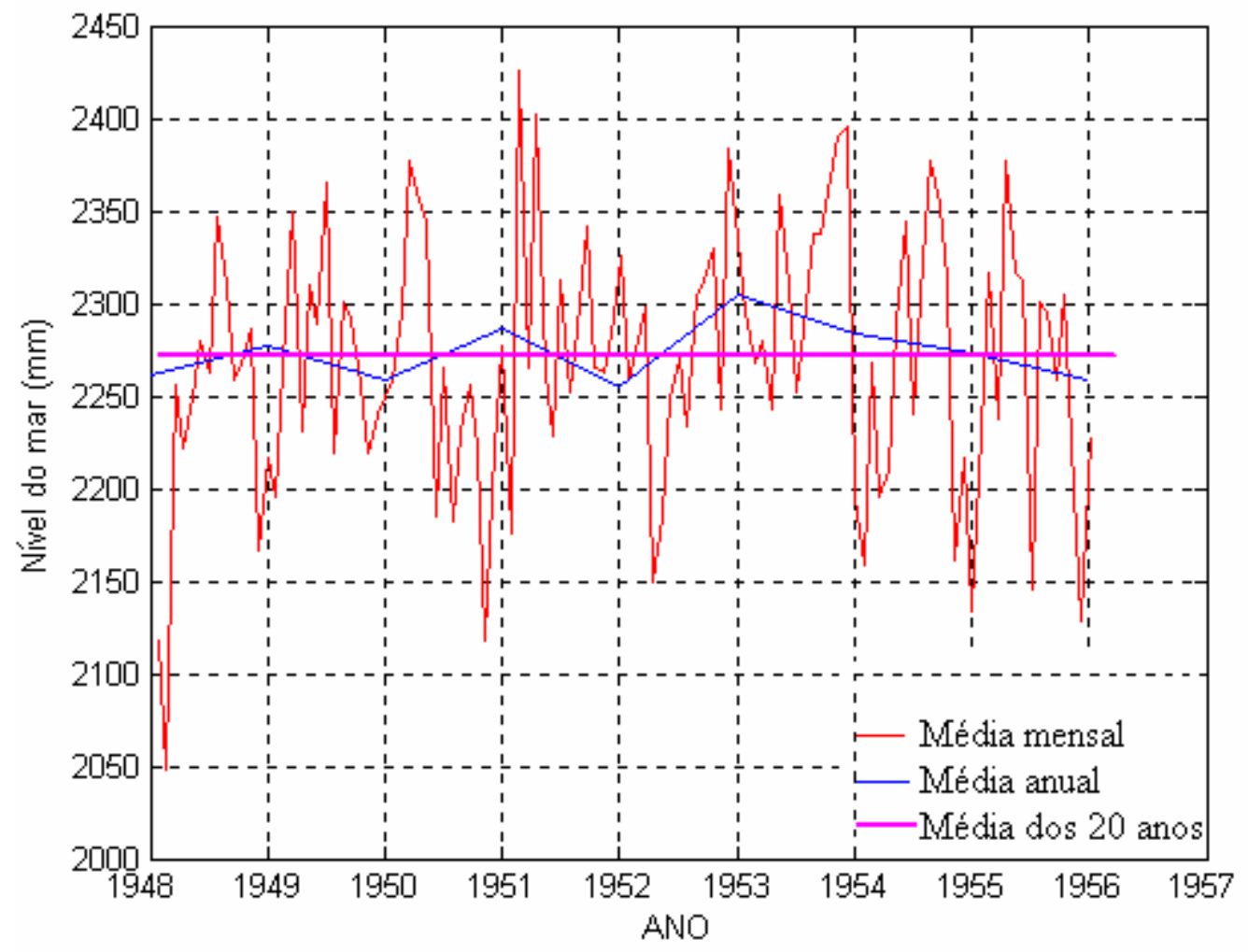

Figura 3.6 - Médias anuais e mensais para o período de 9 anos de observações.

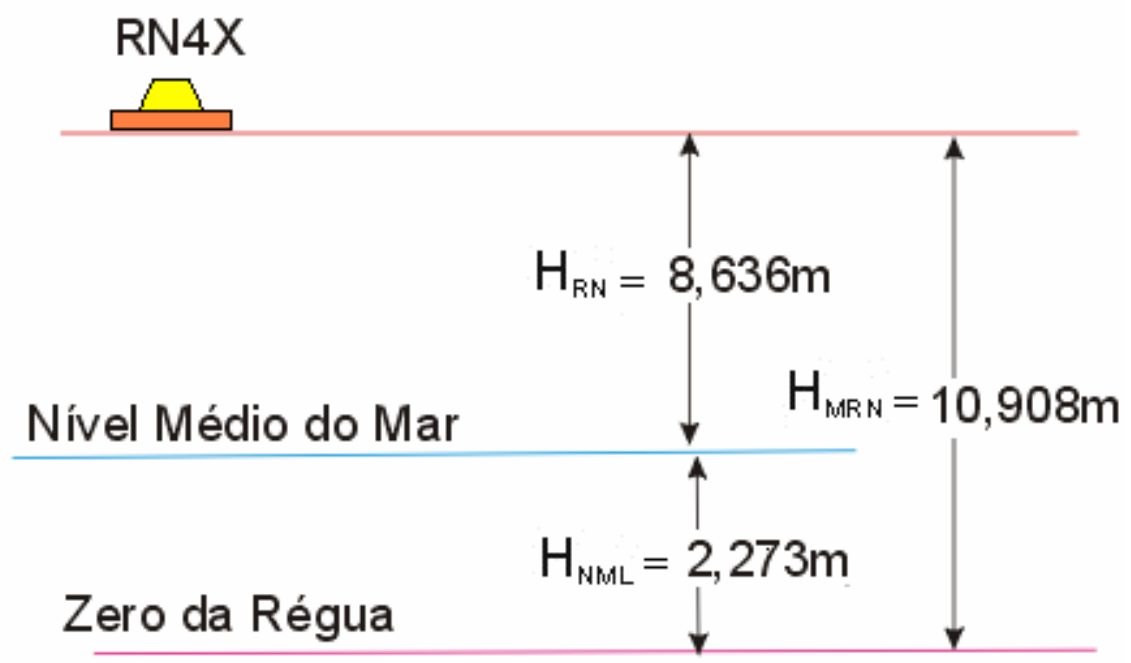

Figura 3.7 - Altitude da RN 4X em relação ao zero da régua do marégrafo e ao NMM.

(Adaptado de Alencar, 1990) 
Comparando o valor do NMM, calculado para os 9 anos de observações (1949-1957), com o valor calculado para período de 20 anos (1949-1969), verifica-se que a diferença entre o valor oficial adotado $(2,273 \mathrm{~m})$ com o valor calculado para o período de 20 anos (Tabela 3.3), é de 0,005 m. Essa variação pequena indica que a média determinada a partir dos dados para o período de 9 anos não apresenta problemas, apesar do curto período de observações.

Tabela 3.3 - Estatísticas dos valores mensais para o período 1949-1969.

\begin{tabular}{|l|c|}
\hline Estatísticas & $\begin{array}{c}\text { Valor numérico } \\
(\mathrm{m})\end{array}$ \\
\hline Média & $\mathbf{2 , 2 7 8}$ \\
\hline Desvio padrão & 0,077 \\
\hline Máximo & 2,505 \\
\hline Mínimo & 2,048 \\
\hline
\end{tabular}

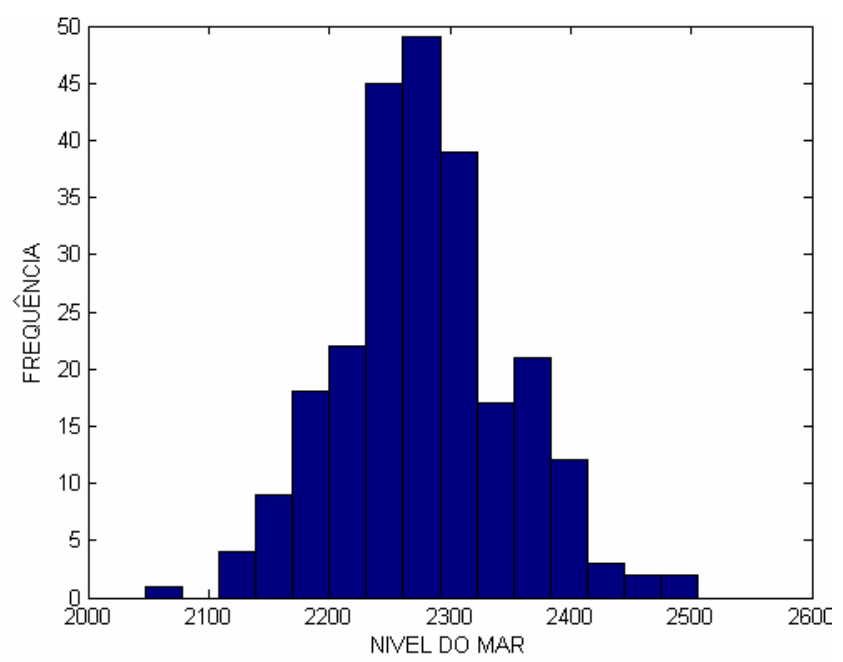

Figura 3.8 - Histograma das observações maregráficas para o período 1949-1969.

A Figura 3.9 apresenta as médias mensais e anuais para o período de 20 anos (19491969) assim como a média calculada para o mesmo período.

As variações anuais e mensais resultam de uma série de fatores como as variações de pressão atmosférica, as correntes marinhas, os ventos, as mudanças nas configurações batimétricas, o derretimento das geleiras, entre outros (Vanícek \& Krakiwsky, 1982). 


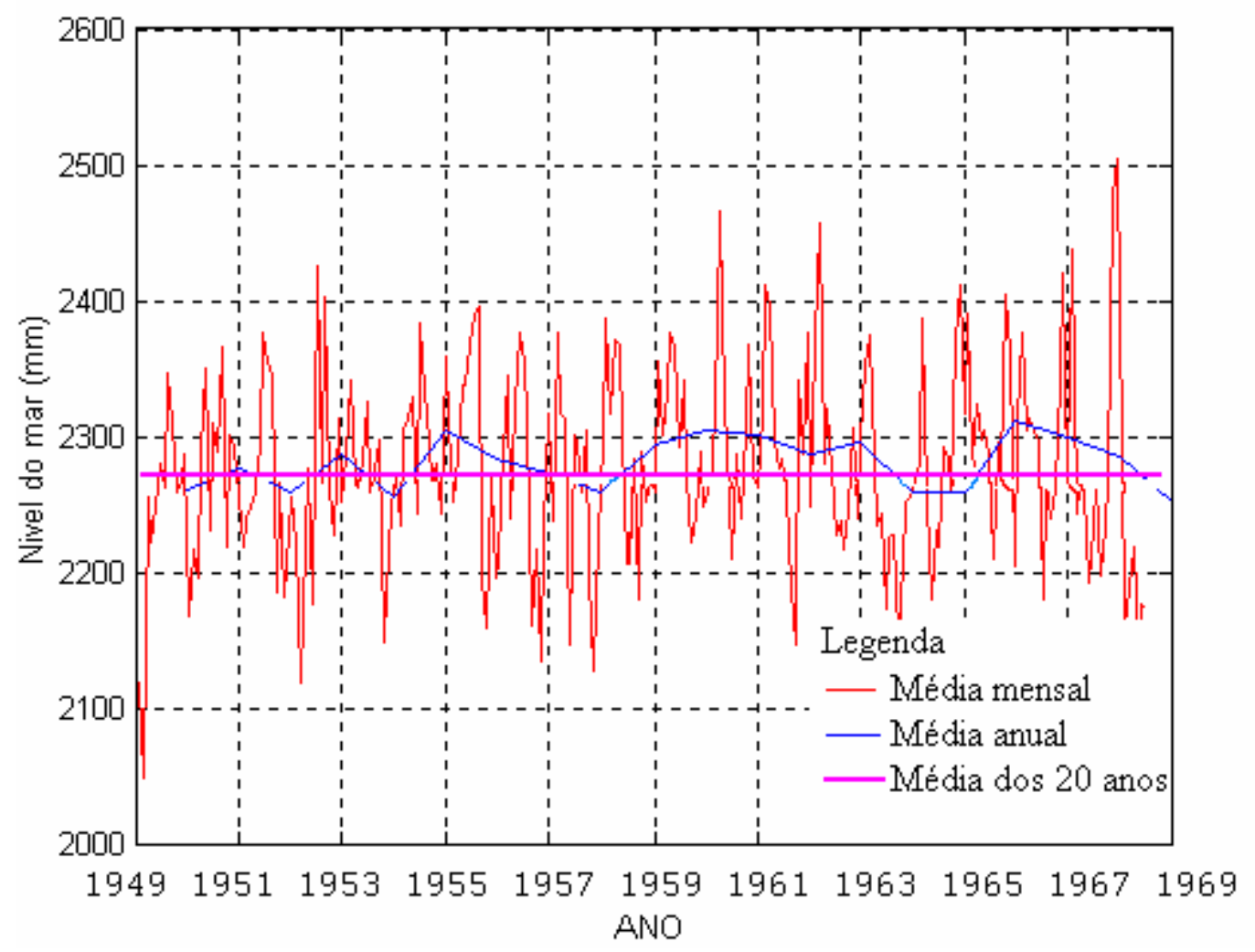

Figura 3.9 - Médias mensais e anuais para o período 1949-1969.

\section{Marégrafo}

O marégrafo no qual foi registrado o NMM no Datum de Imbituba, é constituído por um flutuador instalado no interior de um tubo vertical, conhecido como poço tranquilizador, cujo interior comunica-se com o mar por pequenos orifícios em sua porção inferior. $\mathrm{O}$ movimento do flutuador é transmitido por um cabo até o sistema gráfico de registro (Figura $3.10)$ 


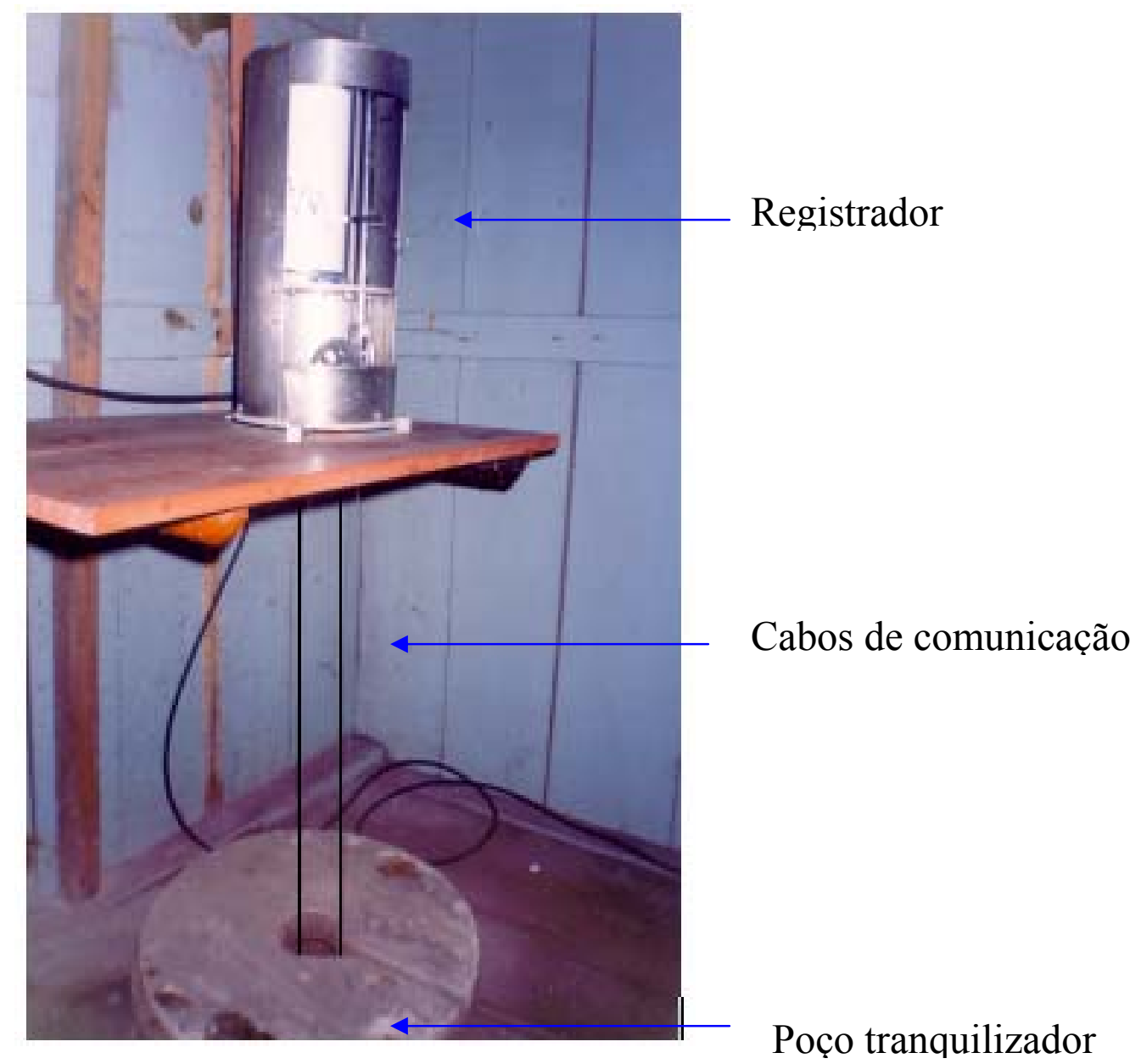

Figura 3.10 - Sistema de registro do marégrafo de Imbituba

\section{Relação entre os NMMs da costa brasileira}

As diferenças entre os NMMs registrados nos marégrafos da costa brasileira, determinadas por nivelamento em relação ao de Imbituba (Figura 3.11), podem estar associadas à propagação de erros no nivelamento, e às características oceanográficas ao longo da costa; entretanto, a análise dessas diferenças deve ser feita com cuidado, considerando fatores como o tempos de observações em períodos diferentes e a multiplicidade de padrões de operação, e o tratamento das observações. As diferenças entre o NMM registrado no Datum de Imbituba e outros marégrafos da costa brasileira foram determinadas através da RAFB. 


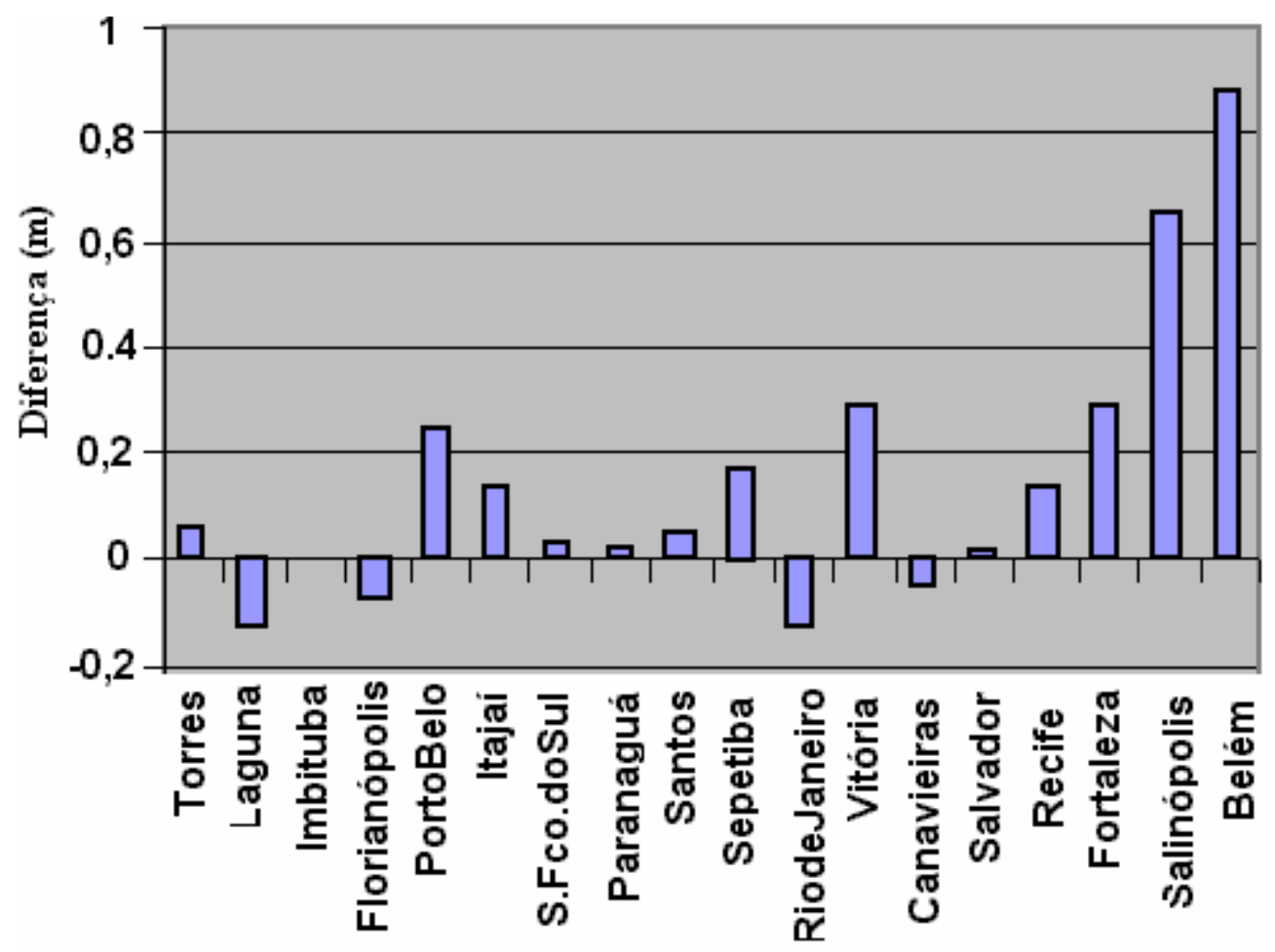

Figura 3.11 - Diferenças entre os marégrafos da costa brasileira

(Fonte: Alencar, 1990)

Com a implantação da Rede Maregráfica Permanente para Geodésia (RMPG) esse problema pode ser melhor estudado, pois a coleta de dados será feita simultaneamente, e o gerenciamento dos dados é unificado, facilitando a comparação entre os marégrafos.

\section{Características oceanográficas e o nível médio do mar}

Como foi mencionado, a relação estabelecida entre os níveis do mar (Figura 3.11), está sujeita a erros de nivelamento e erros oriundos dos registros maregráficos. Entretanto, as diferenças registradas nos marégrafos de Salinópolis e de Belém, estão muito acima da precisão da RAFB; como pode ser observado na Figura 3.11, o nível do mar em Belém está aproximadamente $90 \mathrm{~cm}$ acima do nível do mar registrado em Imbituba. Essas diferenças provavelmente são causadas, em parte pelas características oceanográficas das regiões, e em parte por erros acumulados nas longas linhas de nivelamento da RAFB.

A temperatura, a salinidade e a descarga dos rios estão diretamente ligados à densidade da água do oceano, que influencia diretamente o nível do mar (Carlsson, 1998). O nível do mar aumenta com o decréscimo da densidade, o que foi verificado por Lisitzin (1974) no mar Báltico. 
A relação entre a densidade e a temperatura da água do oceano, para salinidade constante é mostrada na Figura 3.12.

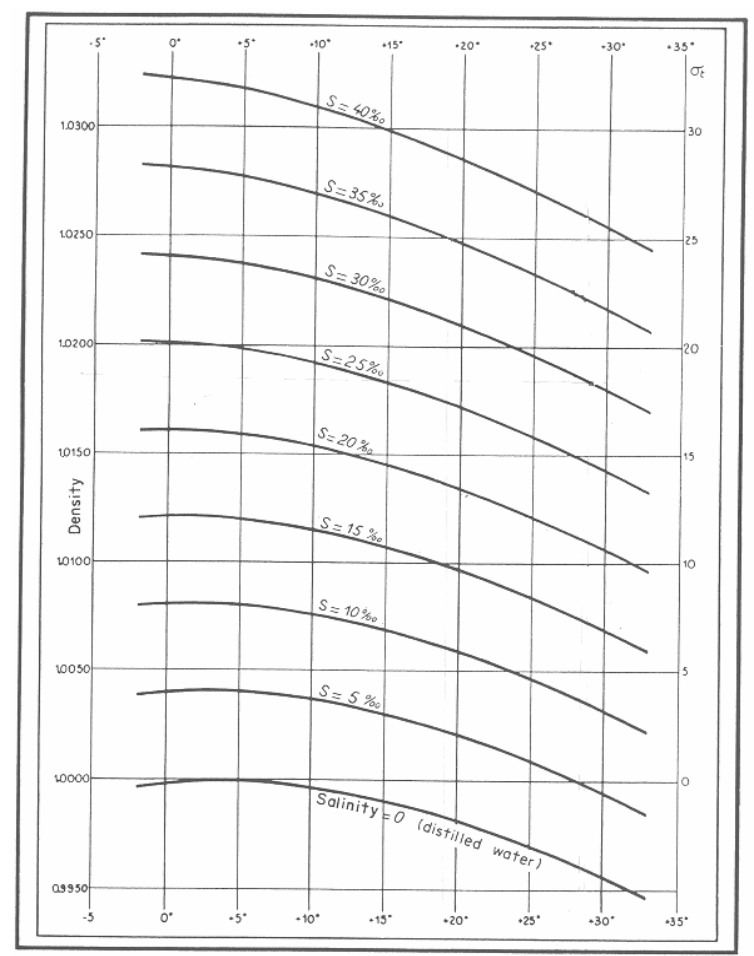

Figura 3.12 - Variações de densidade em função da temperatura para salinidade constante (Fonte: Tchernia, 1974)

A temperatura influencia indiretamente a densidade da água por meio da precipitação e evaporação, que contribuem para a diminuição e o aumento da salinidade, respectivamente. A salinidade superficial geralmente é maior nas zonas tropicais (cerca de 36 gramas de sal/ $1000 \mathrm{ml}$ de água $(36 \%$ oo) ) devido à evaporação que excede a precipitação. A densidade da água é diretamente proporcional à dissolução de sais. Assim, a salinidade junto à costa apresenta valores menores, comparados ao resto do oceano, devido à descarga de água doce (Pickard, 1974).

A descarga de rios pode alterar o NMM em vários decímetros, dependendo da localização e do volume de água doce descarregada no mar (Vanicek \& Krakiwsky, 1982). A Figura 3.13, mostra a localização dos rios e marégrafos na costa brasileira.

As variações de temperatura e salinidade na costa brasileira são ilustradas nas Figuras 3.15 e 3.16, respectivamente. A baixa salinidade nas proximidades de Belém e Salinópolis (Figura 3.13), é explicada pela descarga do grande volume de água doce do rio Amazonas. 


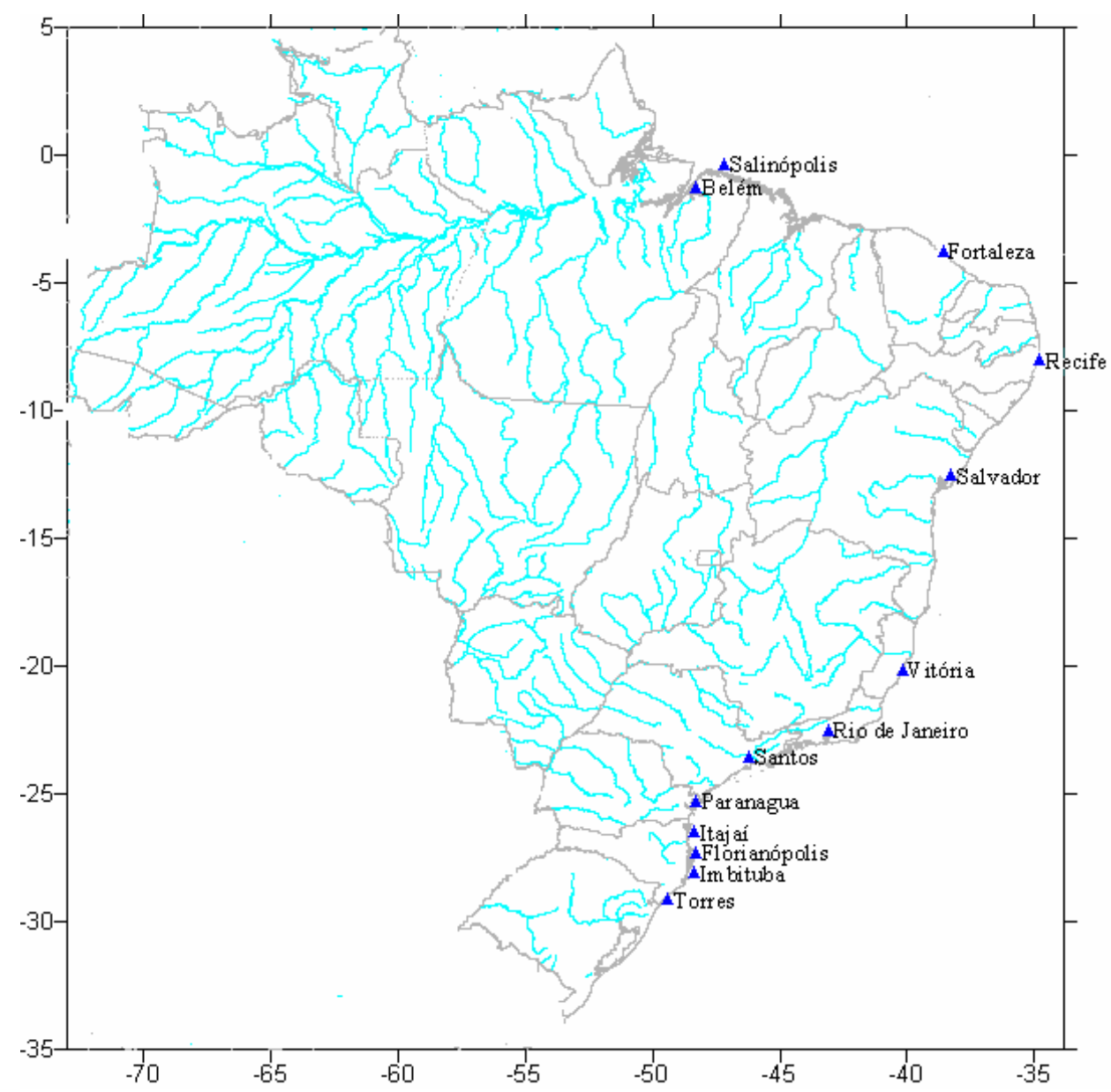

Figura 3.13 - Localização dos rios e marégrafos implantados na costa brasileira

A partir da salinidade (Figura 3.14) e temperatura (Figura 3.15), e da relação entre densidade, temperatura e salinidade (Figura 3.12), pode-se determinar a densidade.

A diferença entre os níveis do mar, calculada pela densidade, é determinada de forma relativa, ou seja, calcula-se a altura da coluna d'água para uma determinada pressão no ponto de referência (neste caso, Imbituba) e, posteriormente, para os pontos em questão, utilizando a mesma pressão. A diferença entre os níveis do mar é dada pela diferença entre as alturas das colunas d'água em relação ao ponto de referência.

A pressão (p) num ponto imerso num líquido, é expressa por (Lisitzin, 1974)

$$
\mathrm{p}=\bar{\rho} \mathrm{gt}
$$


onde $\bar{\rho}$ é a densidade média da água, g é a aceleração de gravidade. Portanto, obtém-se a altura da coluna d'água $(\mathrm{t}$ ), para uma determinada pressão

$$
\mathrm{t}=\frac{\mathrm{p}}{\bar{\rho} \mathrm{g}}
$$

A diferença entre o nível do mar $\left(\Delta \mathrm{NM}_{0}\right)$, calculada através de dados oceanográficos, tem a expressão

$$
\Delta \mathrm{NM}_{0}=\mathrm{t}_{\mathrm{P}}-\mathrm{t}_{\mathrm{R}}
$$

onde $t_{P}$ é a altura da coluna d'água no ponto de interesse, e $t_{R}$ é altura da coluna no ponto de referência.

As estimativas da diferença entre os NMMs são aproximadas devido à baixa precisão dos dados oceanográficos. 


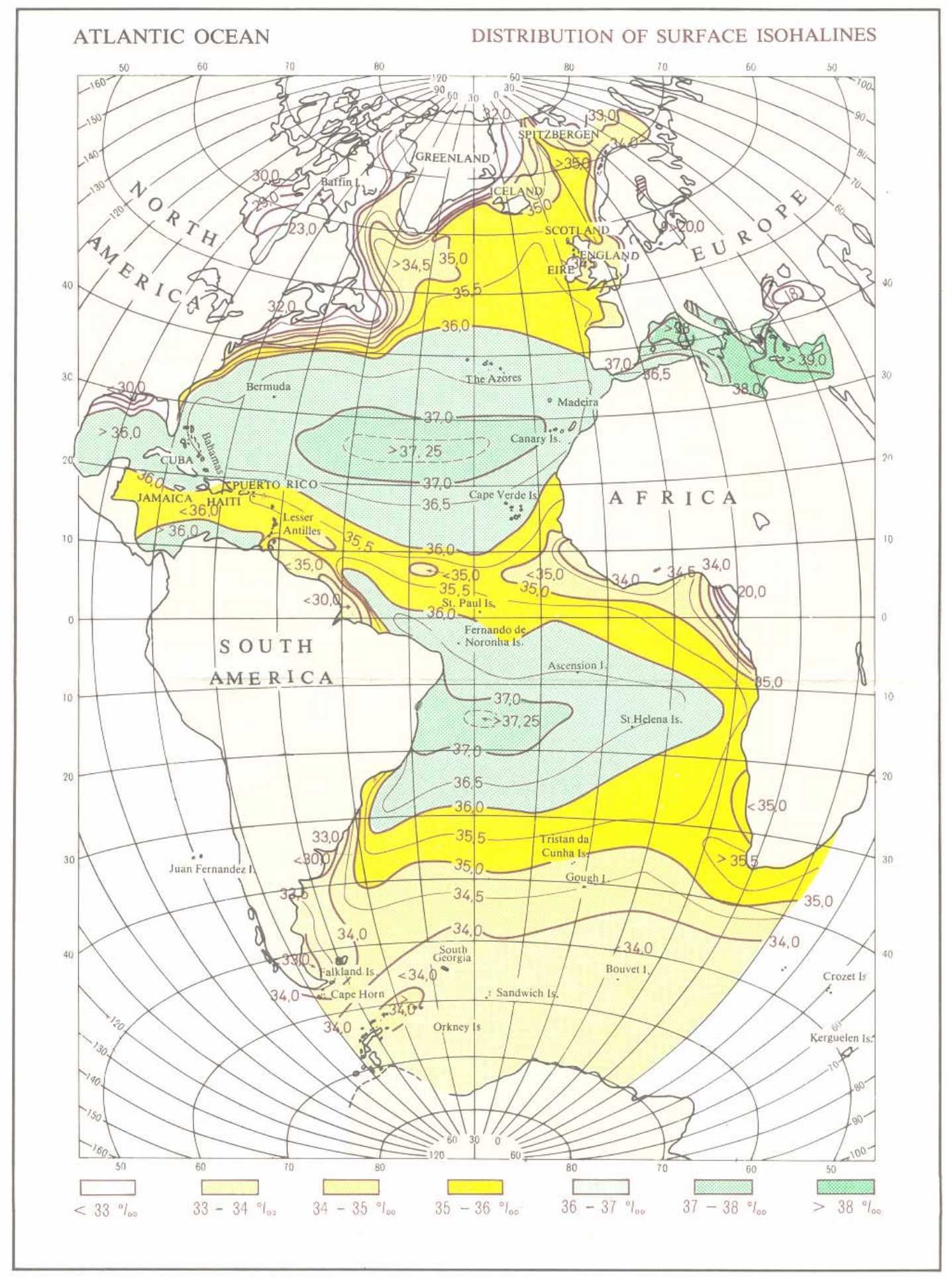

Figura 3.14 - Mapa de salinidade no oceano Atlântico

(Fonte: Tchernia 1980) 


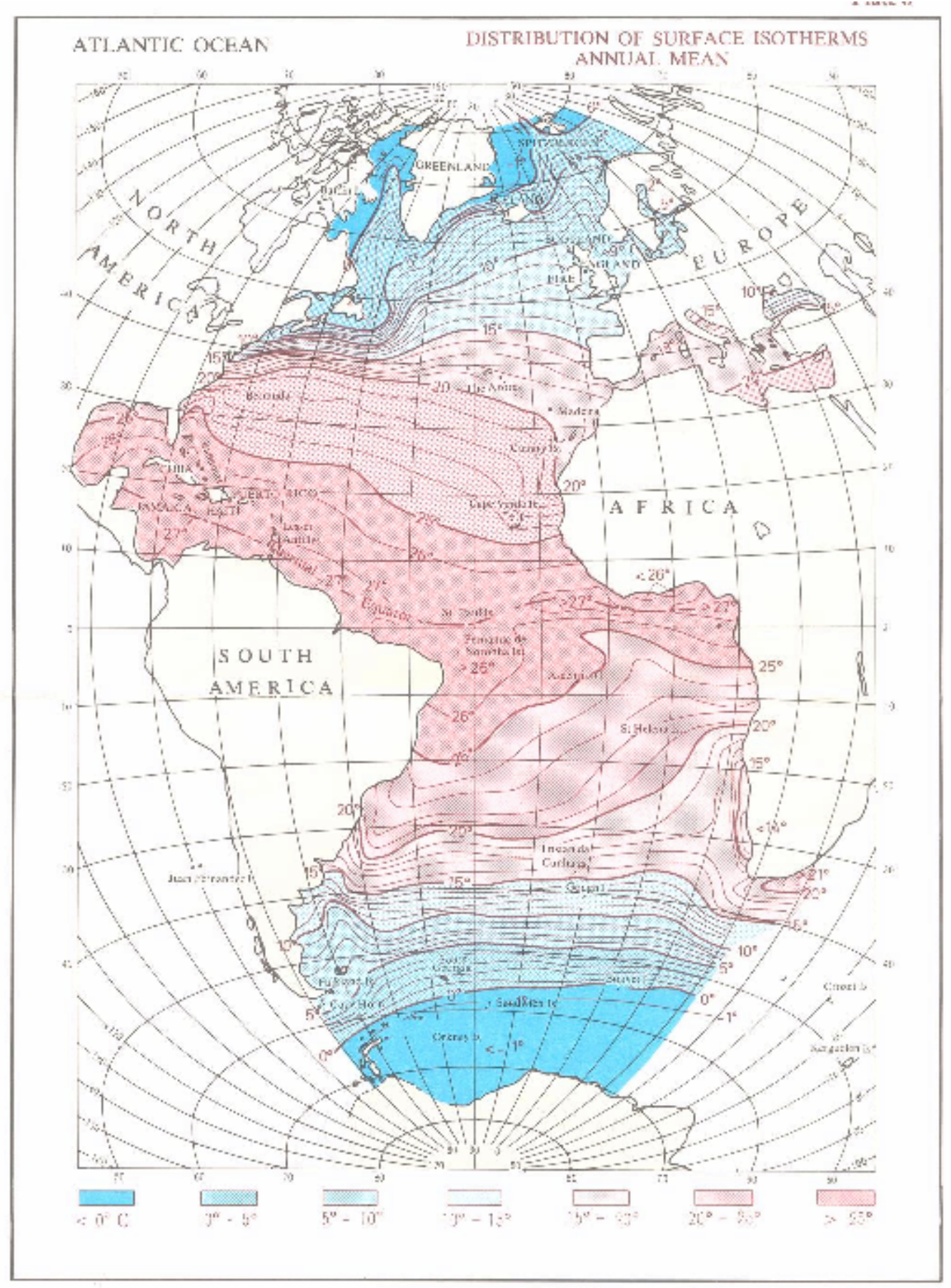

Figura 3.15 - Mapa de temperatura da água no oceano Atlântico

(Fonte: Tchernia 1980)

A Tabela 3.4 contém as informações oceanográficas e as diferenças entre os níveis do mar determinados a partir de dados oceanográficos $\left(\Delta \mathrm{NM}_{\mathrm{O}}\right)$ e nivelamento $\left(\Delta \mathrm{NM}_{\mathrm{N}}\right)$, nos marégrafos mostrados na Figura 3.13. 
Tabela 3.4 - Características oceanográficas e diferenças entre os níveis do mar

\begin{tabular}{|l|c|c|c|c|c|}
\hline \multirow{2}{*}{} & \multicolumn{3}{|c|}{ Informações oceanográficas } & \multicolumn{2}{c|}{$\begin{array}{c}\text { Diferença do nível do mar em } \\
\text { relação a Imbituba }\end{array}$} \\
\hline Nome & $\begin{array}{c}\text { Temperatura } \\
{ }^{\circ} \mathrm{C}\end{array}$ & $\begin{array}{c}\text { Salinidade } \\
\text { o }\end{array}$ & $\begin{array}{c}\text { Densidade } \\
\mathrm{g} / \mathrm{cm}^{3}\end{array}$ & $\begin{array}{c}\Delta \mathrm{NM}_{\mathrm{O}} \\
(\mathrm{m})\end{array}$ & $\begin{array}{c}\mathrm{NM}_{\mathrm{N}} \\
(\mathrm{m})\end{array}$ \\
\hline Torres & 18 & 33,0 & 1,0230 & 0,025 & 0,058 \\
\hline Laguna & 18 & 34,0 & 1,0240 & 0,050 & $-0,126$ \\
\hline Imbituba & 18 & 35,0 & 1,0255 & 0 & 0 \\
\hline Florianópolis & 19 & 35,5 & 1,0256 & $-0,010$ & $-0,070$ \\
\hline Porto Belo & 20 & 35,5 & 1,0257 & $-0,020$ & 0,240 \\
\hline Itajaí & 20 & 35,5 & 1,0257 & $-0,020$ & 0,140 \\
\hline S. Fco. do Sul & 20 & 35,5 & 1,0257 & $-0,020$ & 0,013 \\
\hline Paranaguá & 21 & 35,5 & 1,0250 & 0,050 & 0,001 \\
\hline Santos & 21 & 35,5 & 1,0250 & 0,050 & 0,050 \\
\hline Sepetiba & 22 & 35,5 & 1,0251 & 0,040 & 0,165 \\
\hline Rio de Janeiro & 22 & 35,5 & 1,0251 & 0,030 & $-0,123$ \\
\hline Vitória & 23 & 36,0 & 1,0249 & 0,060 & 0,284 \\
\hline Canavieiras & 24 & 37,0 & 1,0251 & 0,070 & $-0,006$ \\
\hline Salvador & 25 & 37,0 & 1,0252 & 0,050 & 0,011 \\
\hline Recife & 26 & 36,5 & 1,0249 & 0,490 & 0,130 \\
\hline Fortaleza & 27 & 36,5 & 1,0247 & 0,400 & 0,290 \\
\hline Salinópolis & 28 & 29,0 & 1,0248 & 0,610 & 0,880 \\
\hline Belém & 28 & 30,0 & 1,0246 & 0,760 & \\
\hline & & & 350 & \\
\hline
\end{tabular}

A Figura 3.16 mostra as diferenças entre os níveis do mar calculadas pelos dados oceanográficos e pelo nivelamento, tendo Imbituba como ponto de referência. Os resultados mostrados na Tabela 3.4 e na Figura 3.16, indicam que as diferenças entre os NMMs são causadas em parte pelas diferenças de densidade da água do mar, já que os cálculos efetuados a partir de dados de densidade confirmam os valores encontrados por meio do nivelamento, principalmente em Belém e Salinópolis, onde as diferenças são maiores. 


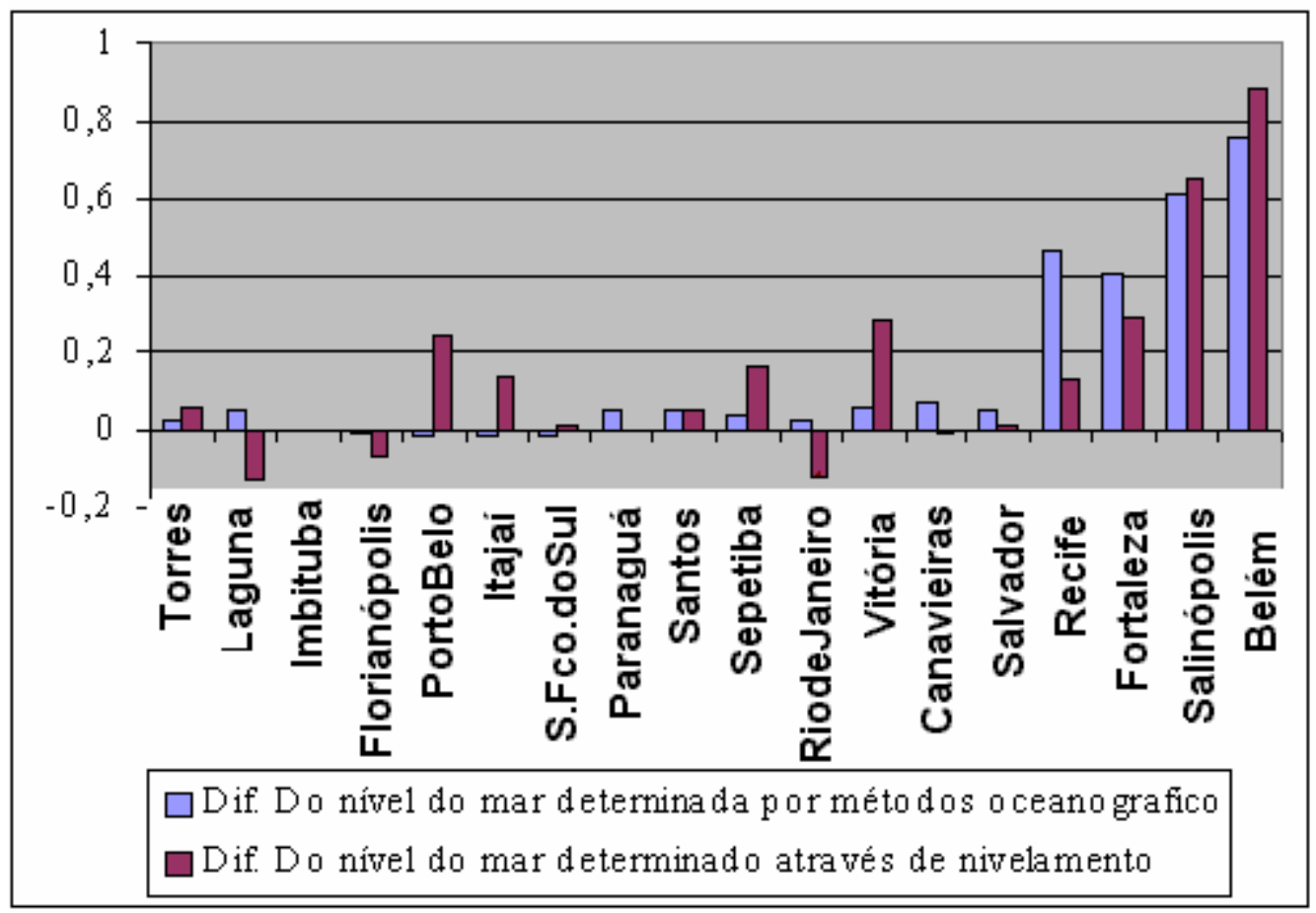

Figura 3.16 - Diferenças dos níveis do mar na costa brasileira em relação à Imbituba (Unidade: $\mathrm{m}$ ).

As variações do nível do mar, sobretudo em regiões costeiras extensas, tornam incompatíveis os Data altimétricos definidos pelo NMM, justificando a adoção de um Datum altimétrico global. Entre as metodologias utilizadas para compatibilizar Data altimétricos locais, destaca-se a redução ao geóide gravimétrico, usando GPS e redes altimétricas, como será visto no Capítulo 5.

\section{Rede Maregráfica Permanente para Geodésia (RMPG)}

A RMPG foi concebida em 1997 pelo IBGE, com a finalidade de determinar e acompanhar a evolução dos Data altimétricos do Sistema Geodésico Brasileiro (IBGE, 2005).

Em 2001, o Departamento de Geodésia (DEGED) do IBGE instalou sensores maregráficos e meteorológicos digitais, juntamente com equipamentos convencionais da RMPG. A coleta de dados da RPMG foi iniciada em 2001 na estação de Macaé (RJ) e Imbituba, e em 2003 na estação de Salvador (BA). Das 6 estações maregráficas implantadas, apenas 3 estão em funcionamento: Imbituba, Macaé e Salvador (Figura 3.17). A Figura 3.18, 
ilustra os marégrafos analógico e digital instalados no Datum de Imbituba (Luz \& Guimarães, 2003).

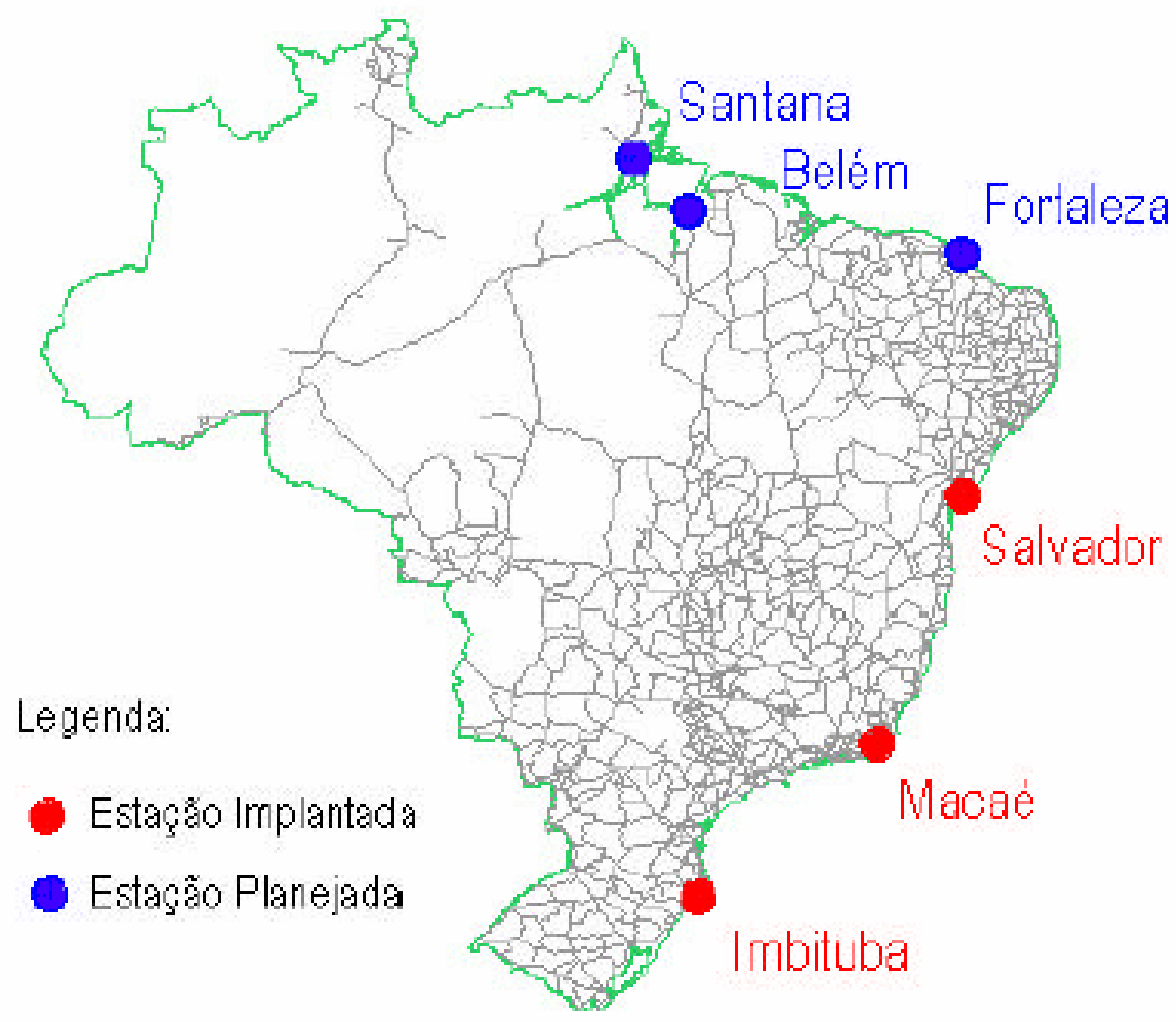

Figura 3.17- Localização da Rede Maregráfica Permanente para Geodésia (Fonte: IBGE, 2005)

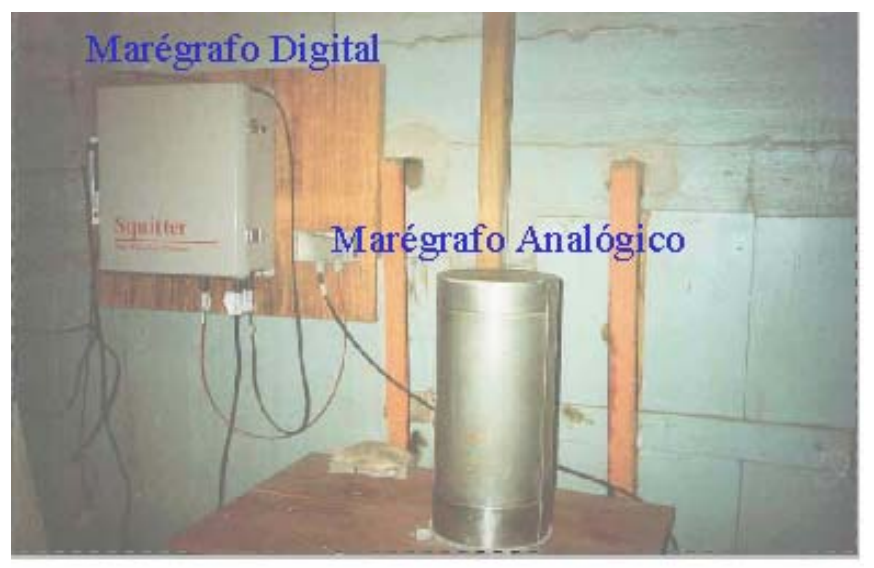

Figura 3.18 - Marégrafos analógico e digital do Datum de Imbituba. 
As primeiras observações maregráficas, com equipamentos digitais, mostram influência meteorológica considerável no marégrafo de Imbituba em relação aos de Macaé e Salvador, como ilustram os registros maregráficos (Figura 3.19).

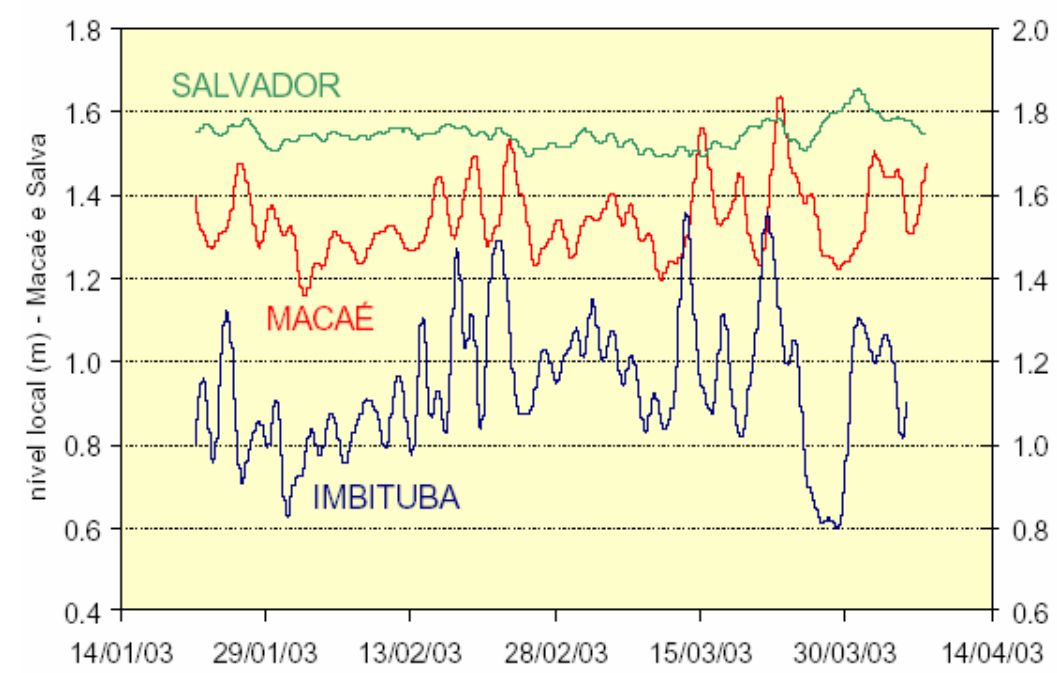

Figura 3.19 - Registro maregráfico das estações da RPMG

(Fonte: Luz \& Guimarães, 2003)

O objetivo da RMPG é servir de instrumento de transição para o futuro Datum altimétrico do Sistema de Referência Geocêntrica para as Américas (SIRGAS), além de possibilitar a correlação entre o Datum de Imbituba e os diversos referenciais altimétricos existentes ao longo do litoral brasileiro (Luz \& Guimarães, 2003).

\section{3 - O DATUM ALTIMÉTRICO NA ERA MODERNA}

Com o avanço das técnicas espaciais, houve uma evolução no conceito de Data geodésicos; entretanto, a realização de um Datum altimétrico global ainda não foi totalmente solucionada, por envolver grandezas que variam no espaço e no tempo. Atualmente, a unificação de Data altimétricos tem sido estudada por geodesistas no mundo todo, e uma síntese das principais propostas para a unificação dos Data altimétrico é apresentada a seguir.

\section{Determinação da topografia oceânica}


A TO é uma das principais causas da diferença entre o NMM em diferentes locais, e da incompatibilidade dos Data altimétricos a eles associados.

Algumas estratégias para a determinação da TO são apresentadas por Lehmann (2000), levando em conta alguns aspectos discutidos por Heck \& Rummel (1990):

1. Abordagem oceanográfica: considerando que a TO é conseqüência das correntes oceânicas, efeitos meteorológicos e variações de salinidade, pode-se determinar a TO pela análise dos fenômenos oceanográficos;

2. Altimetria por satélite: a determinação da TO em áreas oceânicas é feita pela altimetria por satélite. Através dos dados estima-se a TO para as regiões costeiras, onde a altimetria por satélite não apresenta bons resultados.

3. Gravimetria associada com posicionamento por satélite: as coordenadas geocêntricas do Datum altimétrico são usadas como informações adicionais no ajustamento por mínimos quadrados, para determinação da TO e desvios das anomalias gravimétricas ;

4. Problema do valor de contorno em geodésia: considera o Datum altimétrico como um ponto interior do problema de valor de contorno geodésico (Lehmann, 2000).

\section{Conexão de Data altimétricos através do geopotencial}

O método proposto por Bursa et al. (1999), para conexão de Data altimétricos locais ao Datum altimétrico global, baseia-se na determinação dos valores do geopotencial global $\left(\mathrm{W}_{0}\right)$ e no Datum local $\left(\mathrm{W}_{\mathrm{i}}\right)$. Assim, o sistema de referência global não é definido como a superfície geoidal, e sim como o geopotencial $\left(\mathrm{W}_{0}\right)$. A relação entre o valor dos geopotenciais global e local é apresentada na Figura 3.20. 


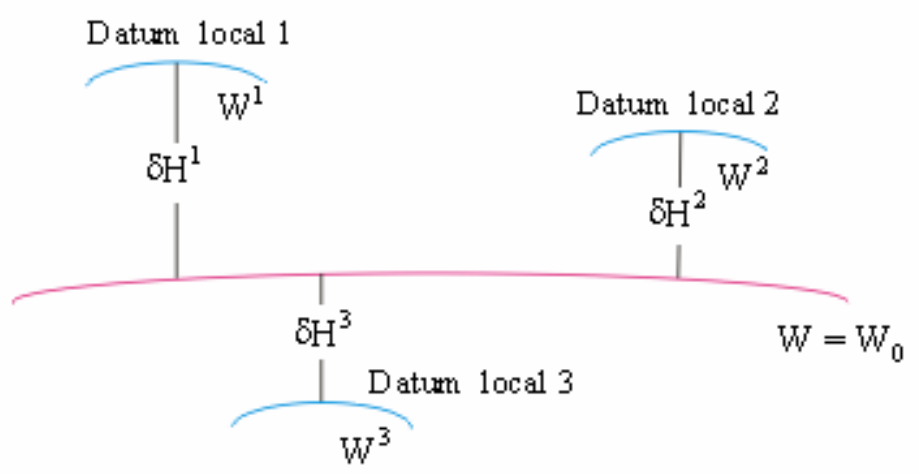

Figura 3.20 - Relação entre Data locais e o Datum global (Adaptada de Bursa et al. ,1999)

O método apresentado por Bursa et al. (1999), requer os seguintes dados para a determinação dos valores geopotenciais global $\left(\mathrm{W}_{0}\right)$ e local $\left(\mathrm{W}^{\mathrm{i}}\right)$ :

1. Dados obtidos por GPS/Nivelamento;

2. Um modelo geopotencial;

3. A constante gravitacional geocêntrica;

4. A velocidade angular de rotação da Terra;

5. O coeficiente harmônico zonal de grau 2.

Nesse modelo, são apontados dois caminhos para conectar Data locais ao Datum global:

1. Combinando o valor geopotencial global $\left(\mathrm{W}_{0}\right)$, determinado a partir de dados de altimetria por satélite (TOPEX/POSEIDON) e do modelo EGM96, com o valor geopotencial no i-ésimo local $\left(\mathrm{W}^{\mathrm{i}}\right)$, determinado no Datum altimétrico local a partir de dados de GPS/Nivelamento, determina-se a altitude entre a superfície equipotencial global e a superfície equipotencial local $\left(\delta \mathrm{H}^{\mathrm{i}}\right)$

$$
\delta \mathrm{H}^{\mathrm{i}}=\frac{\mathrm{W}_{0}-\mathrm{W}^{\mathrm{i}}}{\mathrm{g}^{\mathrm{i}}}
$$

onde g é a gravidade no Datum altimétrico local. 
2. Usando o valor do geopotencial $\left(\mathrm{W}_{0}^{\mathrm{i}}\right)$, determinado através de dados de GPS/Nivelamento e do modelo EGM96 no Datum de referência, e o valor do geopotencial no Datum local $\left(\mathrm{W}^{\mathrm{i}}\right)$, determina-se a altitude entre a superfície equipotencial global e a superfície equipotencial local $\left(\delta \mathrm{H}_{1}^{\mathrm{i}}\right)$

$$
\delta \mathrm{H}_{1}^{\mathrm{i}}=\frac{\mathrm{W}_{0}^{\mathrm{i}}-\mathrm{W}^{\mathrm{i}}}{\mathrm{g}^{\mathrm{i}}}
$$

Usando esse método, o valor de $\left(\delta \mathrm{H}^{\mathrm{i}}\right)$ obtido por Bursa et al. (2004), para o Datum de Imbituba é o seguinte: $0,03 \pm 0,07 \mathrm{~m}$.

A metodologia para a determinação do geopotencial por meio da combinação de dados de GPS/Nivelamento e modelos geopotenciais, é apresentada a seguir.

\section{Determinação do geopotencial local.}

O geopotencial pode ser determinado a partir da combinação GPS/Nivelamento, altitude normal e modelo geopotencial. Essa metodologia, apresentada por Jekeli (2000), está ilustrada na Figura 3.21.

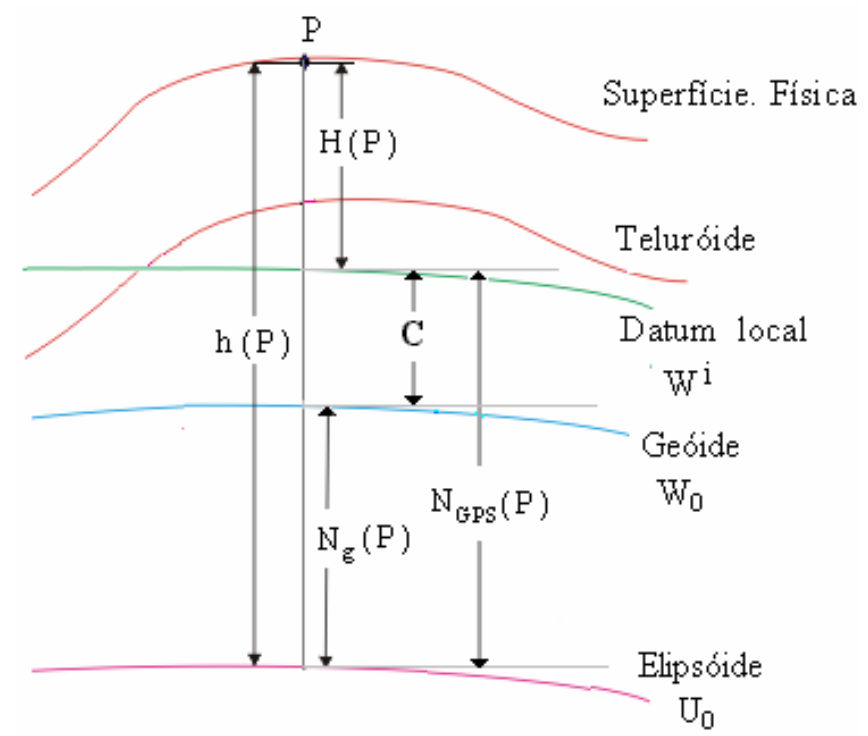

Figura 3.21 - Geopotencial local, anomalia de altitude e altitudes normal e elipsoidal.

(Adaptada de Jekeli, 2000) 
A altura geoidal gravimétrica $\mathrm{N}_{\mathrm{g}}$ em $\mathrm{P}$, é expressa por

$$
\mathrm{N}_{\mathrm{g}}=\frac{\mathrm{T}}{\gamma}=\frac{\mathrm{W}_{0}-\mathrm{U}}{\gamma}
$$

onde $\mathrm{T}$ é o potencial anômalo e $\gamma$ é a gravidade normal. A altura geoidal referente ao Datum local, tem a forma(Figura 3.21).

$$
\mathrm{N}_{\mathrm{GPS}}=\mathrm{N}_{\mathrm{g}}+\mathrm{C}=\mathrm{N}_{\mathrm{g}}+\frac{\mathrm{W}_{0}-\mathrm{W}^{\mathrm{i}}}{\mathrm{g}}
$$

e

$$
\mathrm{h}=\mathrm{H}+\mathrm{N}_{\mathrm{GPS}}
$$

onde C é o número geopotencial no Datum local.

Substituindo-se (3.7) e (3.8) em (3.9) tem-se o geopotencial do Datum altimétrico local ( $\mathrm{W}^{\mathrm{i}}$ )

$$
\mathrm{W}^{\mathrm{i}}=\mathrm{W}_{0}-\gamma\left(\mathrm{h}-\mathrm{H}-\mathrm{N}_{\mathrm{g}}\right)
$$

onde $\mathrm{W}_{0}$ é o geopotencial dado pelo modelo geopotencial global no Datum, $\mathrm{H}$ é a altitude ortométrica determinada a partir do Datum local, e h é a altitude geométrica determinada por GPS.

Conexão de Data altimétricos através de modelos geoidais. 
A compatibilização dos Data altimétricos locais à uma superfície equipotencial global, através de modelos geoidais, requer, além do geóide gravimétrico, as altitudes geométrica e ortométrica na RN diretamente vinculada ao marégrafo (Raap \& Balalsubramania, 1992).

Adotando a superfície do geóide gravimétrico global como referência, pode-se compatibilizar os Data altimétricos locais, definidos pelo NMM, ao geóide gravimétrico pela determinação da diferença entre a altura geoidal GPS $\left(\mathrm{N}_{\mathrm{GPS}}\right)$, e a altura geoidal gravimétrica $\left(\mathrm{N}_{\mathrm{g}}\right)$ no Datum local (Figura 3.22).

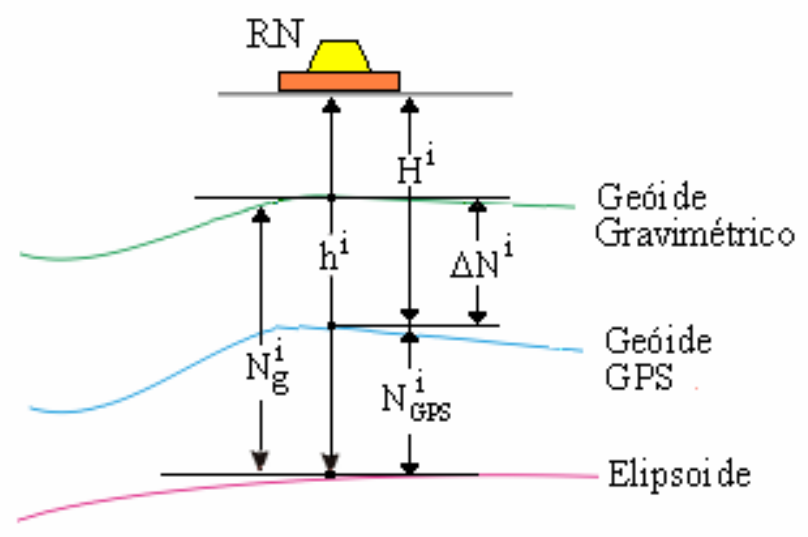

Figura 3.22 - Relação entre o geóide GPS e o geóide gravimétrico
A altura geoidal GPS ( $\mathrm{N}_{\mathrm{GPS}}^{\mathrm{i}}$ ) no Datum local (i) é expressa pela diferença
$\mathrm{N}_{\text {GPS }}^{\mathrm{i}}=\mathrm{h}^{\mathrm{i}}-\mathrm{H}^{\mathrm{i}}$

onde $\mathrm{h}^{\mathrm{i}}$ é a altitude geométrica no Datum local, e $\mathrm{H}^{\mathrm{i}}$ é a altitude ortométrica calculada a partir do NMM local.

A componente sistemática no Datum $\left(\Delta \mathrm{N}^{\mathrm{i}}\right)$, com o respectivo erro $\left(\sigma_{\Delta \mathrm{N}^{\mathrm{i}}}\right)$, são

$$
\Delta \mathrm{N}^{\mathrm{i}}=\mathrm{N}_{\mathrm{GPS}}^{\mathrm{i}}-\mathrm{N}_{\mathrm{g}}^{\mathrm{i}}
$$




$$
\sigma_{\Delta N^{i}}=\sqrt{\sigma_{h^{i}}^{2}+\sigma_{H^{i}}^{2}+\sigma_{N_{g}^{i}}^{2}}
$$

onde $\sigma_{\mathrm{h}_{\mathrm{i}}}^{2}$ é a variância da altitude geométrica, $\sigma_{\mathrm{H}_{\mathrm{i}}}^{2}$ é a variância da altitude ortométrica e $\sigma_{\mathrm{N}_{\mathrm{g}}^{\mathrm{i}}}^{2}$ é a variância da altura geoidal gravimétrica.

Como será visto no Capítulo 5, pode-se estimar a componente sistemática no Datum local através das componente sistemática, obtidas nas RNs próximas, para otimizar a aproximação da componente sistemática no Datum. Também pode ser adotado um modelo matemático que ajusta uma superfície que compatibiliza o geóide GPS ao geóide gravimétrico.

A conexão de Data altimétricos através da comparação de geóide gravimétrico e geóide GPS justifica-se pelos motivos que seguem:

1. A determinação da componente sistemática compatibiliza o geóide gravimétrico ao geóide local materializado pelo marégrafo, referindo toda a rede de nivelamento vinculada ao Datum local à uma superfície geoidal global.

2. Os avanços na determinação de modelos geoidais, e a precisão do GPS na obtenção de altitude geométrica, justificam a utilização da altimetria por GPS.

3. A adoção de uma superfície equipotencial global definida por modelos geoidais como referência possibilita o uso do GPS na obtenção da altitude ortométrica de forma eficiente.

4. O método é de fácil aplicação.

\section{Causas da componente sistemática}

A componente sistemática resulta da incompatibilidade de referenciais, erros sistemáticos e aleatórios da altura geoidal gravimétrica, e das altitudes geométrica e ortométrica envolvidas no cálculo de alturas geoidais (Kotsakis \& Sideris, 1999). Ela envolve os erros associados aos dados utilizados na determinação de modelos geoidais, posicionamento e erros da altitude ortométrica.

Os erros da altitude geométrica são oriundos das fontes de erro do sistema GPS, entre as quais os efeitos da ionosfera, troposfera, multicaminho, geometria inadequada dos satélites, obstrução do sinal GPS (Monico, 2000). 
Os erros das altitudes ortométricas são provenientes de erros aleatórios e sistemáticos na rede altimétrica em questão, os erros mais comuns estão ligados a erros de ajustamento da rede altimétrica e erros de nivelamento geométrico, que são provocados pela imprecisão do aparelho, verticalidade inadequada da mira, erros na graduação da mira, erros de leitura e colimação, entre outros.

Os erros inerentes ao geóide gravimétrico decorrem da propagação dos erros observacionais dos dados utilizados (modelo geopotencial, anomalias gravimétricas e modelo topográfico digital), além de erros ligados à densidade de dados de gravidade e aproximações feitas no cálculo do geóide gravimétrico.

Outros erros que devem ser considerados estão relacionados à determinação do NMM e às variações nas estações de controle. A maioria das estações maregráficas são do tipo convencional (analógica), inclusive o marégrafo no qual foram feitas as medições maregráficas em Imbituba no período 1949-1957. Esse modelo de marégrafo (Figura 3.9) apresenta diversos inconvenientes em relação aos objetivos geodésicos, como utilização de régua de referência, cuja precisão da leitura é prejudicada pela incidência de ondas, erros provenientes de registro gráfico advindos da digitalização dos dados, erros na escala vertical do registrador, ação de ondas e de correntes de alta freqüência, as quais causam a diminuição do nível da água no interior do poço tranquilizador (Luz \& Neves, 1995). As RNs posicionadas podem ter sofrido variações temporais das coordenadas e consequentemente variações na altitude ortométrica devido a movimentos crustais, sedimentação do terreno, etc.

São chamados erros sistemáticos os erros provenientes do processamento de dados na determinação do geóide gravimétrico, erros de ajustamento da rede altimétrica e erros de longo comprimento de onda do geóide gravimétrico (Kotsakis \& Sideris, 1999).

Além dos erros, outra causa da componente sistemática é a incompatibilidade de referenciais, que resulta dos referenciais envolvidos no geóide gravimétrico e na altitude geométrica (ambos utilizam elipsóides como referência), e na altitude ortométrica por se referir à superfície equipotencial perturbada pela TO.

A posição do geóide GPS em relação ao geóide gravimétrico depende do referencial da altitude ortométrica.

A componente sistemática $(\Delta \mathrm{N})$ pode ser expressa por 


$$
\Delta \mathbf{N}=\mathbf{A}^{\mathrm{T}} \mathbf{X}+\mathbf{v}
$$

onde $\mathbf{X}$ é o vetor dos parâmetros a serem determinados, $\mathbf{A}$ é o vetor dos coeficientes, e $\mathbf{v}$ é o vetor dos resíduos. O termo $\mathbf{A}^{\mathbf{T}} \mathbf{X}$ representa a incompatibilidade dos sistemas de referência somados aos erros sistemáticos. No Capítulo 5 , será mostrado o modelo matemático utilizado para estimar a componente sistemática resultante dos erros sistemáticos somados à incompatibilidade de referenciais.

\section{Unificação de Data altimétricos para as Américas}

O SIRGAS tem como objetivo a adoção de um sistema de referência unificado que proporcione precisão compatível com as técnicas atuais de posicionamento. Alguns argumentos que justificam a adoção do Datum altimétrico unificado pelo SIRGAS são:

- A integração regional e global da Geodésia física e geométrica;

- O intercâmbio de informações regionais e globais;

- A unificação dos sistemas de altitudes, tendo em vista as obras de engenharia transnacionais.

As principais metas a serem seguidas pelo SIRGAS são as seguintes (Sánchez, 2005):

1. Determinação do valor geopotencial em cada marégrafo $\left(\mathrm{W}^{\mathrm{i}}\right)$;

2. Determinação do valor geopotencial global $\left(\mathrm{W}_{0}\right)$;

3. Determinação do número geopotencial em cada estação maregráfica $\left(\mathrm{C}_{\mathrm{i}}=\mathrm{W}_{0}-\mathrm{W}_{\mathrm{i}}\right)$;

4. Ajuste das redes de nivelamento;

5. Transformação dos números geopotenciais em altitudes físicas;

6. Cálculo de um modelo geoidal.

Ainda não há definição sobre o tipo de altitude e a metodologia a serem adotados na unificação do referencial altimétrico no SIRGAS. A propostas de Sánchez (2005) postula unificações regional e global. A unificação regional envolve ajustamento das redes de nivelamento, determinação do número geopotencial, e adoção da altitude normal.

Apesar de haver propostas para a adoção da altitude normal pelo SIRGAS, ainda não há estudos sobre a avaliação dos aspectos teóricos e práticos para fundamentar a adoção do tipo de altitude mais adequado. 


\section{Importância da unificação de Data altimétricos}

A unificação de Data altimétricos, vai proporcionar a maior funcionalidade no uso de altitudes em escalas regional e global. Para isso, os Data altimétricos devem estar vinculados a uma superfície equipotencial única, consistente com modelos geoidais gravimétricos, possibilitando o uso do GPS na obtenção da altitude, independente do tipo que venha ser adotado.

A altimetria por GPS traz benefícios em relação ao nivelamento tradicional, principalmente em países com dimensões continentais como é o caso do Brasil, onde a implantação e manutenção de uma rede de nivelamento é inviável em termos econômicos e operacionais. A altimetria por GPS, pode constituir uma alternativa viável tanto do ponto de vista econômico como operacional.

As abordagens apresentadas como solução na unificação de Data altimétricos requerem o conhecimento do campo de gravidade. Recentemente, os recursos computacionais e o aumento de dados gravimétricos proporcionam modelos do campo de gravidade com resolução e precisão sem precedentes. 


\section{4 - DESCRIÇÃO DOS DADOS}

Os dados disponíveis para execução deste projeto de mestrado são: modelo geoidal gravimétrico, dados da RAFB, os dados da Rede GPS no Sul/Sudeste do Brasil (RGSB), implantada pelo IAG/USP, e dados da RBMC.

\section{1 - GEÓIDE GRAVIMÉTRICO}

O geóide gravimétrico usado neste projeto, foi extraído do modelo geoidal gravimétrico da América do Sul, com resolução espacial de 5' de arco (Figura 4.1), determinado através da colocação por mínimos quadrados, usando dados do modelo geopotencial (EGM96), dados gravimétricos terrestres e oceânicos e dados topográficos na forma digital (Sá, 2004).

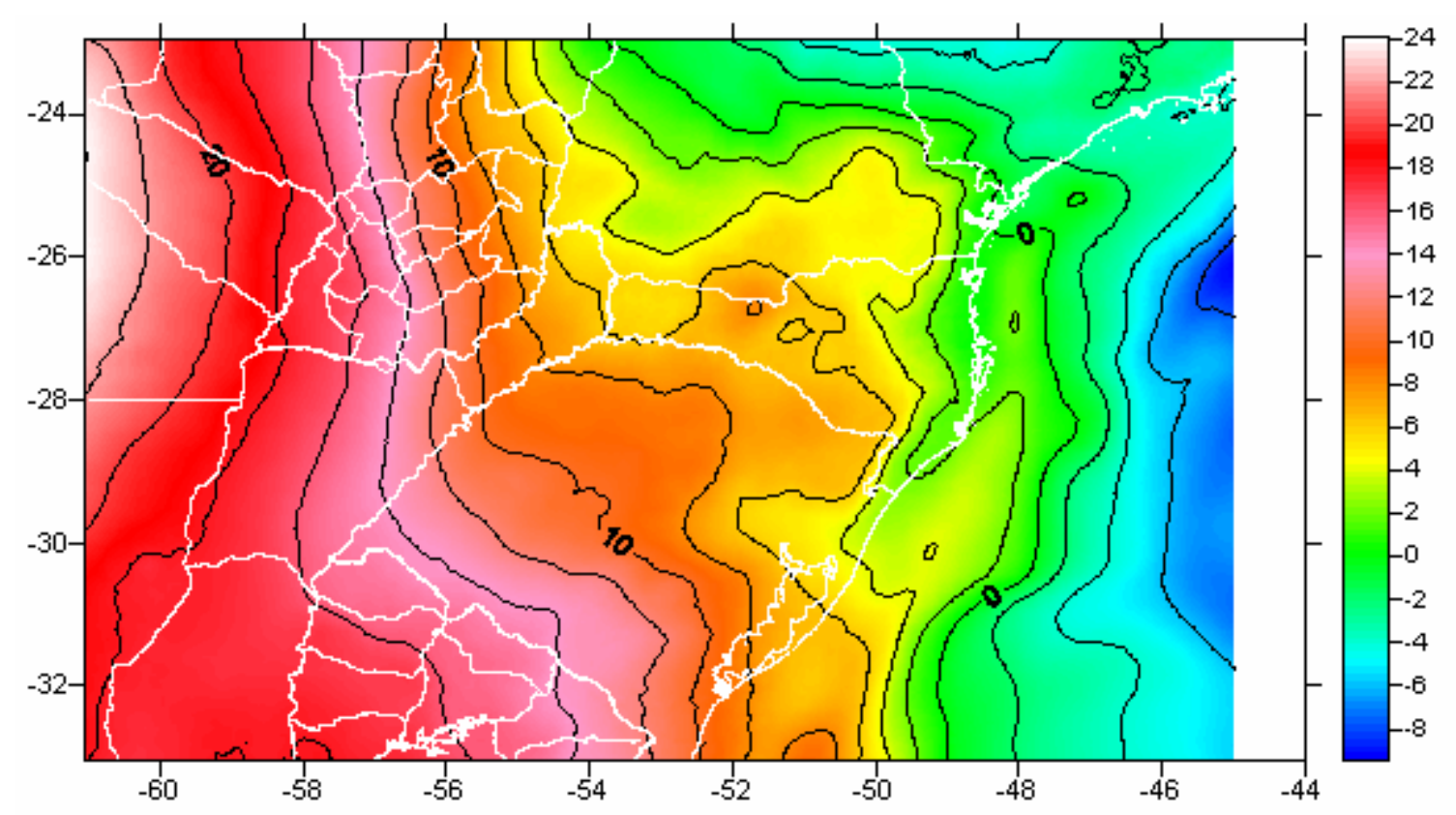

Figura 4.1 - Geóide gravimétrico da região de interesse

(Unidade: $\mathrm{m}$ ) 


\section{Dados empregados no cálculo do geóide gravimétrico}

Os dados gravimétricos que foram utilizados pertencem ao banco de dados mantidos no Laboratório de Geodésia e Gravimetria do IAG/USP. Esses resultaram da integração de três tipos de levantamentos: terrestres, oceânicos e de altimetria por satélite. Os dados terrestres foram obtidos por várias instituições, os oceânicos foram coletados por instituições interessadas em Geofísica marinha e processadas pelo National Geophysical Data Center (NGDC), e os de altimetria por satélite foram obtidos nas missões geodésicas GEOSAT e ERS-1 e convertidos em anomalias ar-livre na forma digital (Sandwell \& Smith, 1997).

As medidas terrestres foram referidas a International Gravity Standartization Net 1971 (IGSN71) pela Rede Gravimétrica Fundamental Brasileira (RGFB). As coordenadas e as altitudes das estações estão referidas ao Sistema Geodésico Brasileiro (SGB).

\section{Anomalia da gravidade}

O campo de gravidade da Terra varia em função da posição geográfica, da altitude, das feições topográficas, da densidade no interior da Terra, e da interação de outros corpos celestes. A componente do campo relacionada com a densidade no interior terrestre, é usada na prática para a determinação da forma e estrutura da Terra. Para separar a componente relacionada com a variação de densidade é necessário obter a aceleração da gravidade na superfície do geóide (Sá, 2004). A redução gravimétrica ao geóide envolve o cálculo de vários efeitos gravitacionais, que serão vistos a seguir.

\section{Anomalia ar-livre}

A correção ar-livre remove o efeito gravitacional correspondente à altitude do ponto de observação, e pode ser obtida pelo gradiente vertical da aceleração da gravidade e da altitude ortométrica do ponto

$$
\mathrm{C}_{\mathrm{a}}=\frac{\partial \mathrm{g}}{\partial \mathrm{H}} \mathrm{H}=0,3086 \mathrm{H}
$$

Portanto, a expressão para o cálculo da anomalia ar-livre tem a forma 


$$
\Delta \mathrm{g}_{\mathrm{a}}=\mathrm{g}+\mathrm{C}_{\mathrm{a}}-\gamma
$$

onde $\frac{\partial g}{\partial \mathrm{H}}$ é o gradiente vertical da aceleração de gravidade, g é a gravidade observada, $\gamma$ é a gravidade normal, calculada pela fórmula do Geodetic Reference System 1967 (GRS67), e H é a altitude ortométrica.

\section{Anomalia Helmert}

$\mathrm{Na}$ determinação do geóide, utiliza-se a anomalia Helmert, que é a combinação da anomalia ar-livre com a correção topográfica. A correção topográfica remove o efeito das irregularidades topográficas externas ao geóide, que é uma das exigências do problema do valor de contorno.

Portanto, a anomalia Helmert é expressa por (Sá, 2004)

$$
\Delta \mathrm{g}_{\mathrm{a}}=\mathrm{g}+\mathrm{C}_{\mathrm{a}}-\gamma+\mathrm{C}_{\mathrm{T}}
$$

onde $\mathrm{C}_{\mathrm{T}}$ é a correção das irregularidade topográficas.

\section{Anomalia Bouguer}

Além da correção ar-livre, utiliza-se a correção Bouguer; tal correção remove matematicamente o efeito das massas topográficas externas ao geóide, e tem a expressão

$$
\mathrm{C}_{\mathrm{B}}=-2 \pi \mathrm{G} \rho \mathrm{H}=-0,1119 \mathrm{H}
$$

Portanto, a anomalia Bouguer simplificada a partir da ar-livre, tem a forma:

$$
\Delta \mathrm{g}_{\mathrm{b}}=\Delta \mathrm{g}_{\mathrm{a}}+\mathrm{C}_{\mathrm{B}}
$$

onde $\mathrm{G}=6,672 * 10^{-8} \mathrm{~cm}^{-3} \mathrm{~g}^{-1} \mathrm{~s}^{-2}$ é a constante universal de gravitação, e $\rho=2,67 \mathrm{gcm}^{-3}$ é a densidade média da crosta.

As anomalias gravimétricas, referidas ao GRS67, foram convertidas para o Geodetic Reference System 1980 (GRS80) pela expressão (IAG, 1980): 


$$
\Delta \mathrm{g}_{80}=\Delta \mathrm{g}_{67}-\left(0,8316+0,0782 \operatorname{sen}^{2} \varphi-0,0007 \operatorname{sen}^{4} \varphi\right)
$$

onde $\varphi$ é a latitude geodésica.

\section{Modelo Topográfico Digital}

A topografia é o resultado de processos dinâmicos que se desenvolvem tanto no interior quanto na superfície da Terra e constitui uma informação básica nas Geociências (Sá, 2004). Na descrição da topografia (geralmente em relação ao geóide materializado pelos marégrafos) são usados grandes volumes de dados fornecidos pelas técnicas terrestres, aéreas e espaciais, nas quais os dados com distribuição geográfica regular são ordenados de forma matricial.

O modelo topográfico da região em estudo foi extraído do modelo topográfico unificado MTU3, determinado a partir dos modelos topográficos Shuttle Radar Topography Mission (SRTM) e Global Sea Floor Topography (GSFT) (Sá, 2004).

\section{Modelo Geopotencial}

O conhecimento do potencial gravitacional da Terra em escala global é de grande interesse para o desenvolvimento de diversas ciências como Geodésia, Geofísica, Oceanografia e outras (Souza, 2002).

Modelos geopotenciais, expressos em harmônicos esféricos, são determinados através da integração de dados do campo de gravidade. Atualmente, os modelos geopotenciais integram os sistemas de referência geodésicos e vêm sendo usado como esferóides combinados com dados locais para a representação do campo de gravidade anômalo de alta resolução (Sá, 2004).

O EGM96 (Lemoine et al., 1998) é o resultado do trabalho conjunto realizado pela National Imagery and Mapping Agency (NIMA), National Aeronautic and Space Administration (NASA) por meio do Goddard Space Flight Center (GSFC) e OSU. Sua resolução espacial é de 30' de arco ou, aproximadamente, $55 \mathrm{~km}$. Os parâmetros e coeficientes foram calculados a partir dos dados especificados abaixo:

- Dados de gravidade terrestre; 
- Altimetria por satélite TOPEX/POSSEIDON, ERS1, GEOSAT e

- Órbita de mais de 20 satélites.

O modelo terrestre adotado pelo geóide, determinado a partir do EGM96, é o World Geodetic System 1984 (WGS84), portanto as ondulações do geóide são referidas ao WGS84.

A metodologia empregada na determinação do EGM96 envolveu a combinação de duas soluções, uma de baixo grau (até 70) e outra de alto grau (71 a 360). Na solução de baixo grau foram integrados os dados de rastreio de satélites. Na solução de alto grau, foi utilizado um modelo digital ar-livre gerado pela colocação dos mínimos quadrados.

O modelo EGM96, de grau e ordem 360, foi usado para a representação da componente determinística de todos os funcionais envolvidos no processamento do atual geóide da América dos Sul. Um dos motivos da escolha do EGM 96 está relacionado ao cálculo dos coeficientes de alto grau que foram computados a partir de um grande número de dados gravimétricos do território brasileiro.

O campo de gravidade do modelo EGM96 é expresso pelo potencial anômalo (2.9), o qual é elemento fundamental na representação do campo de gravidade. Com isso, o potencial anômalo proporciona a componente determinística para todos os funcionais do campo a partir dos coeficientes de modelos geopotenciais.

Assim, pode-se expressar a anomalia ar-livre e a altura geoidal a partir das equações (2.14) e (2.13), respectivamente.

\section{Metodologia utilizada no cálculo do geóide gravimétrico}

Na determinação do geóide gravimétrico da América do Sul, foi usada a Colocação por Mínimos Quadrados (CMQ), que é uma técnica matemática adequada para a representação do campo de gravidade da Terra, pois possibilita o uso de diferentes tipos de dados, além de proporcionar os erros da aproximação. A equação básica que representa o modelo matemático tem a forma (Moritz, 1980; Sá, 2004):

$$
\mathbf{l}=\mathbf{A X}+\mathbf{s}+\mathbf{n}
$$

Como a componente determinística, será representada pelo modelo EGM96, a expressão se reduz ao modelo não paramétrico $(\mathbf{X}=0)$ 
$\mathbf{l}=\mathbf{s}+\mathbf{n}$

A solução para o vetor dos sinais e da respectiva variância é dada por (Moritz, 1980)

$$
\begin{aligned}
& \mathbf{s}=\mathbf{C}_{\mathrm{st}} \mathbf{C}^{-1}(\mathbf{l}-\mathbf{A X}) \\
& \boldsymbol{\sigma}_{\mathrm{s}}^{2}=\mathbf{C}_{\mathrm{ss}}-\mathbf{C}_{\mathrm{st}} \mathbf{C}^{-\mathbf{1}} \mathbf{C}_{\mathrm{ts}}
\end{aligned}
$$

onde $\mathbf{A X}$ é a componente determinística, $\mathbf{X}$ é o vetor dos parâmetros que representam a componente determinística, $\mathbf{l}$ é o vetor das observações, $\mathbf{s}$ é o vetor dos sinais, $\mathbf{n}$ é o vetor dos erros observacionais, $\mathbf{C}_{\mathrm{st}}, \mathbf{C}_{\mathrm{ss}}$ e $\mathbf{C}_{\mathrm{ts}}$ são covariâncias obtidas pelas funções ajustadas às covariâncias amostrais calculadas com os dados associados ao campo de gravidade e $\boldsymbol{\sigma}_{\mathrm{s}}^{2}$ é a variância dos sinais

\section{2 - REDE ALTIMÉTRICA}

As altitudes ortométricas utilizadas no cálculo do geóide, combinando GPS/Nivelamento, pertencem à RAFB, implantada pelo IBGE a partir da década de 40. Desde então, foram implantadas cerca de 65.000 mil RNs ao longo das principais rodovias e ferrovias brasileiras, correspondendo a mais de 160.000 quilômetros de duplo nivelamento geométrico (Luz \& Guimarães, 2001).

A RAFB (Figura 4.2) é de grande importância para o Brasil, pois a altitude ortométrica é imprescindível em atividades como: apoio ao mapeamento topográfico, construção de redes de distribuição de água e saneamento, planejamento urbano e diversas obras de engenharia. 


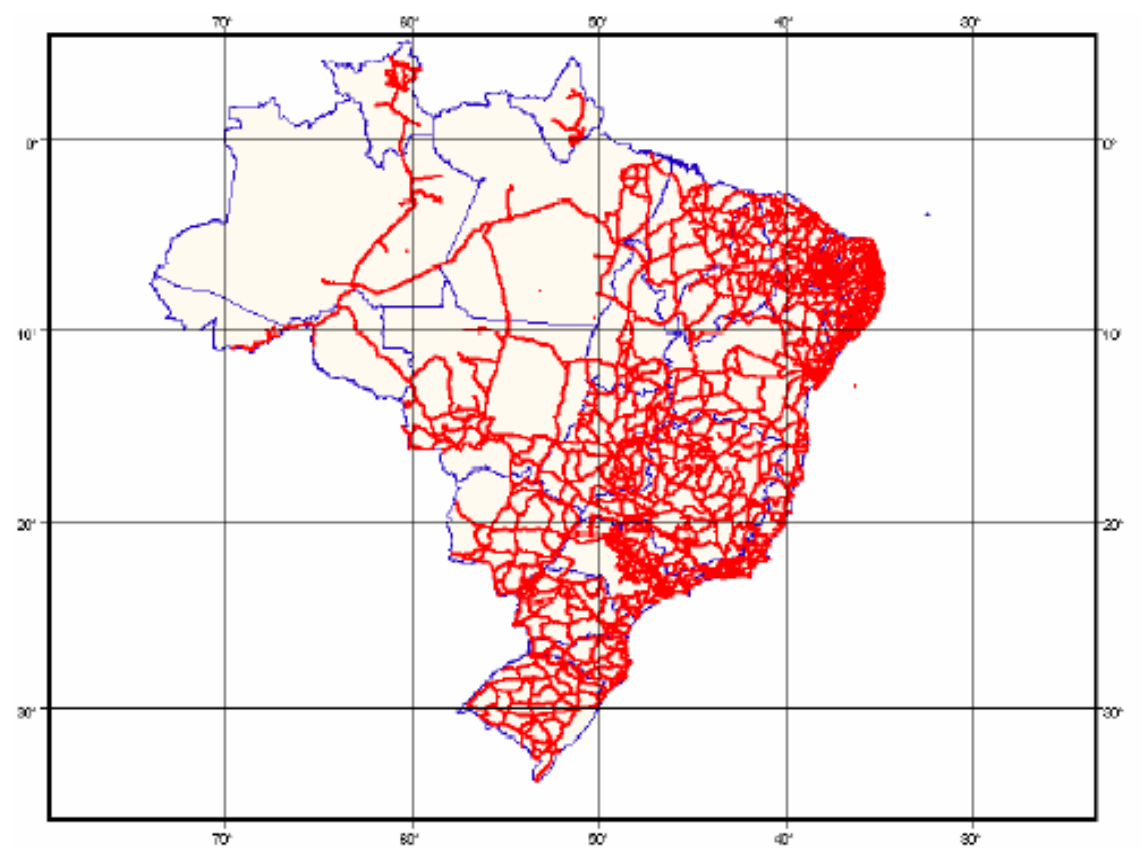

Figura 4.2 - Referências de nível da rede altimétrica fundamental do Brasil

(Fonte: IBGE, 2005)

\section{Materialização das RNs da RAFB.}

Geralmente, uma RN é materializada por uma chapa metálica circular cravada em uma superfície estável, tais como afloramentos rochosos e bases de concreto (Figura 4.3).

Ao longo de rodovias e ferrovias, onde não há estruturas adequadas para a chapa metálica, são construídos marcos de concreto com profundidade de aproximadamente $80 \mathrm{~cm}$ e altura de aproximadamente $20 \mathrm{~cm}$, em cujo topo é incrustada a chapa metálica ( Figura 4.6).

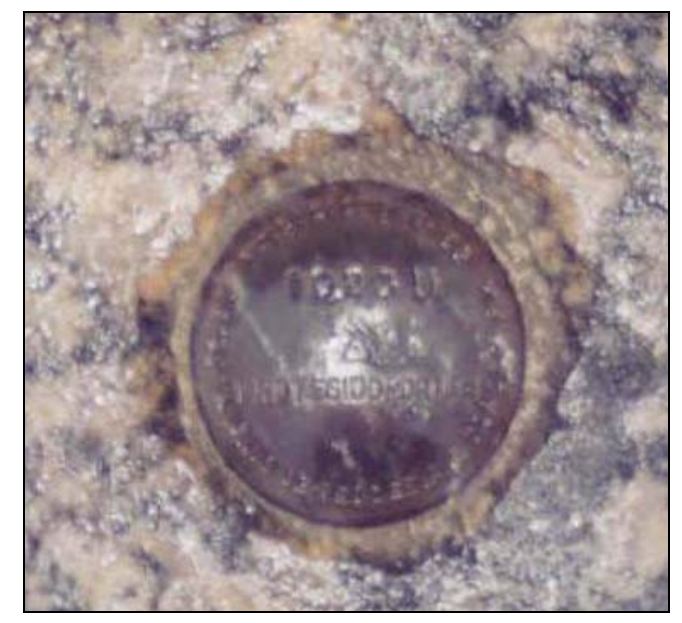

Figura 4.3 - Chapa metálica cravada em concreto 


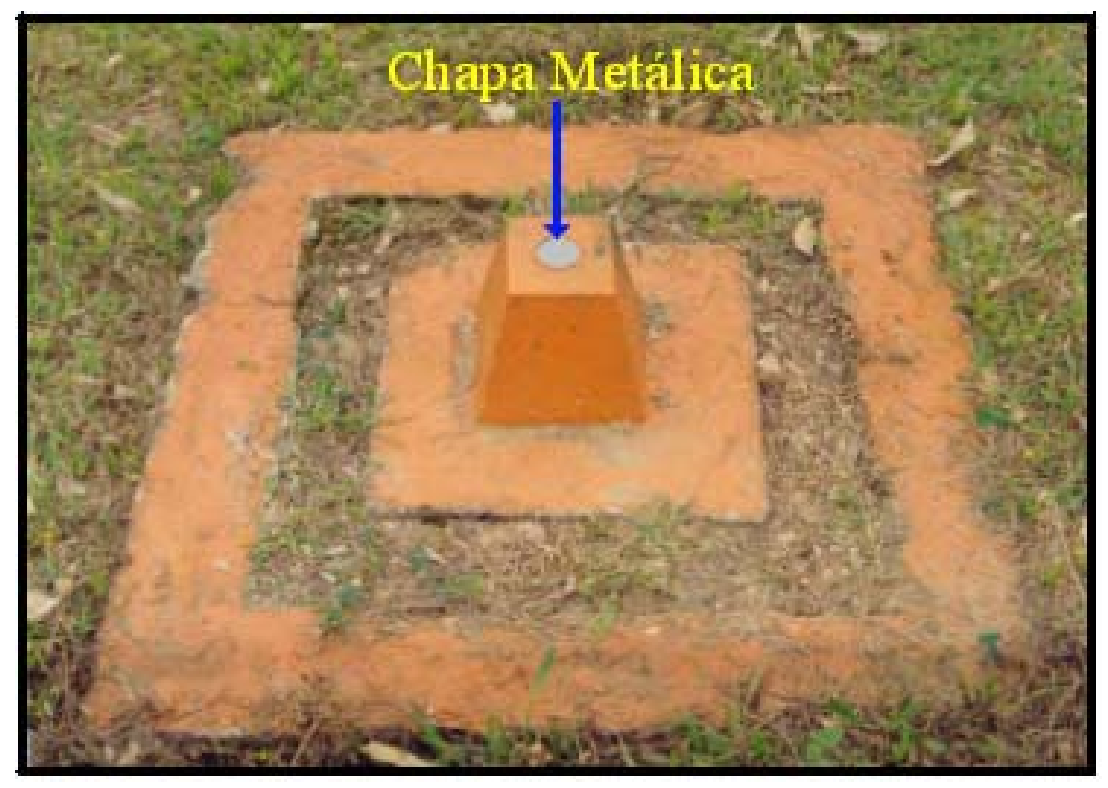

Figura 4.4 - Marco de concreto utilizado na implantação de RNs

\section{Determinação das altitudes}

As altitudes ortométricas nas RNs da RAFB foram determinadas por nivelamento tradicional, empregando-se níveis ópticos, tripés e miras de invar com dupla graduação.

Há dois tipos de altitudes no banco de dados do IBGE: as preliminares e as ajustadas. As preliminares resultaram de ajustamentos da rede realizados entre 1945 e 1975. As ajustadas foram determinadas com a digitação dos nivelamentos, verificação e particionamento das linhas, e novo ajustamento da rede. As diferenças entre as altitudes das RNs ajustadas e preliminares variam de 25 a 80 cm (Luz \& Guimarães, 2001).

As altitudes ortométrica utilizadas são as da Rede GPS do Sul/Sudeste do Brasil (RGSB), ilustrada na Figura 4.6. As estatísticas dos erros, obtidos pela expressão (5.8), são mostradas na Tabela 4.1. 
Tabela 4.1 - Estatísticas dos erros das altitudes ortométricas

\begin{tabular}{|l|c|}
\hline Estatísticas & $\begin{array}{c}\text { Valor numérico } \\
(\mathrm{m})\end{array}$ \\
\hline Número .de dados & 247 \\
\hline Média & 0,103 \\
\hline Desvio padrão & 0,035 \\
\hline Máximo & 0,169 \\
\hline Mínimo & 0,000 \\
\hline
\end{tabular}

\section{3 - REDE BRASILEIRA DE MONITORAMENTO CONTÍNUO}

A RBMC (Figura 4.5), foi implantada pelo IBGE com o objetivo de viabilizar o uso do posicionamento relativo para usuários que possuam 1 ou mais receptores, além de disponibilizar observações em duas freqüências (L1 e L2), para pesquisas relacionadas ao monitoramento tectônico, refração atmosférica, etc. As estações da RBMC coletam dados continuamente, que são centralizados no Rio de Janeiro, e colocados à disposição do usuário no formato Receiver Independent Data Exchange Format (RINEX), pela internet no site do IBGE (www.ibge.gov.br).

\section{4 - DADOS DA REDE GPS DO SUL/SUDESTE DO BRASIL}

A RGSB, implantada sobre RNs da RAFB pelo IAG/USP, com objetivo de obter uma rede de estações GPS contendo coordenadas geodésicas e altitude ortométrica nessa região. Com esses dados, pode-se determinar a altura geoidal combinando dados por GPS/nivelamento, que será chamada altura geoidal GPS $\left(\mathrm{N}_{\mathrm{GPS}}\right)$, pela diferença entre a altitude geométrica $(\mathrm{h})$ e ortométrica $(\mathrm{H})$

$$
\mathrm{N}_{\mathrm{GPS}}=\mathrm{h}-\mathrm{H}
$$

A RGSB possui 247 estações distribuídas nas regiões Sul, Sudeste e Centro Oeste (Figura 4.6). O erro padrão médio da altitude geométrica nas estações da RGSB é aproximadamente 5 cm (Tabela 4.2), o que é suficiente para os objetivos deste projeto. 


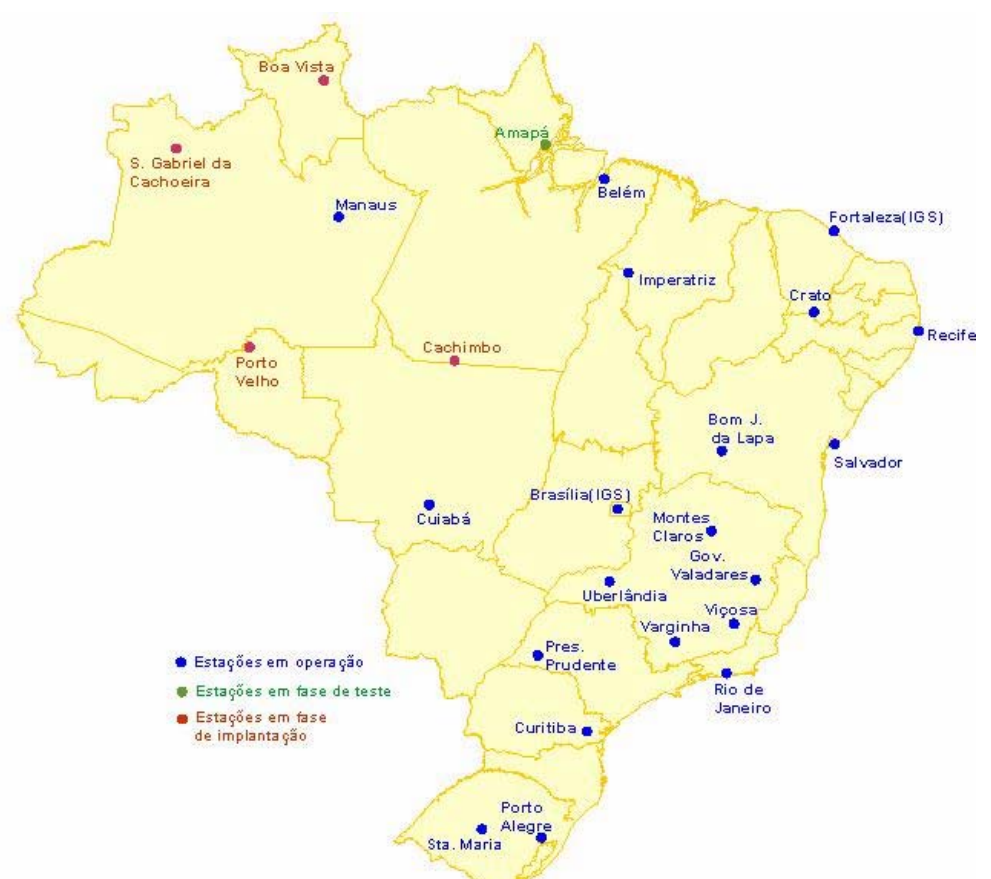

Figura 4.5 - Rede brasileira de monitoramento contínuo (Fonte IBGE, 2005)

Tabela 4.2 - Estatísticas dos erros da altitude geométrica

\begin{tabular}{|l|c|}
\hline Estatísticas & $\begin{array}{c}\text { Valor numérico } \\
(\mathrm{m})\end{array}$ \\
\hline Número de dados & 247 \\
\hline Média & 0,049 \\
\hline Desvio padrão & 0,017 \\
\hline Máximo & 0,107 \\
\hline Mínimo & 0,007 \\
\hline
\end{tabular}




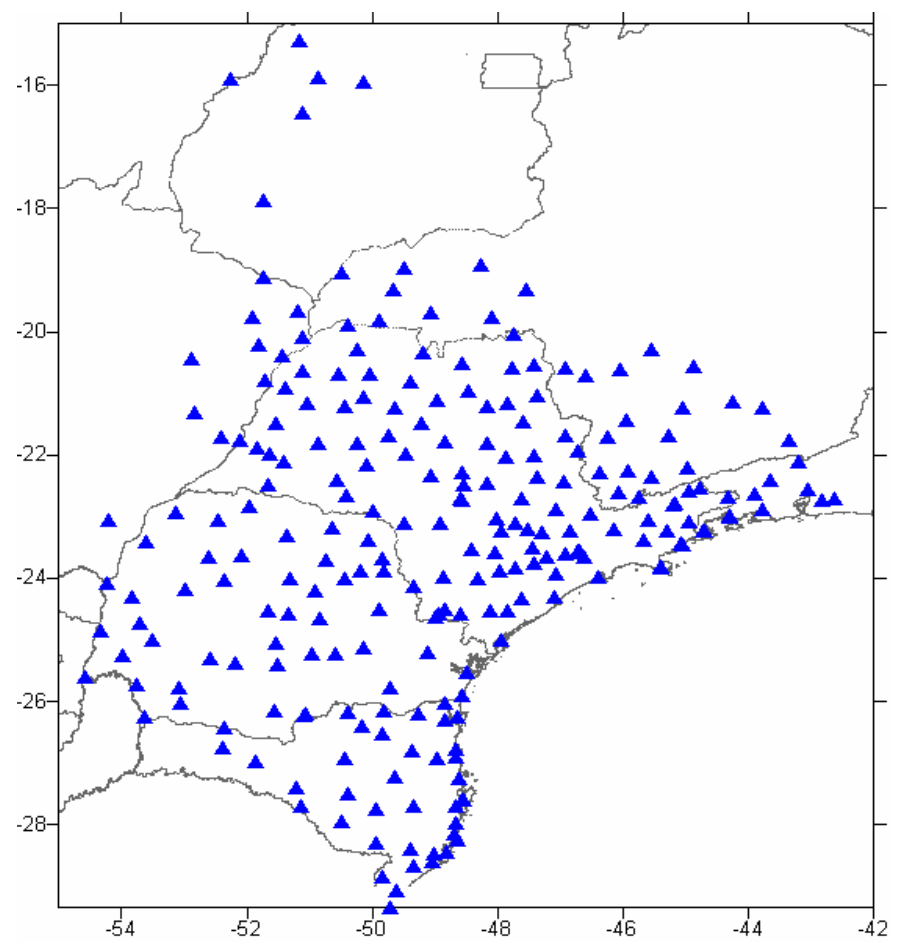

Figura 4.6 - Rede GPS do Sul/Sudeste do Brasil implantada pelo IAG/USP

Os dados apresentados na Tabela 4.3 fazem parte da rede GPS do Estado de Santa Catarina, implantada para a execução deste projeto. A distribuição geográfica das estações da RGSB no Estado de Santa Catarina é mostrada na Figura 4.7.

Tabela 4.3 - Estações da RGSB no Estado de Santa Catarina

\begin{tabular}{|l|c|c|c|c|}
\hline Localização & $\begin{array}{c}\text { Latitude } \\
(\varphi)\end{array}$ & $\begin{array}{c}\text { Longitude } \\
(\lambda)\end{array}$ & $\begin{array}{c}\text { Altitude geométrica } \\
(\mathrm{h}) \\
(\mathrm{m})\end{array}$ & $\begin{array}{c}\sigma_{\mathrm{h}} \\
(\mathrm{m})\end{array}$ \\
\hline Arroio & $-28,154473$ & $-48,692475$ & 17,8100 & 0,0316 \\
\hline Bom Jesus & $-26,735551$ & $-52,394383$ & 682,894 & 0,0445 \\
\hline Campo alegre & $-26,189905$ & $-49,267066$ & 880,731 & 0,0391 \\
\hline Canoinhas & $-26,179961$ & $-50,396633$ & 782,709 & 0,0644 \\
\hline Criciúma & $-28,680405$ & $-49,34411$ & 52,6930 & 0,0416 \\
\hline Florianópolis & $-27,597463$ & $-48,576425$ & 34,4600 & 0,0487 \\
\hline Garuva & $-26,028527$ & $-48,855654$ & 31,3000 & 0,0597 \\
\hline Gaspar & $-26,929266$ & $-48,957884$ & 18,2640 & 0,0328 \\
\hline Imbituba A(91854) & $-28,236614$ & $-48,656078$ & 11,7490 & 0,0001 \\
\hline
\end{tabular}




\begin{tabular}{|c|c|c|c|c|}
\hline Imbituba B(3010c) & $-28,240422$ & $-48,658776$ & 6,36300 & 0,0687 \\
\hline Irany & $-26,96939$ & $-51,854001$ & 1115,01 & 0,0431 \\
\hline Itajai & $-26,906824$ & $-48,661902$ & 3,78200 & 0,0352 \\
\hline \begin{tabular}{|l} 
Jaguaruna \\
\end{tabular} & $-28,600568$ & $-49,051803$ & 10,9340 & 0,0335 \\
\hline Joinville & $-26,310601$ & $-48,855047$ & 11,3920 & 0,0536 \\
\hline Laguna & $-28,439907$ & $-48,812721$ & 19,8490 & 0,0512 \\
\hline Lauro Muller & $-28,393141$ & $-49,396241$ & 221,891 & 0,0520 \\
\hline Mafra & $-26,138996$ & $-49,812661$ & 792,470 & 0,0494 \\
\hline Palhoça & $-27,695219$ & $-48,661772$ & 5,15800 & 0,0401 \\
\hline Paulo Lopes & $-27,96059$ & $-48,679142$ & 4,92700 & 0,0587 \\
\hline Piçarras & $-26,781947$ & $-48,668568$ & 8,51300 & 0,0276 \\
\hline São F. Sul & $-26,242295$ & $-48,640063$ & 1,91200 & 0,0287 \\
\hline Tijucas & $-27,242788$ & $-48,631931$ & 2,01000 & 0,0304 \\
\hline Tubarão & $-28,469891$ & $-49,014938$ & 9,596 & 0,0460 \\
\hline União Vitoria B & $-26,209273$ & $-51,076834$ & 951,659 & 0,0395 \\
\hline Alfredo Wagner & $-27,701009$ & $-49,334423$ & 465,249 & 0,0363 \\
\hline Anita Garibaldi & $-27,685469$ & $-51,130593$ & 880,894 & 0,0507 \\
\hline Benedito Novo & $-26,800878$ & $-49,358935$ & 142,389 & 0,0638 \\
\hline Bocaina Sul & $-27,744479$ & $-49,94453$ & 860,494 & 0,0739 \\
\hline Capão Alto & $-27,956127$ & $-50,484437$ & 982,014 & 0,0574 \\
\hline Florianópolis & $-27,106428$ & $-48,546833$ & 3,72800 & 0,0438 \\
\hline Imbituba C (3010b) & $-28,237967$ & $-48,654332$ & 10,8420 & 0,0427 \\
\hline Imbituba D (cbd3a) & $-28,231509$ & $-48,650397$ & 7,46500 & 0,0592 \\
\hline Papanduva & $-26,394734$ & $-50,16267$ & 820,491 & 0,0680 \\
\hline Ponte Alta & $-27,484336$ & $-50,380029$ & 859,727 & 0,0592 \\
\hline Rio Sul & $-27,213797$ & $-49,645324$ & 342,673 & 0,0591 \\
\hline Timbé do Sul & $-28,832915$ & $-49,846829$ & 127,168 & 0,0384 \\
\hline Torres & $-29,341675$ & $-49,7279$ & 21,2070 & 0,0833 \\
\hline Moemas & $-26,531646$ & $-49,84312$ & 942,231 & 0,0320 \\
\hline Santa Cecília & $-26,913299$ & $-50,444574$ & 1099,513 & 0,1002 \\
\hline São Joaquim & $-28,291671$ & $-49,94344$ & 1366,130 & 0,0474 \\
\hline Sombrio & $-29,079198$ & $-49,629203$ & 16,93500 & 0,0626 \\
\hline
\end{tabular}


As estatísticas dos erros padrão da altitude geométrica da RGSB no Estado de Santa Catarina (Tabela 4.4), mostram coerência com as demais estações (Tabela 4.1).

Tabela 4.4 - Estatísticas dos erros da altitude geométrica da RGSB no Estado de Santa Catarina.

\begin{tabular}{|l|c|}
\hline Estatísticas & $\begin{array}{c}\text { Valor numérico } \\
(\mathrm{m})\end{array}$ \\
\hline Número de dados & 42 \\
\hline Média & 0,0487 \\
\hline Desvio padrão & 0,0174 \\
\hline Máximo & 0,1002 \\
\hline Mínimo & 0,0001 \\
\hline
\end{tabular}

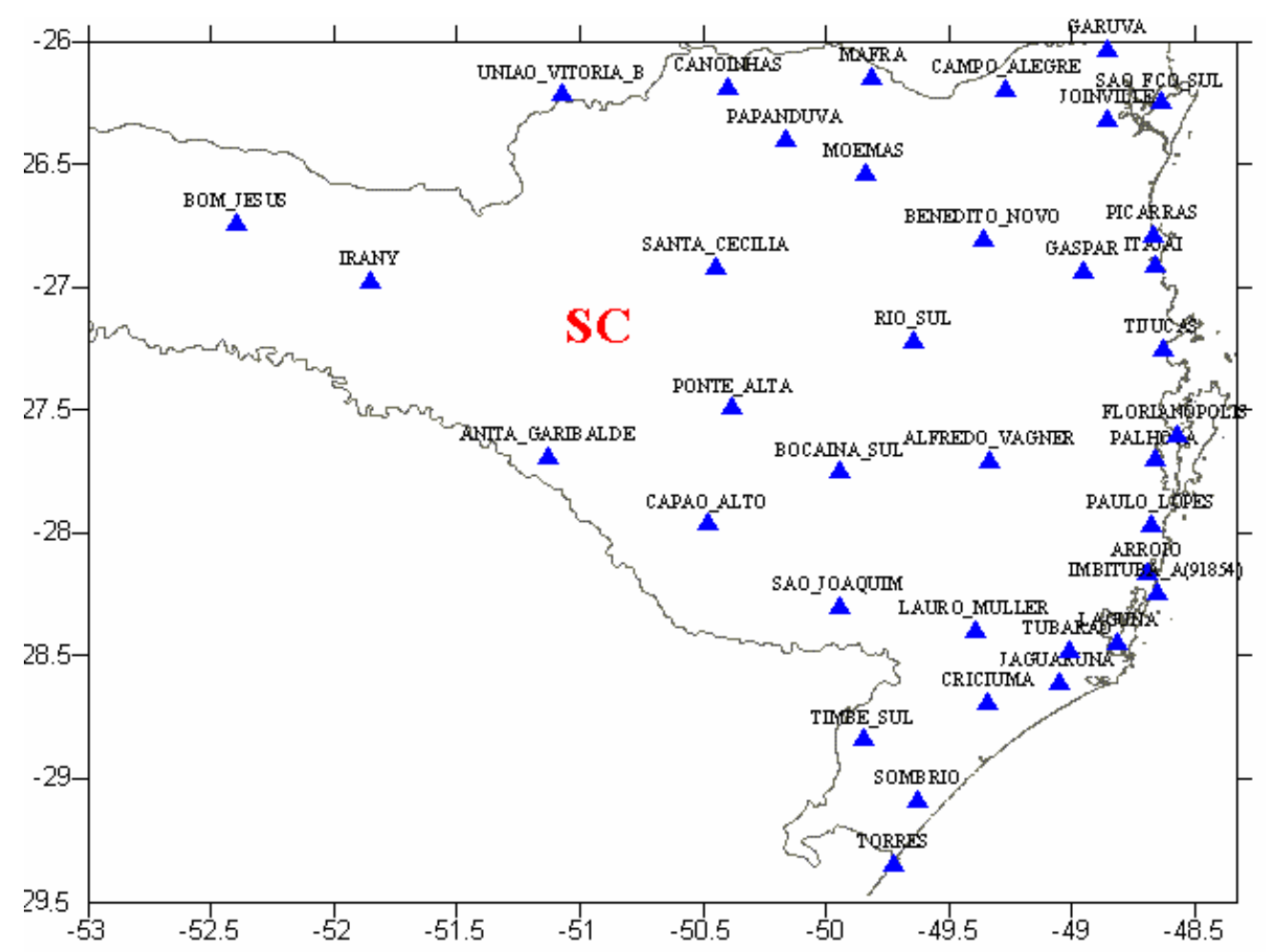

Figura 4.7 - Rede GPS do Sul/Sudeste do Brasil no Estado de Santa Catarina

As estações da RGSB, documentadas em fichas descritivas, contêm os dados geodésicos, a descrição do local, o croqui em planta, e as fotografias de localização e detalhe. As estações da RGSB, implantadas no porto de Imbituba (Figura 3.3), têm as fichas descritivas mostradas nas Figuras 4.8, 4.9 e 4.10. 
UNIVERSIDADE DE SÃO PAULO

IAG - DEPARTAMENTO DE GEOFÍSICA

LABORATÓRIO DE GEODESIA E GRAVIMETRIA

ESTACÃO GPS

\begin{tabular}{|c|c|c|c|c|c|c|}
\hline \multicolumn{3}{|l|}{$\begin{array}{l}\text { Nome } \\
\text { IMBITUBA_B }\end{array}$} & \multicolumn{2}{|c|}{$\begin{array}{l}\text { Referência de nível } \\
3010 \mathrm{~B}\end{array}$} & $\begin{array}{l}\mathrm{UF} \\
\mathrm{SC}\end{array}$ & \multirow{2}{*}{$\begin{array}{l}\text { Data } \\
28 / 04 / 05 \\
\begin{array}{l}\text { Erro padrão } \\
\pm 0,0623 \mathrm{~m}\end{array}\end{array}$} \\
\hline \multicolumn{2}{|c|}{$\begin{array}{l}\text { Latitude } \\
\text { S } 22^{\circ} 18^{\prime} 38,16396^{\prime \prime}\end{array}$} & $\begin{array}{l}\text { Erro padrão } \\
\pm 0,0246 \mathrm{~m}\end{array}$ & \multicolumn{3}{|c|}{$\begin{array}{l}\text { Longitude } \\
\text { W } 048^{\circ} 51^{\prime} 18,16782^{\prime \prime}\end{array}$} & \\
\hline $\begin{array}{l}\text { Altit. Geométrica } \\
11,3963 \mathrm{~m}\end{array}$ & $\begin{array}{l}\text { Erro padrão } \\
\pm 0.0536 \mathrm{~m}\end{array}$ & \multicolumn{2}{|c|}{$\begin{array}{l}\text { Altit. ortométrica }(\mathrm{P}) \\
20,586 \mathrm{~m}\end{array}$} & \multicolumn{2}{|c|}{$\begin{array}{l}\text { Altit. ortométrica (A) } \\
20,209 \mathrm{~m}\end{array}$} & $\begin{array}{c}\text { Erro padrão } \\
-\end{array}$ \\
\hline $\begin{array}{l}\text { Referencial } \\
\text { SIRGAS (ITRF2000.4) }\end{array}$ & $\begin{array}{l}\text { Datum vertica } \\
\text { Imbituba }\end{array}$ & $\begin{array}{l}\text { Fonte } \\
\text { IBGE }\end{array}$ & \multicolumn{4}{|c|}{ Observação } \\
\hline
\end{tabular}

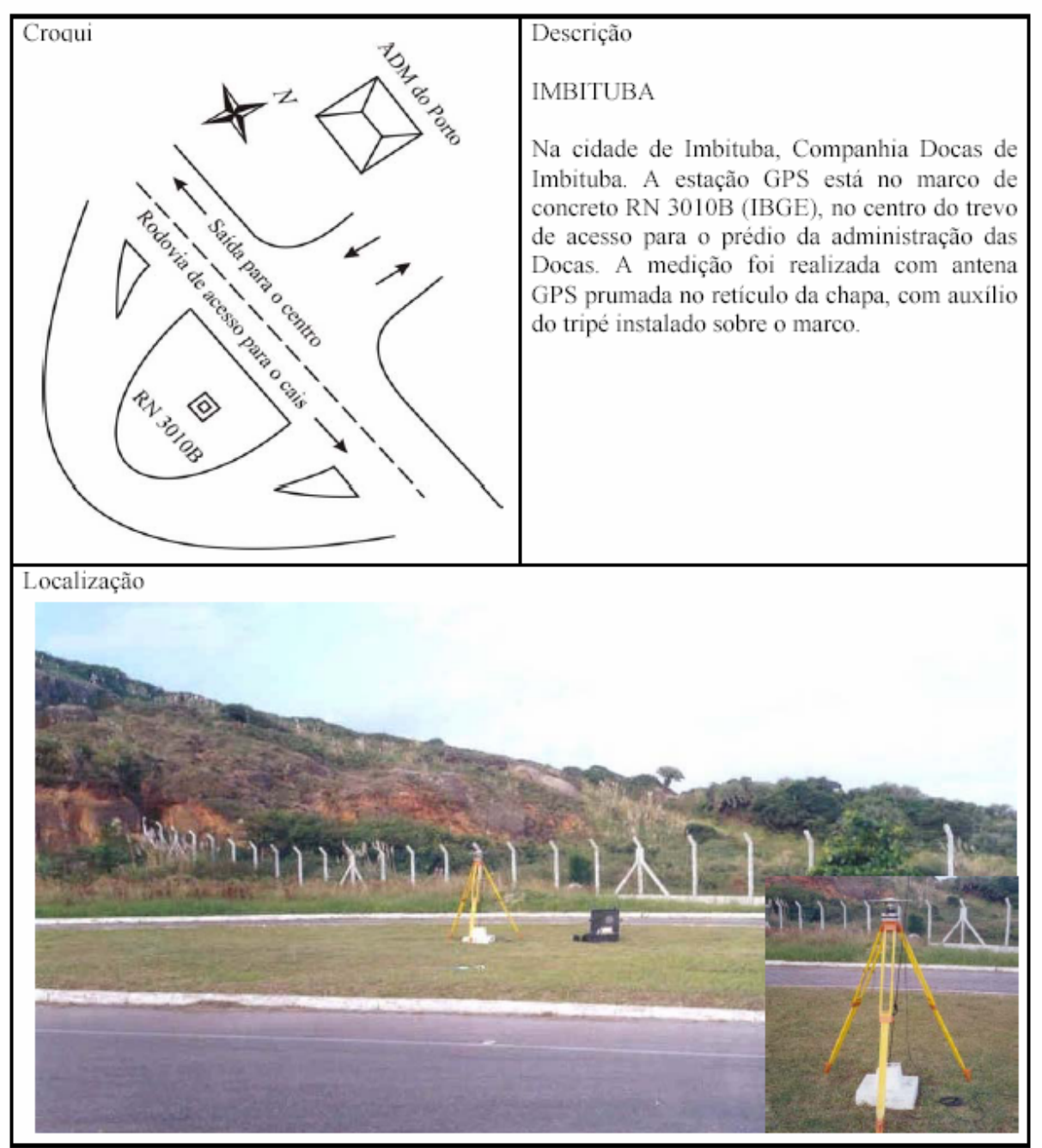

Figura 4.8 - Ficha descritiva da RN 3010B 
UNIVERSIDADE DE SÃO PAULO

IAG - DEPARTAMENTO DE GEOFÍSICA

LABORATÓRIO DE GEODESIA E GRAVIMETRIA

\section{ESTACÃO GPS}

\begin{tabular}{|c|c|c|c|c|c|c|}
\hline \multicolumn{3}{|l|}{$\begin{array}{l}\text { Nome } \\
\text { IMBITUBA }\end{array}$} & \multicolumn{2}{|c|}{$\begin{array}{l}\text { Referência de nível } \\
\text { 3010C }\end{array}$} & $\begin{array}{l}\mathrm{UF} \\
\mathrm{SC}\end{array}$ & $\begin{array}{l}\text { Data } \\
16 / 10 / 04\end{array}$ \\
\hline \multicolumn{2}{|c|}{$\begin{array}{l}\text { Latitude } \\
\text { S } 28^{\circ} 14 ' 25,52100^{\prime \prime}\end{array}$} & $\begin{array}{l}\text { Erro padrão } \\
\pm 0,0190 \mathrm{~m}\end{array}$ & \multicolumn{3}{|c|}{$\begin{array}{l}\text { Longitude } \\
\text { W } 048^{\circ} 39^{\prime} 31,59205^{\prime \prime}\end{array}$} & $\begin{array}{l}\text { Erro padrão } \\
\pm 0,0930 \mathrm{~m}\end{array}$ \\
\hline $\begin{array}{l}\text { Altit. geométrica } \\
6,3676 \mathrm{~m}\end{array}$ & \begin{tabular}{|l|} 
Erro padrão \\
$\pm 0,0687 \mathrm{~m}$
\end{tabular} & \multicolumn{2}{|c|}{$\begin{array}{l}\text { Altit. ortométrica (P) } \\
\mathrm{m}\end{array}$} & \multicolumn{2}{|c|}{$\begin{array}{l}\text { Altit. ortométrica (A) } \\
5,0480 \mathrm{~m}\end{array}$} & $\begin{array}{c}\text { Erro padrão } \\
-\end{array}$ \\
\hline Referencial & $\begin{array}{l}\text { Datum verti } \\
\text { Imbituba }\end{array}$ & $\begin{array}{l}\text { Fonte } \\
\text { IBGE }\end{array}$ & & & & \\
\hline
\end{tabular}

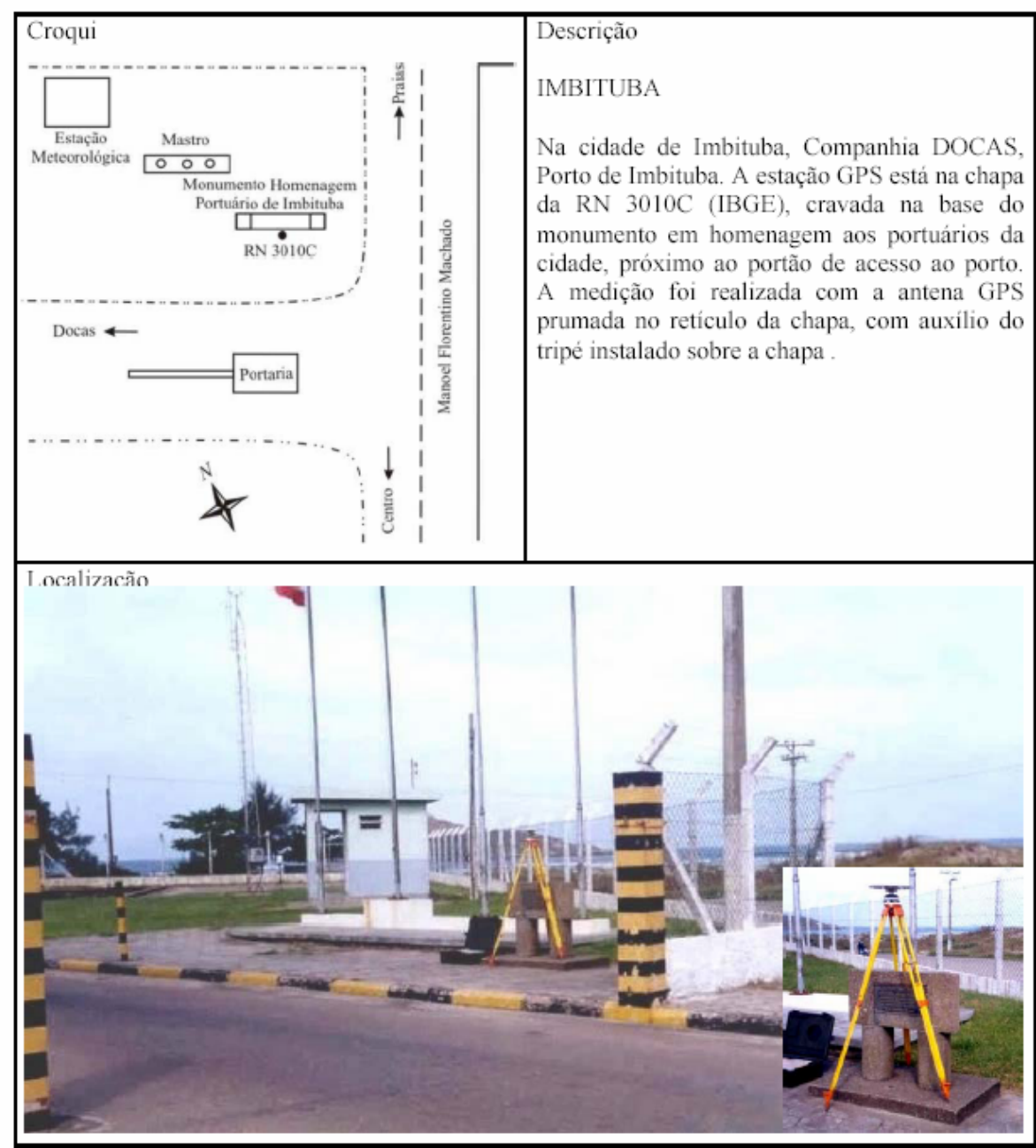

Figura 4.9- Ficha descritiva da RN 3010 C 
UNIVERSIDADE DE SÃO PAULO

IAG - DEPARTAMENTO DE GEOFÍSICA

LABORATÓRIO DE GEODESIA E GRAVIMETRIA

\section{EST ACÃO GPS}

\begin{tabular}{|c|c|c|c|c|c|c|}
\hline \multicolumn{3}{|l|}{$\begin{array}{l}\text { Nome } \\
\text { IMBITUBA_C }\end{array}$} & \multicolumn{2}{|c|}{$\begin{array}{l}\text { Referência de nível } \\
\text { CDB3AM }\end{array}$} & $\begin{array}{l}\text { UF } \\
\text { SC }\end{array}$ & \multirow{2}{*}{$\begin{array}{l}\text { Data } \\
29 / 04 / 05 \\
\begin{array}{l}\text { Erro padrão } \\
\pm 0,0623 \mathrm{~m}\end{array}\end{array}$} \\
\hline \multicolumn{2}{|c|}{$\begin{array}{l}\text { Latitude } \\
\text { S } 22^{\circ} 18^{\prime} 38,16396^{\prime \prime}\end{array}$} & $\begin{array}{l}\text { Erro padrão } \\
\pm 0,0246 \mathrm{~m}\end{array}$ & \multicolumn{3}{|c|}{$\begin{array}{l}\text { Longitude } \\
\text { W } 048^{\circ} 51 \text { ' } 18,16782 "\end{array}$} & \\
\hline $\begin{array}{l}\text { Altit. Geométrica } \\
11,3963 \mathrm{~m}\end{array}$ & $\begin{array}{l}\text { Erro padrão } \\
\pm 0,0536 \mathrm{~m}\end{array}$ & \multicolumn{2}{|c|}{$\begin{array}{l}\text { Altit. ortométrica (P) } \\
20,586 \mathrm{~m}\end{array}$} & \multicolumn{2}{|c|}{$\begin{array}{l}\text { Altit. ortométrica (A) } \\
20,209 \mathrm{~m}\end{array}$} & $\begin{array}{c}\text { Erro padrão } \\
-\end{array}$ \\
\hline $\begin{array}{l}\text { Referencial } \\
\text { SIRGAS (ITRF2000.4) }\end{array}$ & $\begin{array}{l}\text { Datum vertica } \\
\text { Imbituba }\end{array}$ & $\begin{array}{l}\text { Fonte } \\
\text { IBGE }\end{array}$ & \multicolumn{4}{|c|}{ Observação } \\
\hline
\end{tabular}

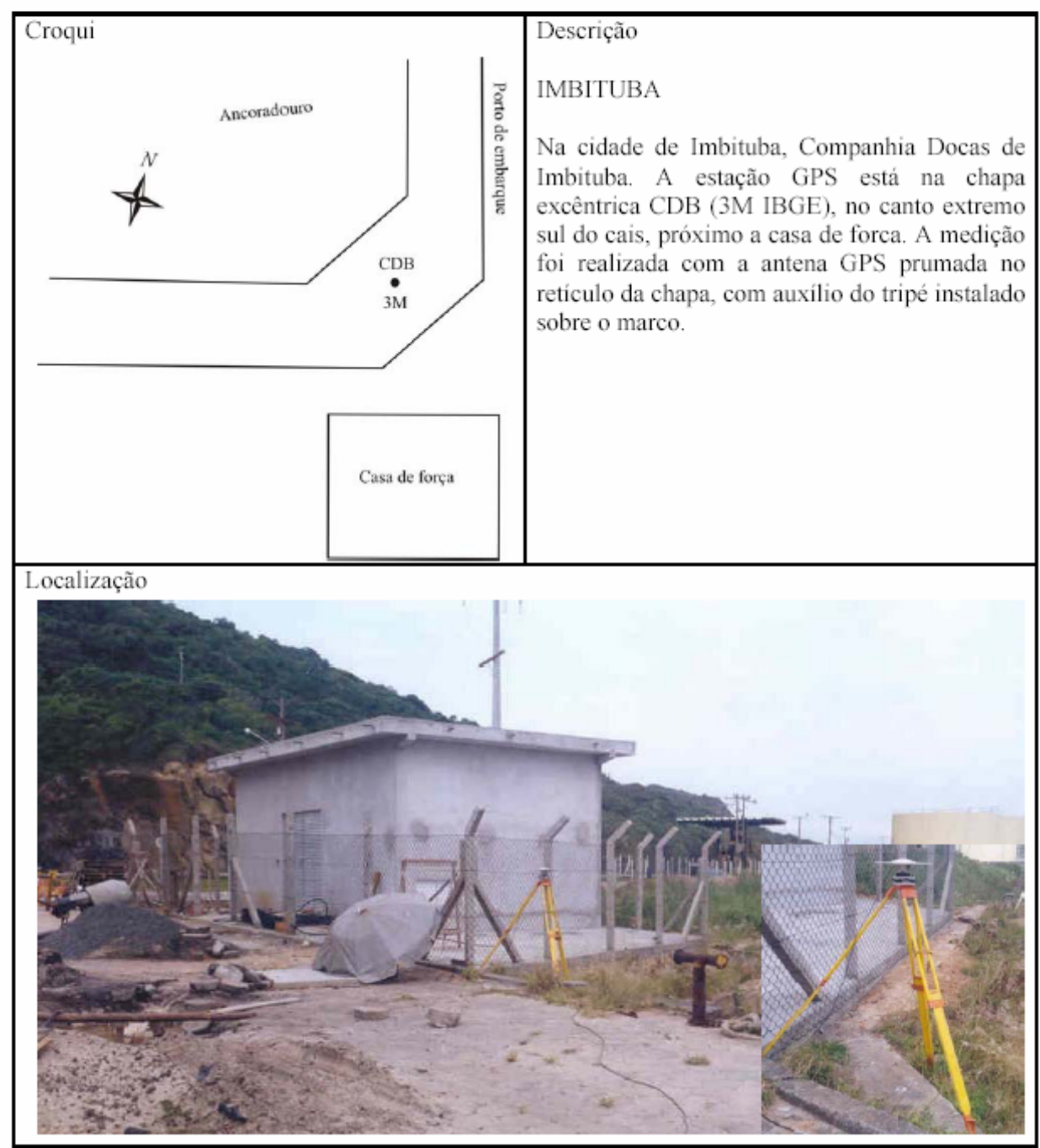

Figura 4.10 - Ficha descritiva da RN CDB3AM 


\section{5 - METODOLOGIA}

Neste capítulo, é apresentada uma síntese da metodologia usada na implantação da rede RGSB no Estado de Santa Catarina, a determinação da componente sistemática na região do Datum altimétrico brasileiro, e a determinação da diferença dos referenciais dos geóides gravimétrico e GPS.

\section{1 - IMPLANTAÇÃO DA REDE GPS NA REGIÃO DO DATUM ALTIMÉTRICO}

A implantação da RGSB no Estado de Santa Catarina, seguiu a mesma sistemática dos Estados anteriores (São Paulo e Paraná), que envolveu as seguintes etapas :

1. Seleção de RNs da RAFB, para formar a distribuição adequada de estações, com maior densidade nas proximidades de Imbituba;

2. Reconhecimento das RNs a serem posicionadas;

3. Posicionamento das RNs escolhidas;

4. Implantação de RNs excêntricas no caso de haver obstruções, já que o posicionamento por GPS requer total visibilidade no local;

5. Anotações para ficha descritiva, contendo a descrição do local, o croqui, em planta, tomada de fotografias para localização e detalhe;

6. Processamento e ajustamento dos dados.

\section{Equipamentos utilizados}

Os equipamentos de campo utilizados na implantação da RGSB no Estado de Santa Catarina foram os seguintes: um receptor de dupla freqüência e 12 canais modelo Z12, equipado com antena ASH700718A, ambos de fabricação ASTECH (Figura 5.1), um tripé e guarda sol. Os receptores da RBMC são do modelo TRIMBLE 4000SSI.

Na implantação de RNs excêntricas foram utilizados, um nível de luneta WILD NA0 e uma mira dobrável (régua graduada).

Outros acessórios necessários no trabalho de campo são: fichas para anotações da descrição e nivelamento, baterias para o receptor, computador portátil para descarga dos dados do receptor, chapas de latão para a instalação de RNs excêntricas, e acessórios que possibilitem a perfuração do concreto e a fixação da chapa. 


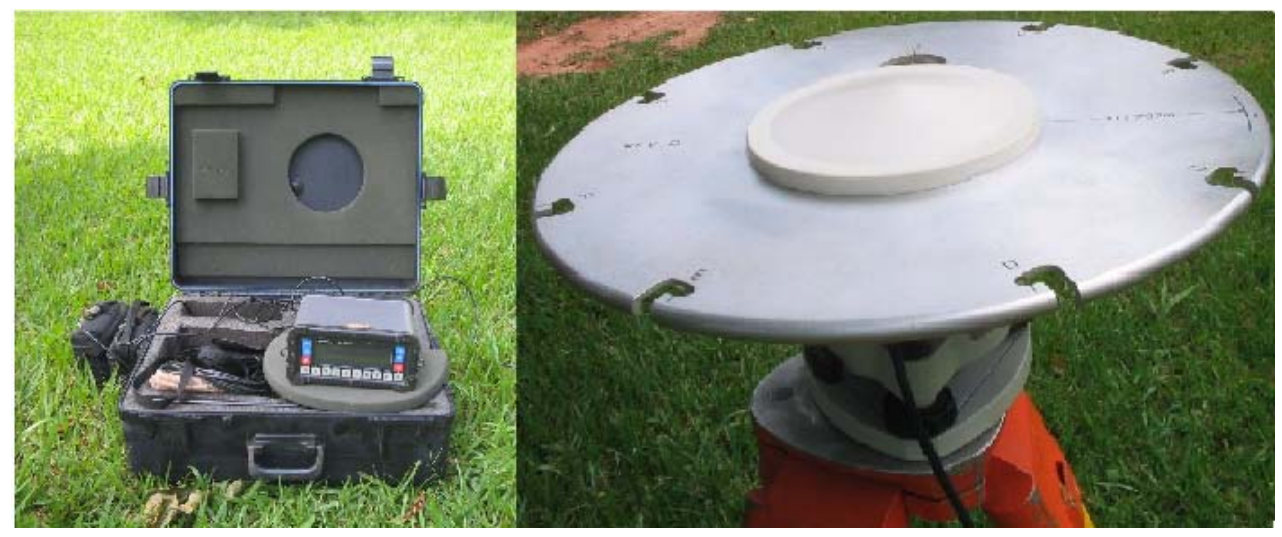

Figura 5.1 - Receptor e antena GPS

Para processamento e ajustamento dos dados GPS foi usado o programa GEOGENIOS, desenvolvido pela Spectra Precision, instalado em computador do Laboratório de Geodésia e Gravimetria do IAG/USP.

\section{Implantação de RNs excêntricas}

As RNs a serem posicionadas devem estar desobstruídas de prédios, árvores ou quaisquer obstáculos que possam interferir nos sinais do satélite. Nas obstruídas, foram implantadas RNs excêntricas, cuja materialização consistiu em fixar uma chapa de latão em estrutura de concreto, de preferência em locais de difícil remoção da chapa. A altitude da RN excêntrica foi determinada por nivelamento e contra-nivelamento geométrico (Figura 5.2).

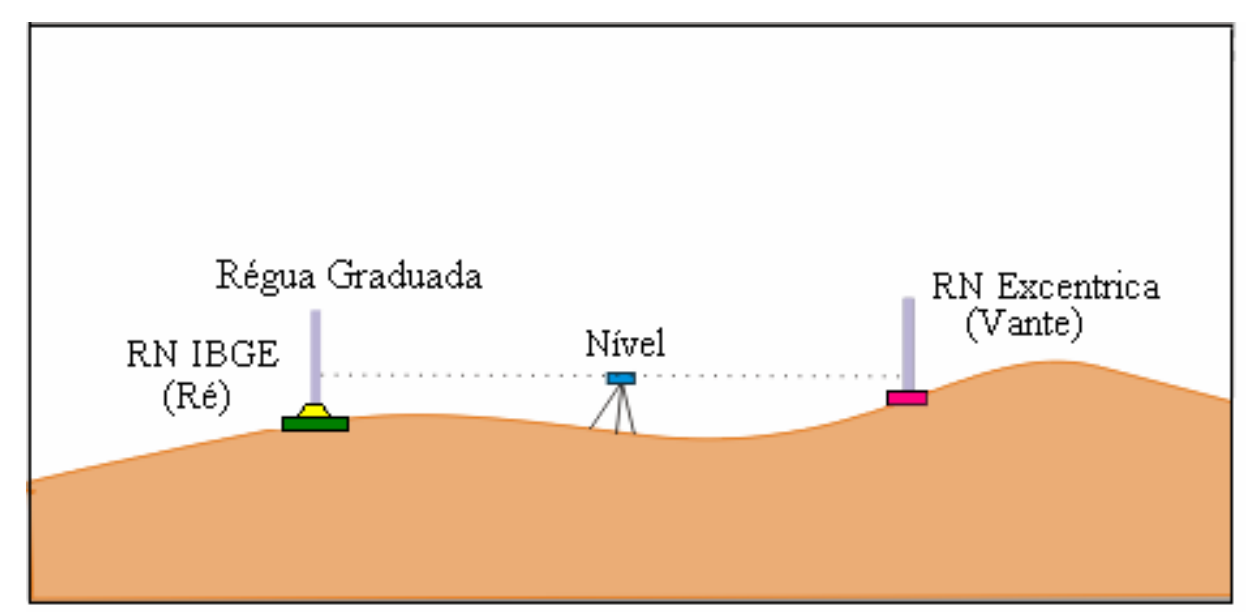

Figura 5.2 - Nivelamento geométrico 
A primeira visada foi feita na RN do IBGE com altitude conhecida (Ré), e a segunda na RN excêntrica (Vante). Para RNs excêntricas distantes da RN do IBGE, foram realizadas várias visadas. A altitude nas RNs excêntricas $\left(\mathrm{H}_{\mathrm{E}}\right)$ foi determinada pela fórmula

$$
\mathrm{H}_{\mathrm{E}}=\mathrm{H}_{\mathrm{A}}+\mathrm{V}_{\text {Ré }}-\mathrm{V}_{\text {Vante }}
$$

onde $\mathrm{H}_{\mathrm{A}}$ é a altitude ortométrica da $\mathrm{RN}$ do IBGE, $\mathrm{V}_{\mathrm{Ré}}$ é o valor lido na régua sobre a $\mathrm{RN}$ de altitude conhecida, e $\mathrm{V}_{\text {Vante }}$ é o valor lido na régua sobre a excêntrica.

\section{Posicionamento de RNs}

No posicionamento por GPS das RNs selecionadas, foi usado o modo o relativo estático, no qual dois ou mais receptores recebem simultaneamente os sinais dos satélites GPS. O tempo de coleta de dados em cada RN foi de quatro horas no Porto de Imbituba, e de três horas no restante da área de estudo. Neste projeto, foram utilizadas como bases fixas as 5 estações da RBMC mais próximas do Estado de Santa Catarina. Para coleta de dados nas RNs do IBGE ou RNs excêntricas, foi instalada a antena GPS sobre a chapa, de modo que o centro de fase da antena coincidisse verticalmente com o centro da chapa, usando plumagem óptica.

O ângulo de elevação mínimo adotado em campo, para a recepção dos sinais GPS, foi de $10^{\circ}$, e o intervalo de gravação de 15 segundos. Além do procedimento de instalação da antena sobre a RN são necessárias anotações para documentação da estação GPS, incluindo o croqui e a descrição do local, e fotografias de localização e detalhe. Outros cuidados importantes no posicionamento por GPS, a medida da altura da antena, sua orientação, e a programação do receptor.

\section{Processamento e ajustamento dos dados}

O processamento iniciou-se com a transferência dos dados do receptor para o computador, pelo programa GEOGENIOS, e a transferência dos dados das estações escolhidas da RBMC do site do IBGE (http://www.ibge.gov.br)

As efemérides precisas utilizadas no processamento dos dados foram obtidas pela internet no site do IGS http://www.igs.nasa.gov. 
No processamento dos dados, foi usada a opção do GEOGENIOS para a dupla diferença de fase; no ajustamento, os dados de entrada ou observações são as componentes $\Delta \mathrm{x}, \Delta \mathrm{y}, \Delta \mathrm{z}$, obtidas no processamento das estações e as respectivas matrizes de variância covariância (MVC). Os parâmetros calculados pelo método dos mínimos quadrados (MMQ) são as coordenadas cartesianas dos pontos observados (SP, 2000).

\section{2 - DETERMINAÇÃO DA COMPONENTE SISTEMÁTICA}

Como foi visto no Capítulo 3, há vários métodos para a conexão de Data altimétricos; entretanto, a utilização de modelos geoidais é um método eficiente e prático. A seguir serão mostradas as aplicações dessa metodologia na determinação da componente sistemática no Datum de Imbituba.

A componente sistemática $(\Delta \mathrm{N})$ nas estações da RGSB é determinada a partir da diferença entre a altura geoidal GPS $\left(\mathrm{N}_{\mathrm{GPS}}\right)$, dado pela expressão (4.13), e a gravimétrica $\left(\mathrm{N}_{\mathrm{g}}\right)$ (Figura 5.3)

$$
\begin{aligned}
& \Delta \mathrm{N}=\mathrm{N}_{\mathrm{GPS}}-\mathrm{N}_{\mathrm{g}} \\
& \sigma_{\Delta \mathrm{N}}=\sqrt{\sigma_{\mathrm{h}}^{2}+\sigma_{\mathrm{H}}^{2}+\sigma_{\mathrm{N}_{\mathrm{g}}}^{2}}
\end{aligned}
$$

onde $\sigma_{\mathrm{h}}^{2}$ é a variância da altitude geométrica, $\sigma_{\mathrm{H}}^{2}$ é a variância da altitude ortométrica e $\sigma_{\mathrm{N}_{\mathrm{g}}}^{2}$ é a variância da altura geoidal.

A partir dos valores determinados através de (5.2), é calculada a componente sistemática no Datum, além de serem ajustadas superfícies para compatibilizar o geóide gravimétrico ao geóide GPS. 


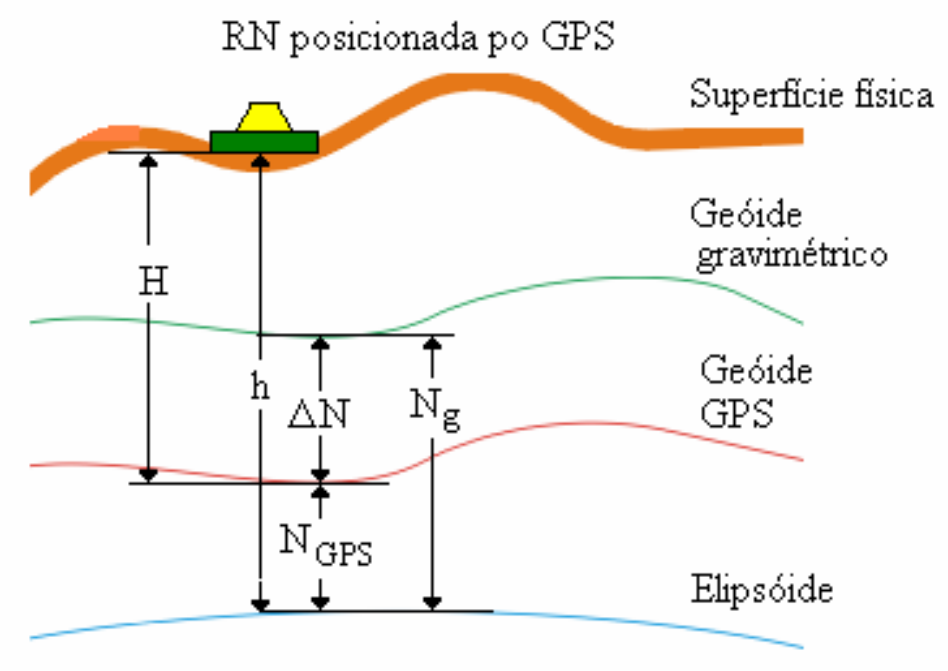

Figura 5.3 - Dados envolvidos na determinação da componente sistemática.

\section{Determinação da componente sistemática no Datum altimétrico brasileiro}

Além da determinação da componente sistemática na $\mathrm{RN} 4 \mathrm{X}$, através da expressão (3.12), foi feito o cálculo da componente sistemática a partir da média ponderada, onde foram utilizadas as 25 estações GPS mais próximas ao Datum altimétrico de Imbituba.

Das 41 estações da RGSB contidas na região (Figura 4.7), foram eliminadas as suspeitas de erros grosseiros, e as localizadas a mais de $200 \mathrm{~km}$ de Imbituba. Na eliminação dos dados com suspeitas de erros grosseiros, foram considerados dados anômalos (provavelmente em altitude ortométrica) aqueles cujos resíduos, em módulo, ultrapassaram 2 vezes o desvio padrão da média. As estações que apresentaram erros grosseiros localizam-se em Florianópolis (2 estações) e Torres (1 estação).

A Figura 5.4, mostra a distribuição geográfica das 25 estações da RGSB mais próximas do Porto de Imbituba, das quais 4 estão nas instalações desse porto. 


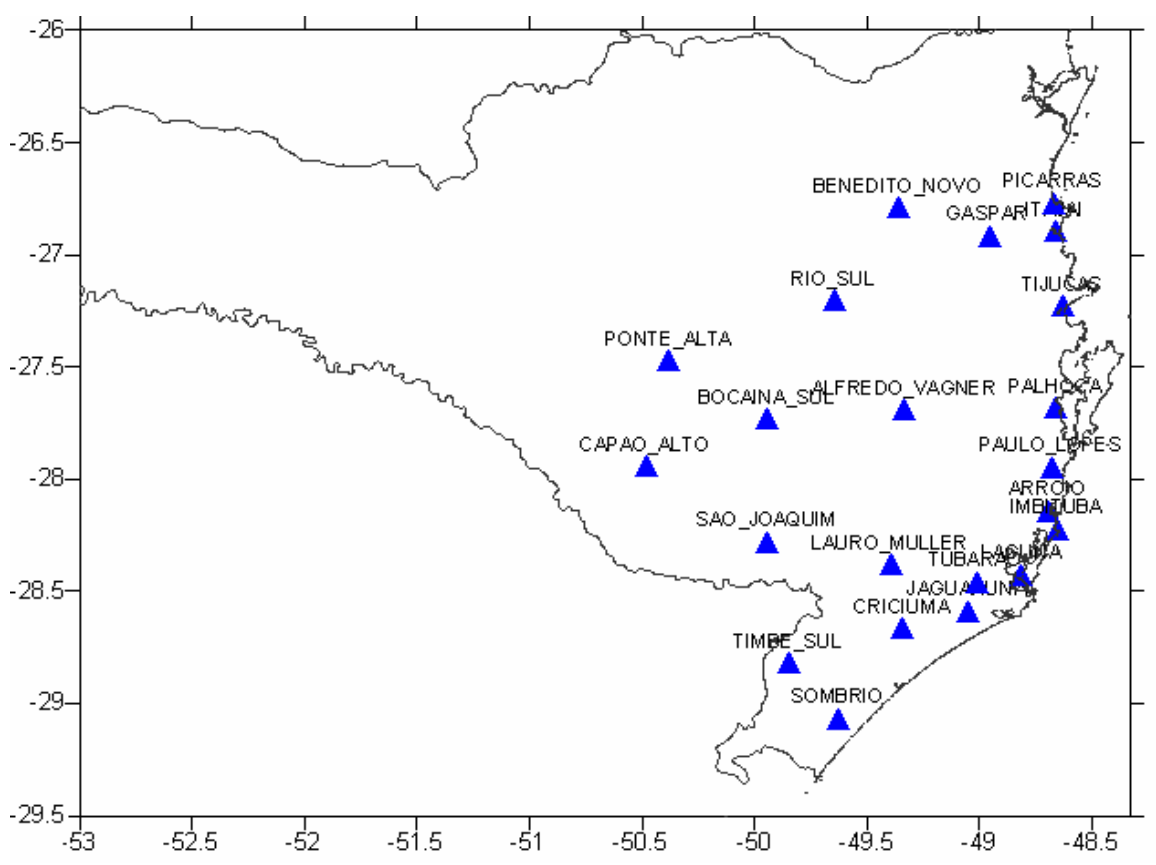

Figura 5.4 - Distribuição das estações mais próximos ao Datum altimétrico de Imbituba.

O conjunto de pontos próximos ao Datum, possibilitou a avaliação dos dados, e a determinação da componente sistemática a ser adotada no Datum.

A média ponderada da componente sistemática $\left(\hat{\Delta}_{\mathrm{D}}\right)$, e a respectiva variância $\left(\sigma^{2} \hat{\Delta} \mathrm{N}_{\mathrm{D}}\right)$, constitui um caso particular do ajustamento (Gemael, 1994)

$$
\begin{aligned}
& \hat{\Delta} \mathrm{N}_{\mathrm{D}}=\left(\mathbf{A}^{\mathrm{T}} \mathbf{P} \mathbf{A}\right)^{-1} \mathbf{A}^{\mathrm{T}} \mathbf{P} \mathbf{L} \\
& \sigma_{\hat{\Delta} \mathrm{N}_{\mathrm{D}}}^{2}=\left(\mathbf{A}^{\mathrm{T}} \mathbf{P} \mathbf{A}\right)^{-1}
\end{aligned}
$$

com o peso inversamente proporcional à variância

$$
\mathrm{P}=\frac{1}{\sigma_{\Delta \mathrm{N}}^{2}}
$$

$\mathrm{e}$ 


$$
\sigma_{\Delta \mathrm{N}}^{2}=\sigma_{\mathrm{H}}^{2}+\sigma_{\mathrm{h}}^{2}+\sigma_{\mathrm{N}_{\mathrm{g}}}^{2}
$$

O erro padrão da altitude ortométrica foi estimado pelo padrão de propagação dos erros com a distância a partir do Datum

$$
\sigma_{\mathrm{H}}= \pm 4 \mathrm{~mm} \sqrt{\mathrm{FK}}
$$

sendo

$$
F=\frac{d_{A B}}{D_{A B}}
$$

onde A é o vetor dos coeficientes contendo 25 linhas e 1 coluna, $\mathbf{P}$ é a matriz diagonal dos pesos formada por $\mathrm{P}, \mathbf{L}$ é o vetor de observações ( $\Delta \mathrm{N}$ de cada estação), $\sigma_{\Delta \mathrm{N}}^{2}$ é a variância da componente sistemática de cada ponto, $\sigma_{\mathrm{H}}^{2}$ é a variância das altitudes ortométricas, $\sigma_{\mathrm{h}}^{2}$ é a variância das altitudes geométrica, $\sigma_{\mathrm{Ng}}^{2}$ é a variância do geóide gravimétrico, $\mathrm{K}$ é a distância geodésica dada em km, F é o fator de conversão da distância geodésica em distância real (Castro, 2002), $\mathrm{d}_{\mathrm{AB}}$ é a distância real entre dois pontos e $\mathrm{D}_{\mathrm{AB}}$ é a distância geodésica entre dois pontos.

\section{Determinação da componente sistemática através da transformação de similaridade}

Outro método utilizado para determinar a componente sistemática foi sua estimativa através do modelo matemático de 8 parâmetros ( 3 de translação, 2 de rotação, 1 de escala e 2 parâmetros do elipsóide), que determina parâmetros para a componente sistemática associada aos erros sistemáticos somados à incompatibilidade de referenciais envolvidos na altura geoidal, altitudes ortométrica e geométrica. O modelo matemático de 8 parâmetros ajusta um valor para a componente sistemática em cada $\mathrm{RN}$ utilizada no cálculo.

No cálculo dos parâmetros do modelo, foram usados todos as estações da RGSB (Figura 4.6) pela maior área de abrangência.

O modelo mais completo, proposto por Kotsakis et al. (2001), tem a forma 


$$
\begin{aligned}
\Delta \mathrm{N} & =-\cos \varphi \cos \lambda d X-\cos \varphi \operatorname{sen} \lambda d \mathrm{Y}-\operatorname{sen} \varphi d Z-\frac{\operatorname{sen} \varphi \cos \varphi \cos \lambda}{W} \mathrm{e}^{2} \mathrm{ad} \omega_{\mathrm{y}} \\
& +\frac{\operatorname{sen} \varphi \cos \varphi \cos \lambda}{\mathrm{W}} \mathrm{e}^{2} \mathrm{ad} \omega_{\mathrm{x}}-(\mathrm{aW}+\mathrm{h}) \mathrm{ds}-\frac{1-\mathrm{f}^{2} \operatorname{sen}^{2} \varphi}{\mathrm{W}} \mathrm{da}-\frac{\operatorname{sen}^{2} \varphi}{\mathrm{W}} \mathrm{a} \sqrt{1-\mathrm{e}^{2}} \mathrm{df}
\end{aligned}
$$

com

$$
\mathrm{W}=\sqrt{1-\mathrm{e}^{2} \operatorname{sen}^{2}} \varphi
$$

onde $\varphi$ e $\lambda$ são as coordenadas geodésicas latitude e longitude, respectivamente, $d X, d Y$ e $\mathrm{dZ}$ são as translações nos eixos $\mathrm{X}, \mathrm{Y}$ e $\mathrm{Z}$, respectivamente, a é o semi-eixo maior do elipsóide $(\mathrm{a}=6378137 \mathrm{~m})$, f é o achatamento $(\mathrm{f}=1 / 298.257222101), \mathrm{e}^{2}$ é a excentricidade $\left(\mathrm{e}^{2}=0.0066943800229\right)$ do elipsóide de referência utilizado pelo sistema SIRGAS (GRS80), $\mathrm{d} \omega_{\mathrm{y}}$ e d $\omega_{\mathrm{x}}$ são os parâmetros de rotação nos eixos Y e X respectivamente, ds é o parâmetro de escala, da é a diferença entre o raio equatorial dos elipsóides e df é a diferença no achatamento dos elipsóides.

Como usualmente ocorre, o número de observações é maior que o número de incógnitas. Assim, os parâmetros do modelo foram determinados pelo MMQ (Gemael, 1994)

$$
\begin{aligned}
& \hat{\mathbf{X}}=\left(\mathbf{A}^{\mathrm{T}} \mathbf{P} \mathbf{A}\right)^{-1} \mathbf{A}^{\mathrm{T}} \mathbf{P} \mathbf{L} \\
& \sigma_{\hat{\mathrm{X}}}^{2}=\left(\mathbf{A}^{\mathrm{T}} \mathbf{P} \mathbf{A}\right)^{-1}
\end{aligned}
$$

onde $\mathbf{X}$ é o vetor dos parâmetros estimados, A é a matriz dos coeficientes, $\mathbf{P}$ é a matriz diagonal dos pesos, obtidos pela expressão (5.4), e $\mathbf{L}$ é o vetor das observações ( $\Delta \mathrm{N}$ de cada estação).

A seguir serão mostrados os resultados da aplicação dos modelos matemáticos para a determinação da componente sistemática no Datum e na RAFB. 


\section{6 - RESULTADOS}

Neste capítulo, são mostrados os resultados obtidos na comparação do geóide gravimétrico com o geóide GPS visando a determinação da componente sistemática no Datum altimétrico brasileiro, e suas implicações para RAFB.

\section{1 - A COMPONENTE SISTEMÁTICA NA REGIÃO DO DATUM}

A componente sistemática obtida pela expressão (5.2), com o respectivo erro obtido por (5.3), nas 25 estações GPS mais próximas ao Datum altimétrico, brasileiro é mostrada na Tabela 6.1.

Tabela 6.1 - Componente sistemática na região do Datum de Imbituba

\begin{tabular}{|l|c|c|c|c|}
\hline NOME & $\begin{array}{c}\text { Latitude } \\
(\varphi)\end{array}$ & $\begin{array}{c}\text { Longitude } \\
(\lambda)\end{array}$ & $\begin{array}{c}\Delta \mathrm{N} \\
(\mathrm{m})\end{array}$ & $\begin{array}{c}\sigma_{\Delta \mathrm{N}} \\
(\mathrm{m})\end{array}$ \\
\hline Arroio & $-28,1545$ & $-48,6925$ & $-0,574$ & 0,222 \\
\hline Criciúma & $-28,6804$ & $-49,3441$ & $-0,429$ & 0,230 \\
\hline Gaspar & $-26,9293$ & $-48,9579$ & $-0,218$ & 0,188 \\
\hline Imbituba & $-28,2366$ & $-48,6561$ & $-0,356$ & 0,230 \\
\hline Imbituba & $-28,2404$ & $-48,6588$ & $-0,39$ & 0,221 \\
\hline Irani & $-26,9068$ & $-48,6619$ & 0,006 & 0,223 \\
\hline Jaguaruna & $-28,6006$ & $-49,0518$ & $-0,606$ & 0,188 \\
\hline Laguna & $-28,4399$ & $-48,8127$ & $-0,592$ & 0,230 \\
\hline Lauro Muller & $-28,3931$ & $-49,3962$ & $-0,323$ & 0,215 \\
\hline Palhoça & $-27,6952$ & $-48,6618$ & $-0,498$ & 0,223 \\
\hline Paulo Lopes & $-27,9606$ & $-48,6791$ & $-0,724$ & 0,196 \\
\hline Piçarras & $-26,7819$ & $-48,6686$ & $-0,232$ & 0,223 \\
\hline Tijucas & $-27,2428$ & $-48,6319$ & $-0,205$ & 0,223 \\
\hline Tubarão & $-28,4699$ & $-49,0149$ & $-0,519$ & 0,214 \\
\hline A. Vagner & $-27,701$ & $-49,3344$ & 0,033 & 0,264 \\
\hline B. Novo & $-26,8009$ & $-49,3589$ & $-0,035$ & 0,197 \\
\hline Bocaina Sul & $-27,7445$ & $-49,9445$ & $-0,179$ & 0,251 \\
\hline Capão Alto & $-27,9561$ & $-50,4844$ & $-0,5$ & 0,233 \\
\hline Imbituba & $-28,238$ & $-48,6543$ & $-0,339$ & 0,229 \\
\hline Imbituba & $-28,2315$ & $-48,6504$ & $-0,430$ & 0,228 \\
\hline Ponte Alta & $-27,4843$ & $-50,38$ & $-0,323$ & 0,213 \\
\hline Rio Sul & $-27,2138$ & $-49,6453$ & $-0,295$ & 0,214 \\
\hline S. Joaquim & $-28,2917$ & $-49,9434$ & $-0,128$ & 0,254 \\
\hline Sombrio & $-29,0792$ & $-49,6292$ & $-0,327$ & 0,287 \\
\hline Timbé Sul & $-28,8329$ & $-49,8468$ & $-0,478$ & 0,253 \\
\hline
\end{tabular}

A Tabela 6.2 mostra as estatísticas da componente sistemática nas 25 estações GPS mais próximas ao Datum altimétrico brasileiro. 
Tabela 6.2 - Estatísticas da componente sistemática nas 25 estações GPS mais próximas ao Datum altimétrico brasileiro.

\begin{tabular}{|l|c|}
\hline Estatísticas & $\begin{array}{c}\text { Valor numérico } \\
(\mathrm{m})\end{array}$ \\
\hline Média & $-0,341$ \\
\hline Desvio padrão & 0,196 \\
\hline Máximo & 0,033 \\
\hline Mínimo & $-0,724$ \\
\hline
\end{tabular}

A superfície ilustrada na Figura 6.1 mostra a componente sistemática contida em uma região de $200 \mathrm{~km}$ em torno do Datum de Imbituba.

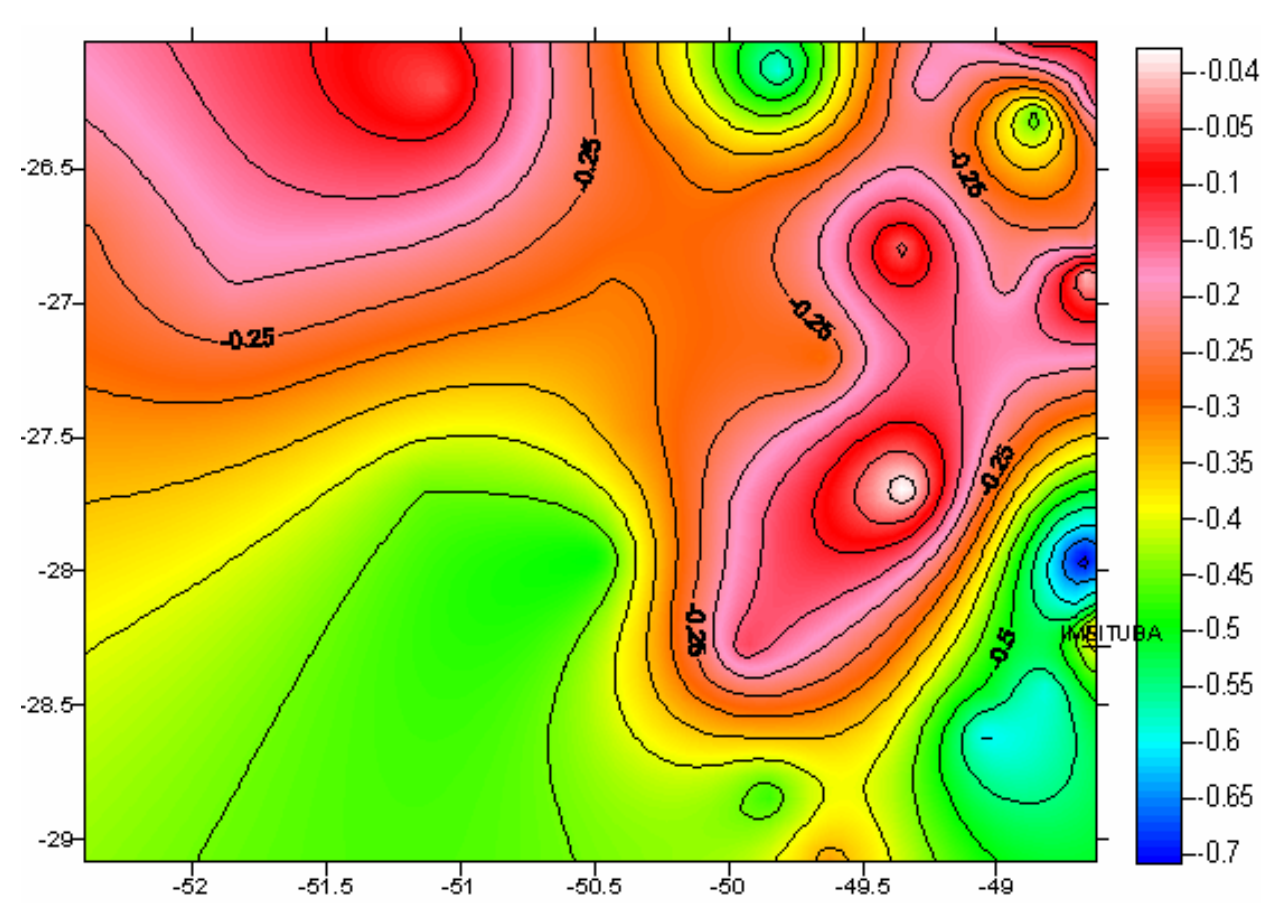

Figura 6.1 - Superfície determinada a partir da componente sistemática.

A componente sistemática nas 4 RNs mais próximas ao Datum de Imbituba é mostrada na Tabela 6.3. Essas RNs estão localizadas no terreno de propriedade da Companhia Docas Imbituba (Figura 3.3). 
Tabela 6.3 - Componente sistemática nas RNs localizadas no Porto de Imbituba

\begin{tabular}{|l|c|c|c|}
\hline Nome da RN & $\begin{array}{c}\Delta \mathrm{N} \\
(\mathrm{m})\end{array}$ & $\begin{array}{c}\sigma_{\Delta \mathrm{N}} \\
(\mathrm{m})\end{array}$ & $\begin{array}{c}\text { Distância da RN 4X } \\
(\mathrm{m})\end{array}$ \\
\hline SAT 91854 & $-0,356$ & 0,230 & 55 \\
\hline $3010 \mathrm{C}$ & $-0,390$ & 0,221 & 490 \\
\hline $3010 \mathrm{~B}$ & $-0,339$ & 0,229 & 228 \\
\hline CBD3A & $-0,430$ & 0,228 & 449 \\
\hline
\end{tabular}

Como não é possível posicionar por GPS a RN 4X, devido à obstrução do sinal por uma edificação próxima, o IBGE instalou a uma distância de aproximadamente $55 \mathrm{~m}$ da RN 4X o marco geodésico SAT 91854, cujas coordenadas foram determinadas com alta precisão por GPS. Portanto, o valor da componente sistemática na RN 4X pode ser considerado o mesmo do referido marco geodésico $(-0,356 \mathrm{~m})$.

A média ponderada da componente sistemática obtida pela expressão (5.4), utilizando os dados apresentados na Tabela 6.1 , é igual a $-0,351 \mathrm{~m}$, e o respectivo erro dado pela expressão (5.5) é $0,008 \mathrm{~m}$.

Utilizando o modelo matemático de transformação de similaridade, foi determinado valores para a componente sistemática que corrige a incompatibilidade dos referenciais somados aos erros sistemáticos. O modelo matemático usado é expresso por (5.10), cujos parâmetros (Tabela 6.4) foram determinados pelo método dos mínimos quadrados a partir da expressão (5.12), utilizando os dados mostrados na Figura 4.6.

A partir dos parâmetros apresentados na Tabela 6.4, foi determinado um valor para a componente sistemática em cada RN da RGSB. A superfície ilustrada na Figura 6.2 representa a componente sistemática determinada através de (5.10) na região do Datum de Imbituba .

A componente sistemática, estimadas pelo modelo de 8 parâmetros nas 4 RNs localizadas no Porto de Imbituba, (Figura 3.3) são mostradas na Tabela 6.5 
Tabela 6.4 - Parâmetros da transformação de similaridade

\begin{tabular}{|l|c|}
\hline Parâmetro & $\begin{array}{c}\text { Valor numérico } \\
(\mathrm{m})\end{array}$ \\
\hline Translação em X & $-36,94900$ \\
\hline Translação em Y & 6,778000 \\
\hline Translação em Z & $-152,1100$ \\
\hline Rotação em Y & $-0,003200$ \\
\hline Rotação em X & $-0,001700$ \\
\hline Escala & $-0,000070$ \\
\hline Semi eixo (a) & 516,8300 \\
\hline Achatamento (f) & 0,000005 \\
\hline
\end{tabular}

Tabela 6.5 - Componente sistemática modelada nas RNs localizadas nas proximidades do Datum .

\begin{tabular}{|l|c|}
\hline Nome da RN & $\begin{array}{c}\text { Componente } \\
\text { sistemática } \\
(\mathrm{m})\end{array}$ \\
\hline SAT 91854 & $-0,332$ \\
\hline 3010C & $-0,332$ \\
\hline 3010B & $-0,332$ \\
\hline CBD3A & $-0,334$ \\
\hline Média & $\mathbf{- 0 , 3 3 2}$ \\
\hline
\end{tabular}

\section{Resíduos}

Os resíduos obtidos pelo modelo matemático de 8 parâmetros, expressões (5.10) e (5.12), foram comparados com os resíduos obtidos a partir dos modelos matemáticos de 6 parâmetros (sem os parâmetros de rotação), 7 parâmetros (sem o parâmetro de escala) e de 6 parâmetros (sem os parâmetros do elipsóide). Observa-se na Tabela 6.6 que os resíduos em toda rede GPS foram menores utilizando-se o modelo de 8 parâmetros (comparar, os desvios 
padrões, Root Mean Square (RMS) e as médias). Os modelos matemáticos com menor RMS são mais indicados.

Os resíduos pequenos, nas RNs localizadas no Porto de Imbituba (Tabela 6.7), podem ser conseqüência da maior precisão das altitudes geométricas, cujo posicionamento foi feito com maior tempo de coleta (4 horas), e das altitudes ortométricas, que estão menos sujeitas a erros, devido à menor distância em relação ao Datum. Os resíduos nas RNs restantes são conseqüência de erros aleatórios, principalmente na altitude ortométrica que está mais sujeita a erros grosseiros.

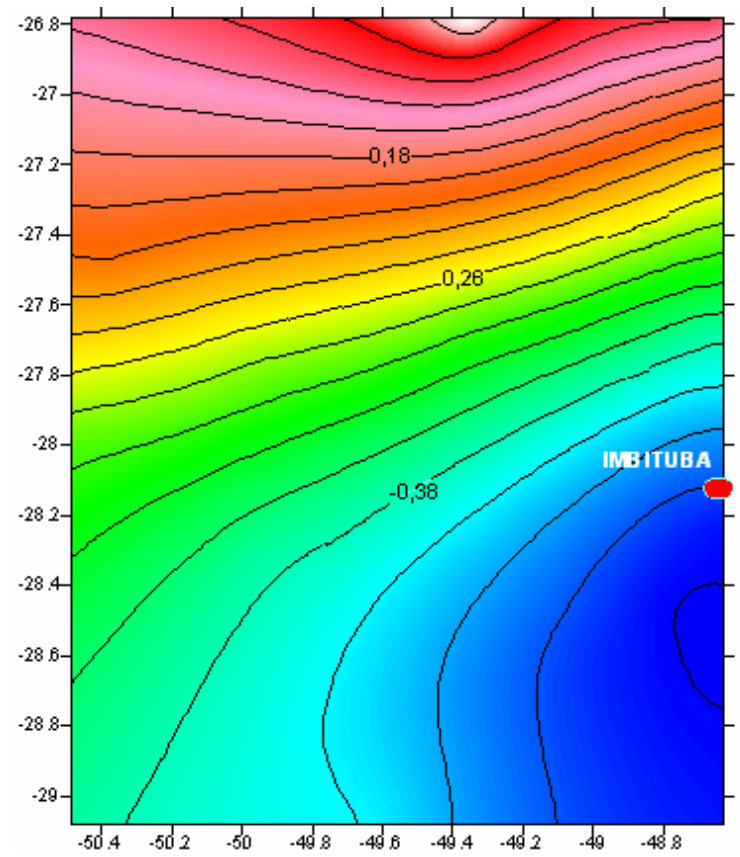

Figura 6.2 - Superfície calculada a partir dos parâmetros

Tabela 6.6 - Comparação dos resíduos determinados a partir de diferentes modelos matemáticos

\begin{tabular}{|l|c|c|c|c|}
\hline Estatísticas & 8 parâmetros & $\begin{array}{c}\text { 6 parâmetros } \\
\text { (sem rotação) } \\
(\mathrm{m})\end{array}$ & $\begin{array}{c}7 \text { parâmetros } \\
(\text { sem escala) } \\
(\mathrm{m})\end{array}$ & $\begin{array}{c}\text { 6 parâmetros } \\
\text { (sem a e f) } \\
(\mathrm{m})\end{array}$ \\
\hline Média & $-0,008$ & $-0,013$ & $-0,008$ & $-0,015$ \\
\hline Desvio padrão & 0,230 & 0,255 & 0,231 & 0,257 \\
\hline RMS & 0,300 & 0,310 & 0,310 & 0,617 \\
\hline Máximo & 0,624 & 0,690 & 0,625 & 0,617 \\
\hline Mínimo & $-0,720$ & $-0,852$ & $-0,720$ & $-0,727$ \\
\hline
\end{tabular}


Tabela 6.7 - Resíduos nas RNs localizadas no Porto de Imbituba.

\begin{tabular}{|l|c|}
\hline Nome da RN & $\begin{array}{c}\text { Resíduo } \\
(\mathrm{m})\end{array}$ \\
\hline SAT 91854 & $-0,024$ \\
\hline $3010 \mathrm{C}$ & $-0,058$ \\
\hline $3010 \mathrm{~B}$ & $-0,005$ \\
\hline CBD3A & $-0,097$ \\
\hline
\end{tabular}

A determinação da componente sistemática, utilizando metodologias diferentes tem como objetivo representar adequadamente a componente sistemática no Datum altimétrico brasileiro, pois o uso apenas da $\mathrm{RN} 4 \mathrm{X}$, está sujeito a possíveis erros, que não foram propagados na rede de nivelamento; esses erros são: erro na determinação da altitude geométrica, altura geoidal e variações posteriores na altitude ortométrica provocadas por movimentos crustais e sedimentação do terreno.

A Tabela 6.8 mostra as componentes sistemáticas determinadas para o Datum de Imbituba, onde $\Delta \mathrm{N}^{\mathrm{i}}$ é a componente sistemática determinada no marco geodésico SAT 91854, através da expressão (5.2), $\hat{\Delta} \mathrm{N}_{\mathrm{D}}$ é a componente sistemática determinada para o Datum através da média ponderada, $\hat{\Delta} \mathrm{N}^{\mathrm{i}}$ é a componente sistemática ajustada pelo modelo de transformação de similaridade no marco geodésico SAT 91854 e $\delta \Delta \mathrm{N}^{\mathrm{i}}$ é a diferença entre as respectivas componentes sistemáticas modeladas e a componente sistemática determinada na no marco geodésico SAT 91854 através da expressão (5.2).

Tabela - 6.8 Componentes sistemáticas determinadas no Datum de Imbituba

\begin{tabular}{|l|c|c|c|}
\hline & $\begin{array}{c}\Delta \mathrm{N}^{\mathrm{i}} \\
(\mathrm{m})\end{array}$ & $\begin{array}{c}\hat{\Delta} \mathrm{N}_{\mathrm{D}} \\
(\mathrm{m})\end{array}$ & $\begin{array}{c}\hat{\Delta} \mathrm{N}^{\mathrm{i}} \\
(\mathrm{m})\end{array}$ \\
\hline Componente sistemática & $-0,356$ & $-0,351$ & $-0,332$ \\
\hline$\delta \Delta \mathrm{N}^{\mathrm{i}}$ & ------ & 0,005 & 0,024 \\
\hline
\end{tabular}

\section{2- IMPLICAÇÕES DA COMPONENTE SISTEMÁTICA PARA A RAFB.}


O histograma ilustrado na Figura 6.3 mostra a componente sistemática, determinada pela expressão (5.2) nas RNs, cuja localização é ilustrada na Figura 4.6, e a Tabela 6.9 mostra seus parâmetros estatísticos.

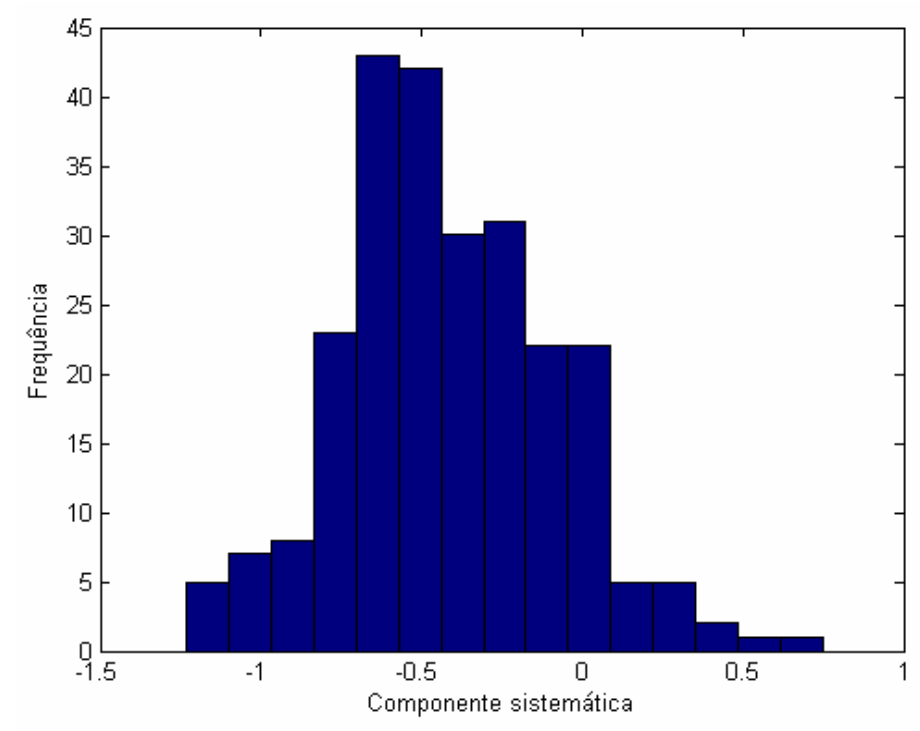

Figura 6.3 - Histograma da componente sistemática.

Tabela 6.9- Estatísticas da componente sistemática

\begin{tabular}{|l|c|}
\hline Estatísticas & $\begin{array}{c}\text { Valor numérico } \\
(\mathrm{m})\end{array}$ \\
\hline Média & $-0,414$ \\
\hline Desvio padrão & 0,330 \\
\hline Máximo & 0,740 \\
\hline Mínimo & $-1,230$ \\
\hline
\end{tabular}

Com objetivo de mostrar os efeitos das componentes sistemáticas determinadas no Datum (Tabela 6.8) e as componentes sistemáticas estimadas através da transformação de similaridade, na RAFB, foi determinada componente residual $(\delta \Delta N)$ (diferença entre os geóides após a remoção da componente sistemática) nos seguintes casos:

1. remoção da componente sistemática determinada no marco SAT 91854 através da expressão (3.12) (-0,356 m);

$$
\delta \Delta \mathrm{N}_{1}=\Delta \mathrm{N}-\Delta \mathrm{N}^{\mathrm{i}}
$$


2. remoção da componente sistemática determinada através da média ponderada $(-0,351 \mathrm{~m})$;

$$
\delta \Delta \mathrm{N}_{2}=\Delta \mathrm{N}-\hat{\Delta} \mathrm{N}_{\mathrm{D}}
$$

3. remoção da componente sistemática estimada através do modelo matemático expresso por (5.10) no marco geodésico SAT 91854 (-0,332 m).

$$
\delta \Delta \mathrm{N}_{3}=\Delta \mathrm{N}-\hat{\Delta} \mathrm{N}^{\mathrm{i}}
$$

4. determinação da componente residual em cada RN da RGSB, através do modelo matemático expresso por $(5.10)$

$$
\delta \Delta \mathrm{N}_{4}=\Delta \mathrm{N}-\hat{\Delta} \mathrm{N}
$$

onde $\Delta \mathrm{N}$ é a componente sistemática de um ponto qualquer, $\Delta \mathrm{N}^{\mathrm{i}}$ é a componente sistemática determinada no marco SAT 91854 através de (3.12), $\hat{\Delta} \mathrm{N}_{\mathrm{D}}$ é a componente sistemática estimada através de (5.3), e $\hat{\Delta} \mathrm{N}^{\mathrm{i}}$ é a componente sistemática estimada no marco geodésico SAT 91854 através do modelo matemático expresso por (5.10) e $\hat{\Delta}$ é a componente sistemática determinada nas RNs da RGSB através da transformação de similaridade . As Figuras 6.4, 6.5, 6.6 e 6.7 mostram os histogramas, e a Tabela 6.10 mostra as componentes residuais obtidas por (6.1), (6.2), (6.3) e(6.4).

Tabela 6.10 - Estatísticas das componentes residuais da rede RGSB

\begin{tabular}{|l|c|c|c|c|}
\hline Estatísticas & $\delta \Delta \mathrm{N}_{1}$ & $\delta \Delta \mathrm{N}_{2}$ & $\delta \Delta \mathrm{N}_{3}$ & $\delta \Delta \mathrm{N}_{4}$ \\
& $(\mathrm{~m})$ & $(\mathrm{m})$ & $(\mathrm{m})$ & $(\mathrm{m})$ \\
\hline
\end{tabular}




\begin{tabular}{|l|c|c|c|c|}
\hline Média & $-0,058$ & $-0,064$ & $-0,082$ & $-0,008$ \\
\hline Desvio padrão & 0,338 & 0,338 & 0,338 & 0,230 \\
\hline RMS & 0,442 & 0,423 & 0,415 & 0,415 \\
\hline Máximo & 1,103 & 1,097 & 1,108 & 0,624 \\
\hline Mínimo & $-0,877$ & $-0,880$ & $-0,898$ & $-0,720$ \\
\hline
\end{tabular}

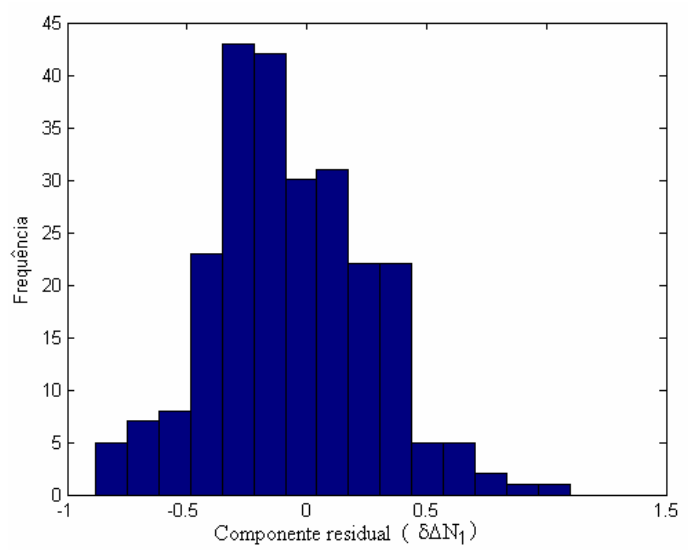

Figura 6.4 - Histograma das componentes residuais resultante da remoção da componente sistemática determinada no marco geodésico SAT 91854. (Unidade: m)

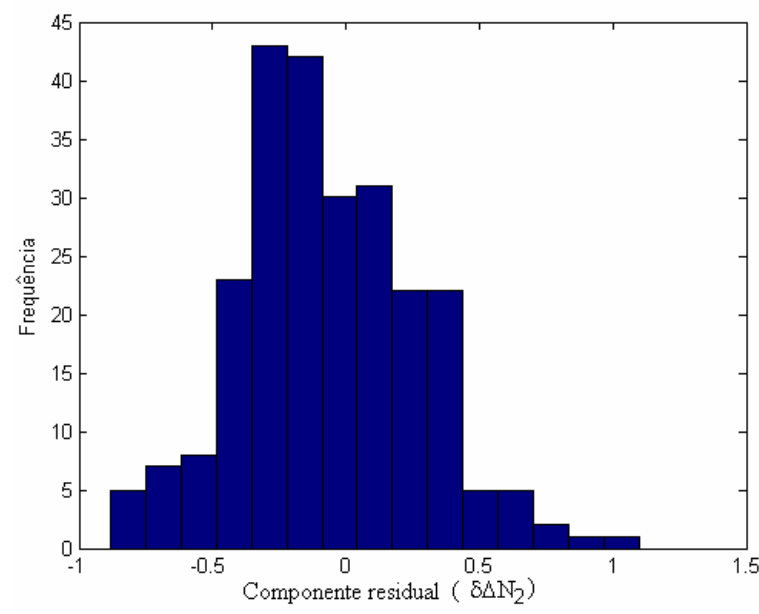

Figura 6.5 - Histograma das componentes residuais resultante da remoção da componente sistemática estimada através da média ponderada (Unidade: m) 


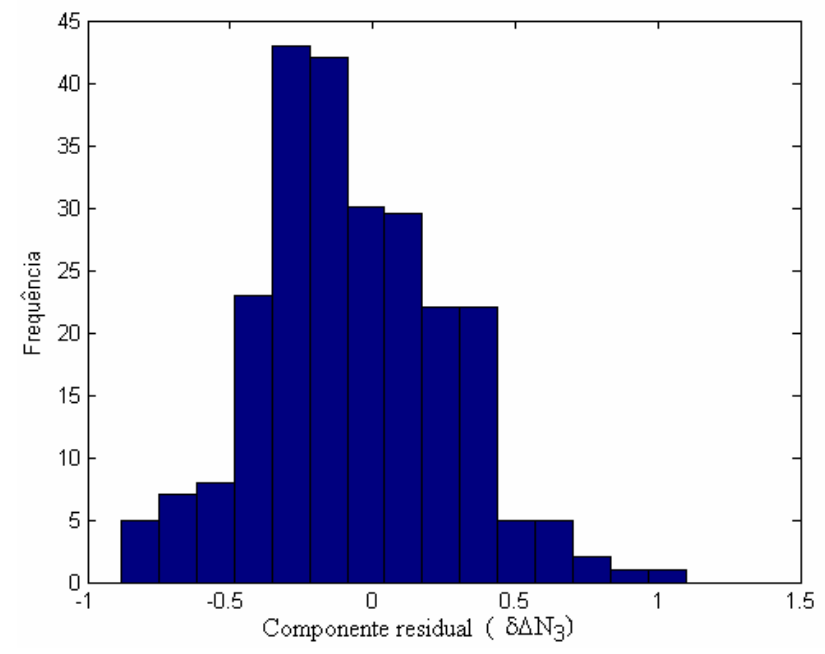

Figura 6.6 - Histograma das componentes residuais resultante da remoção da componente sistemática estimada através da transformação de similaridade no marco geodésico SAT 91854 (Unidade: $\mathrm{m}$ )

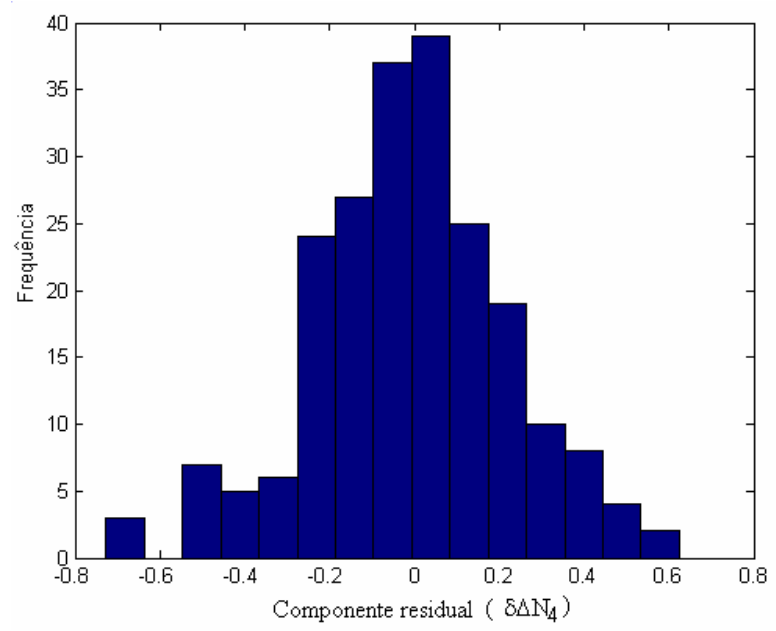

Figura 6.7 - Histograma das componentes residuais resultante da remoção da componente sistemática estimada através do modelo matemático (Unidade: $\mathrm{m}$ )

A componente sistemática obtida no Datum indica que o geóide gravimétrico é incompatível com o NMM e tem importantes implicações na RAFB, já que esta se propaga para toda a rede de altimétrica. Ao comparar o histograma mostrado na Figura 6.3, com os histogramas mostrados nas Figuras 6.4, 6.5, 6.6 e 6.7 verifica-se que as diferenças entre os 
geóides gravimétrico e GPS nas RNs da RAFB, diminuem significativamente após a remoção da componentes sistemáticas determinadas no Datum de Imbituba (Tabela 6.8), sendo que, a determinada no marco geodésico SAT 91854, através de (3.12), apresenta as menores componentes residuais (Tabela 6.10); entretanto o modelo matemático de transformação de similaridade, que ajusta a componente sistemática para cada RN da RGSB, apresentou os melhores resultados (menor média e desvio padrão para as componentes residuais) (Tabela 6.10), sendo assim o mais indicado na compatibilização do geóide gravimétrico com o geóide GPS/Nivelamento. 


\section{7 - CONCLUSÕES}

Atualmente, a unificação de Data altimétricos vem sendo estudada no mundo inteiro, sua importância reside na possibilidade de se obter altitudes ortométricas referidas a um Datum global, permitindo o uso de altitudes em escalas regional e global.

Os Data altimétricos devem ser vinculados à superfície equipotencial do geóide, possibilitando o uso do GPS na obtenção de altitudes ortométricas.

O uso do NMM como referência altimétrica não é conveniente do ponto de vista prático, pois as variações do NMM (TO) provocam inconsistências entre os Data altimétricos e, conseqüentemente, entre as redes de nivelamento.

Os desníveis entre o NMM nos marégrafos interligados por nivelamento, foram investigados por meio dos dados oceanográficos globais disponíveis. Os resultados mostraram que a descarga de um grande volume de água doce e chuvas, e temperaturas elevadas tornam a densidade da água do mar em Belém e Salinópolis consideravelmente menor que a densidade da água em Imbituba. A relação inversa entre densidade e nível do mar, mostrada na expressão (3.3), explica porque o NMM em Belém e Salinópolis está aproximadamente 90 cm acima do NMM em Imbituba.

As diferenças entre as estimativas do NMM (por nivelamento e dados oceanográficos), mostradas na Figura 3.16, são causadas provavelmente pela baixa precisão dos dados oceanográficos, número reduzido e possíveis erros nos dados maregráficos, e eventuais erros na rede de nivelamento.

Na ausência de modelos geoidais, os Data altimétricos podem ser integrados através do geopotencial (Bursa et al., 1999); entretanto, a integração de Data locais usando a superfície geoidal para determinação da componente sistemática, com a adoção de um modelo geoidal global possibilita o uso do GPS na determinação da altitude ortométrica.

A componente sistemática é causada pela incompatibilidade dos referenciais, além dos erros sistemáticos e aleatórios.

A componente sistemática no Datum foi determinada a partir dos geóides gravimétrico e GPS/nivelamento, no marco SAT 91854 (-0,356 m) e através da média ponderada das 25 estações GPS mais próximas $(-0,351 \mathrm{~m})$. Também foi usado o modelo matemático de transformação de similaridade que ajusta valores para a componente sistemática em todas as RNs da rede, a componente sistemática determinada através deste modelo no marco SAT 91854 é $-0,332$ m. A remoção da componente sistemática, obtida no Datum, diminuiu 
significativamente a diferença entre os geóides gravimétrico e GPS/nivelamento nas RNs da RAFB, mostrando as potencialidades do método para a conexão de superfícies equipotenciais a Data locais; entretanto o ajuste da componente sistemática através da transformação de similaridade, cujo modelo matemático é dado pela expressão (5.10), apresentou os melhores resultados.

Os resultados obtidos através da transformação de similaridade (5.10), mostram que a principal causa da componente sistemática no Datum de Imbituba é a incompatibilidade dos referenciais e os erros sistemáticos, visto que forneceu resíduos pequenos. Os resíduos encontrados nas demais RNs são provenientes de erros aleatórios, principalmente nas altitudes ortométricas, cujo erros são subestimados.

A conexão de Data altimétricos através de modelos geoidais é prática e eficiente, no entanto esse método requer um modelo geoidal gravimétrico de alta resolução, obtido a partir de dados gravimétricos adequados em termos de precisão e distribuição geográfica, e uma rede GPS também com esses requisitos, já que a compatibilização dos geóides gravimétrico e GPS/nivelamento mostrou-se mais eficiente utilizando todas as estações da RGSB. 


\section{8 - REFERÊNCIAS}

ALENCAR, J. C. M. -1990- Datum altimétrico brasileiro. Cadernos de Geociências, IBGE, 5:69-73, Rio de Janeiro.

BURSA, M.; KOUBA, J.; KUMAR, M.; MÜLLER, A.; RAJEJ, K.; TRUE, S. A.; VATRT, V. \& VOJTÍSKOVA, M. -1999- Geoidal geopotential and world height system. Studia Geoph. et Geod. 45: 127-132.

BURSA, M.; KENYON, S.; KOUBA, J.; SÍMA, Z.; VATRT, V. \& VOJTÍSKOVÁ, M. 2004- A global vertical reference frame based on four regional vertical datums. Studia Geoph. et Geod. 43: 327-337

CARLSSON, M. -1998- The mean sea-level topography in the Baltic Sea determined by oceanographic methods. Marine Geodesy. 21: 203-217.

CASTRO, A. L. P. de -2002- Nivelamento através do GPS: avaliação e proposição de estratégias. Dissertação de Mestrado. Curso de pós-graduação em Ciências Cartográficas da FCT-UNESP, Presidente Prudente - SP, 174 pp.

CAZENAVE, A. \& NEREM, R.S. -2004- Present-day sea level change: observations and causes. Review of Geophysics, 42(3).

FOTOPOULOS, G. -2003- An analysis on the optimal combination of geoid, orthometric and ellipsoidal height Data. Thesis, Department of Geomatics Engineering, Calgary, Alberta. $238 \mathrm{pp}$.

FREITAS, S. R. C. \& BLITZKOW, D. -1999- Altitudes e Geopotencial. In: IGeS Bulletin (Special Issue for South America). 9: 47-61.

GEMAEL, C. -2002- Introdução à Geodésia Física. Curitiba: UFPR. 304 pp.

GEMAEL, C. -1994- Introdução ao Ajustamento de Observações: Aplicações Geodésicas. Curitiba: UFPR. 319 pp.

HEISKANEN, W. \& MORITZ, H. -1967- Physical geodesy. W. H. Freemann, N. York, 364 pp.

HECK, B. \& RUMMEL, R. -1990- Strategies for solving the vertical Datum problem using terrestrial and satellite geodetic Data. In: Sea Surface Topography and the Geoid, proceedings of the IAG symposia, 104, (ed. H. Sunkel, T. Baker) 116-128.

IAG (International Association of Geodesy) -1980- The geodesist's handbook (I. I. Mueller ed.), Bull. Geod. 54(3): 394-408. 
IBGE (Fundação Instituto Brasileiro de Geografia e Estatística) -2005- Informações obtidas na página mantida pelo IBGE na internet: www.ibge.gov.br.

JEKELI, C. -2000- Heights, the Geopotential, and Vertical Data., Report No. 459.

LEHMAN, R. -2000- Altimetry gravimetry problems with free vertical Datum, J. Geod. 74: 327-334.

LISITZIN, E. -1974- Sea level changes. Elsevier Oceanography Series, 8. Elsevier, Amsterdam. 286 pp.

LEMOINE, F.G.; KENYOU, S.C.; FACTOR, J.K; TRIMMER, R.G.; PAVLIS, N.K.; COX, C.M.; LUTHCKE, S.B.; TORRENCE, M.H.; WANG, Y.M.; WILLIAMSON, RG.;PAVLIS,EC.; RAPP, R.H. \& OLSON,T.R. -1998- The development of joint NASA SGFC and MINA geopotential model EGM96.NASA/TP 206861.

LUZ, R.T. \& GUIMARÃES, V.M. -2001- Realidade e perspectiva da rede altimétrica de alta precisão do sistema geodésico brasileiro. II Colóquio brasileiro de ciências geodésicas, Curitiba.

LUZ, R.T. \& GUIMARÃES, V. M. -2003- Dez anos de monitoramento do nível do mar no IBGE. In: III colóquio brasileiro de ciências geodésicas, Curitiba.

LUZ, R.T.\& NEVES, C.F. -1995- Problemas presentes na observação do nível do mar visando a definição do Datum vertical de grandes redes geodésicas. Anais do XVII Congresso Brasileiro de Cartografia. Salvador.

KOTSAKIS, C.; FOTOPOULOS, G. \& SIDERIS, M.G. -2001- Optimal fitting of gravimetric geoid undulations to GPS/levelling Data using an extended similarity transformation model. Presented at the 27th Annual meeting joint with the 58th Eastern snow conference of the Canadian Geophysical Union, Ottawa, Canada. 14-17.

KOTSAKIS, C. \& SIDERIS, M.G. -1999- On the adjustment of combined GPS/levelling/geoidnetworks. Journal of Geodesy. 73 (8): 412-421.

MONICO, J. F. G. -2000- Posicionamento pelo NAVSTAR-GPS: descrição, fundamentos e aplicações. São Paulo: Editora Unesp, 287 pp.

MORITZ, H. -1980- Advanced physical geodesy. Abacus Press Wichmann, 500 pp.

NEREM, R. S.; JEKELI C. \& KAULA, W.M. -1995- Gravity field determination and characteristics retrospective and prospective. Journal Geophys. Res. 100 (B8): 1505315074

PICKARD, G., L. -1974- Oceanografia física descritiva. Universidade de Columbia Britânica. 180 pp. 
PSMSL (Permanent Service for Mean Sea Level) -2005- Informações obtidas na página http://www.pol.ac.uk.

RAPP, R. H. \& BALASUBRAMANIA, N. -1992- A conceptual formulation of a world height system. Report 421, Department of Geodetic Science and Surveying, The Ohio State University, Columbus.

RAPP, R, H.; WANG, Y. M. \& PAVLIS, N. K. -1991- The Ohio State 1991 geopotential and sea surface topography harmonic coefficient models. Report 410 Dept. of Geod. Sci. and Surv. Ohio State university.

RUMMEL, R. \& TEUNISSEN, P. -1988- Height Datum definition, height Datum conection and the role of the geodetic boundary value problem. Bulletin Geodesique 62: 477-498.

SÁ, N. C. de -2004- O campo de gravidade, o geóide e a estrutura crustal na América do Sul: novas estratégias de representação. Tese de Livre Docência, IAG/USP, São Paulo, 121 pp.

SÁNCHEZ, L. -2005- Datum vertical estado actual y tareas urgentes. SIRGAS Boletim Informativo (8).

SANDWELL, T. D. \& SMITH, W. H. F. -1997- Marine gravity anomaly from GEOSAT and ERS1 satélite altimetry. J. Geophys. Res. 102(B5): 1039-1054.

SOUZA, S. F. -2002- Contribuição do GPS para o aprimoramento do geóide. Tese De Doutorado, IAG/USP, São Paulo, 204 pp

SP (Spectra Precision) -2000- GEOGENIOS 2000 user's manual. Version 2.1 Release 1. Hohenkirchen- Siegertsbrunn, Germany.

TCHERNIA, P. -1980- Descriptive regional oceanography. Oxford: Pergamon Press. 253 pp.

VANICEK, P. \& KRAKIWSKY, E. -1986- Geodesy: the concepts. North- Holand, Amsterdam, $697 \mathrm{pp}$.

WENZEL, G. -1999- Global model of the gravity field of high and ultra- high resolution. Preprint of a paper submited to Buletin of the International Geoid Service, Milan, Italy, 36 pp.

XU, P. -1992- A quality investigation of global vertical Datum connection Geophys. Journal International 110 (2): 361-370. 